\title{
Sensitivity Analysis of Risk Guidelines for Mining Near Impounding Structures and Bodies of Water
}

Thomas Wachtel

West Virginia University

Follow this and additional works at: https://researchrepository.wvu.edu/etd

\section{Recommended Citation}

Wachtel, Thomas, "Sensitivity Analysis of Risk Guidelines for Mining Near Impounding Structures and Bodies of Water" (2012). Graduate Theses, Dissertations, and Problem Reports. 4935.

https://researchrepository.wvu.edu/etd/4935

This Thesis is protected by copyright and/or related rights. It has been brought to you by the The Research Repository @ WVU with permission from the rights-holder(s). You are free to use this Thesis in any way that is permitted by the copyright and related rights legislation that applies to your use. For other uses you must obtain permission from the rights-holder(s) directly, unless additional rights are indicated by a Creative Commons license in the record and/ or on the work itself. This Thesis has been accepted for inclusion in WVU Graduate Theses, Dissertations, and Problem Reports collection by an authorized administrator of The Research Repository @ WVU. For more information, please contact researchrepository@mail.wvu.edu. 


\title{
Sensitivity Analysis of Risk Guidelines for Mining Near Impounding Structures and Bodies of Water
}

\author{
Thomas Wachtel \\ Thesis submitted to the \\ Benjamin M. Statler \\ College of Engineering and Mineral Resources \\ At \\ West Virginia University \\ In partial fulfillment of the requirements \\ For the degree of \\ Master of Science \\ In Civil and Environmental Engineering \\ John Quaranta, Ph.D., P.E., Chair \\ Hema Siriwardane, Ph.D., P.E. \\ Joseph Donovan Ph.D.
}

Department of Civil and Environmental Engineering

Morgantown, West Virginia

2012

Keywords: Mining; Subsidence; Event Tree Analysis; Groundwater Draw 


\section{ABSTRACT \\ Sensitivity Analysis of Risk Guidelines for Mining Near Impounding Structures and Bodies of Water}

\section{Thomas Wachtel}

The coal mining industry has traditionally relied upon approaches that are principally based on US Bureau of Mines Information Circular (IC) 8741 by Babcock and Hooker (1977) for determining proximity distances and safety zones when mining under or near bodies of water. The proximity distance guidelines are limited by controlling the water inundation or seepage primarily for miners' safety. Since this initial work, research into mining under bodies of water has developed from subsidence studies performed by Kendorski (1993) and Bai et al. (1995). Recently, recovery of mineral reserves near bodies of water owned by the government is showing higher occurrence. In the USA, underground coal mining has affected surface bodies of water at public reservoirs and facilities owned or managed by the US Army Corps of Engineers. Lawsuits have become more numerous when detrimental effects of underground mining result. Such as in one case, damages in excess of \$58 million were levied when the coal operator caused the failure of a dam necessitating the draining of a recreation lake (Hopey 2008). Most recently, the US Army Corps of Engineers and the US Department of Justice lost a federal lawsuit in Ohio to stop underground mining at a state park lake (Gray 2011).

Conventional factor of safety analysis methods and Empirical approaches to quantify offset distances for mining under surface bodies of water appear to be in question as they do not adequately support the assessment of risks essential for managing dams, flood systems, and projects (USACE 2008). The research presented here addresses the development of a tolerable risk guideline approach based on offset distances for longwall underground coal mining near surface bodies of water. This research involved identification of subsidence and seepage angles of draw that influence the likelihood of the progression of seepage erosion at the rim of a reservoir. A potential failure mode analysis was developed considering the likelihood and consequences of permeability changes in subsurface soils. An event tree analysis is proposed and formulated to include subsidence and seepage induced parameters based on literature reviews of field data. These event trees are linked to the conventional seepage failure events typically considered in risk analysis methods used by the US Army Corps of Engineers and Bureau of Reclamation. A sensitivity analysis is used to develop further insights in the estimated risk outcomes. For the ranges studied, the analysis determined that at a $200 \mathrm{ft}(61.54 \mathrm{~m})$ offset distance, a permeability increase will occur below the rim of a reservoir $78 \%$ of the time. As the offset distance increases to $600 \mathrm{ft}(184.62 \mathrm{~m})$, the probability of increased permeability will reduce to $6 \%$. The results show the probability that sub-surface erosion may occur from mining at distances far exceeding current offset guidelines recommended by Babcock and Hooker. 


\section{Table of Contents}

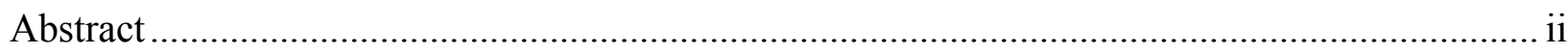

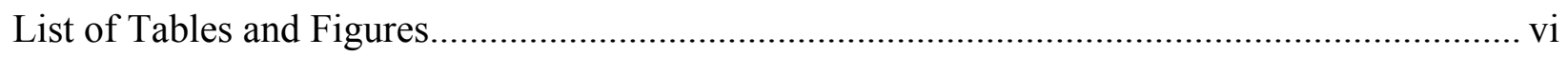

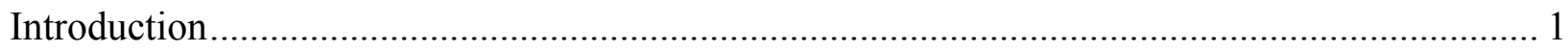

Purpose

Scope

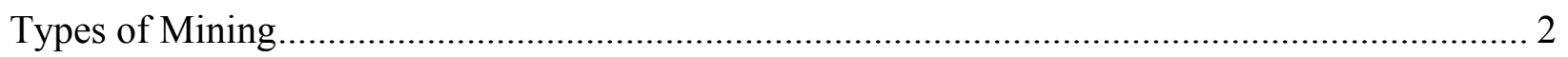

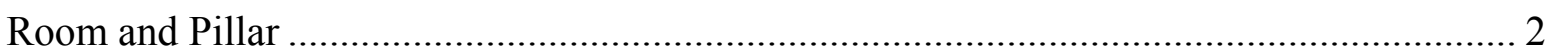

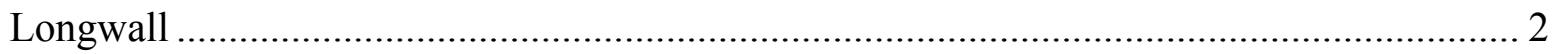

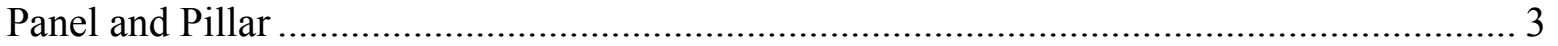

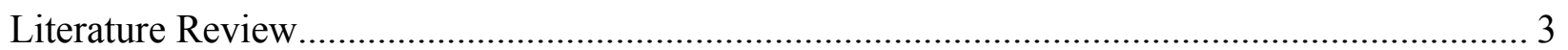

Guidelines for Mining Under Surface Water Phase III (Wardell) ............................................. 3

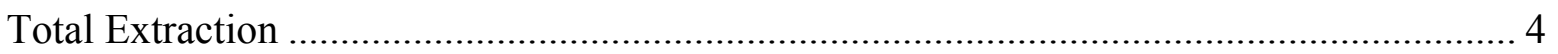

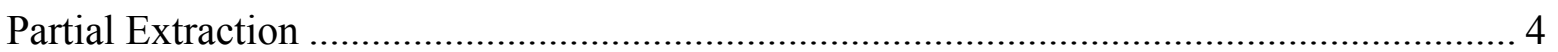

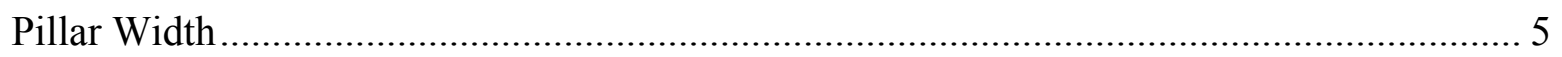

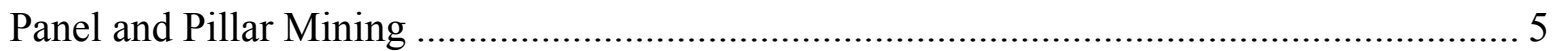

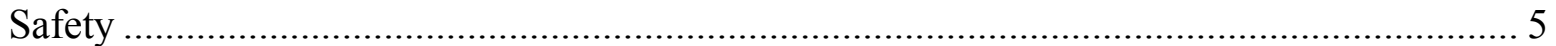

Guidelines for Mining near Water Bodies (Skelly and Loy 1976) ............................................. 6

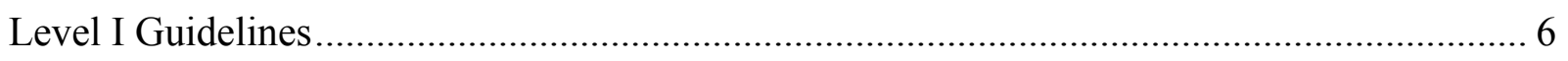

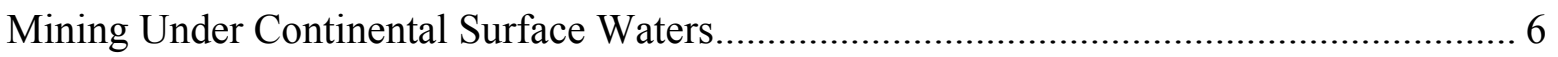

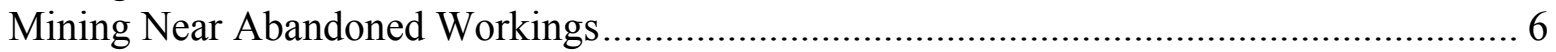

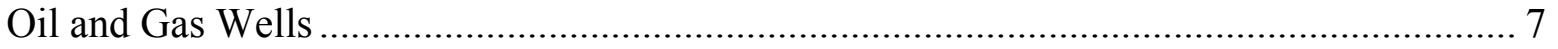

Mining Near Shafts or Other Mine Openings.................................................................. 7

Mining Under Unconsolidated Deposits......................................................................... 7

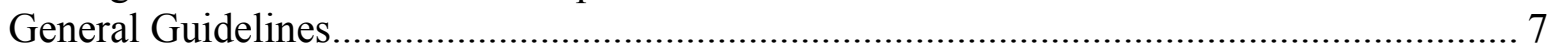

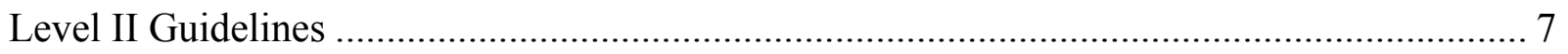

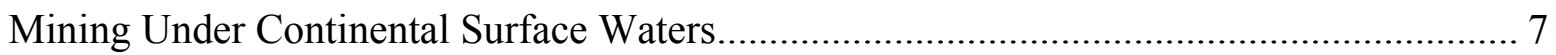

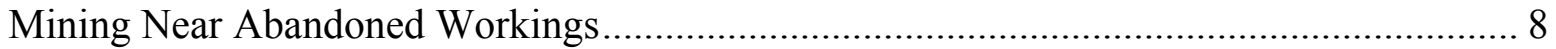

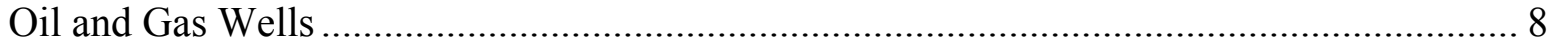

Mining Near Shafts or Other Mine Openings .................................................................... 8

Mining Under Natural Subsurface Hazards ......................................................................... 9

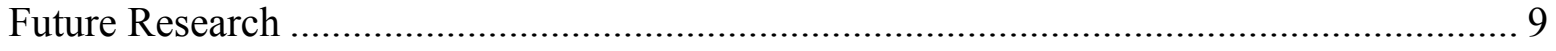

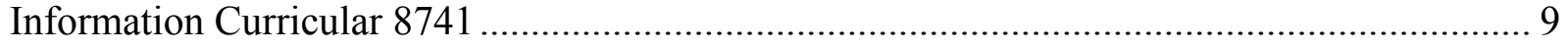

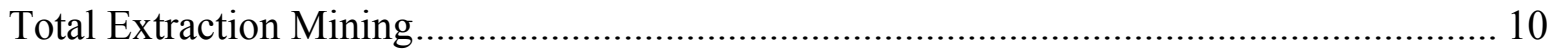

Partial Extraction Mining................................................................................................ 11

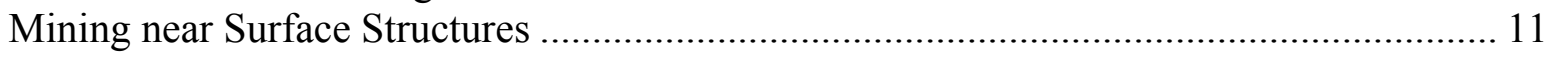

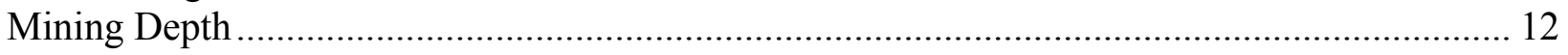

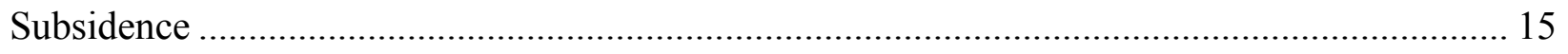

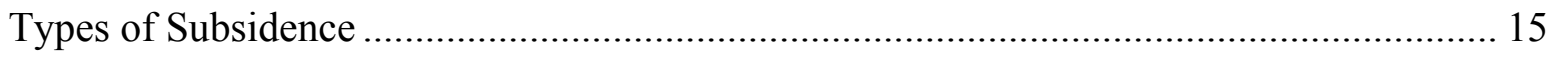

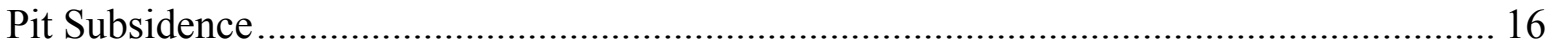

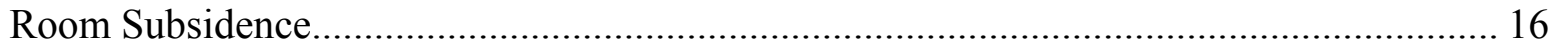




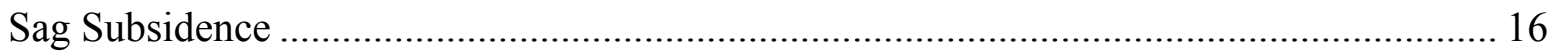

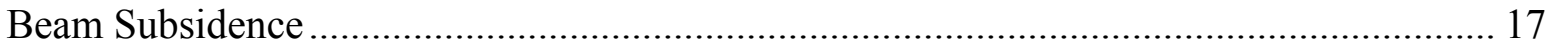

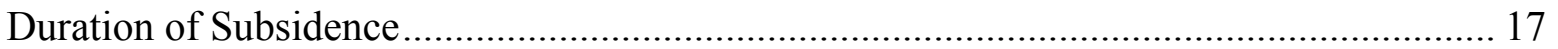

Effects of subsidence ............................................................................................. 18

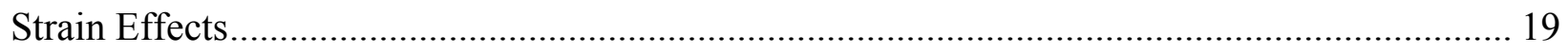

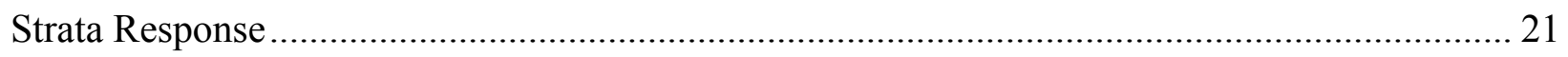

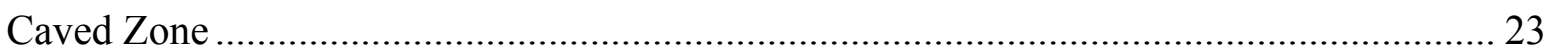

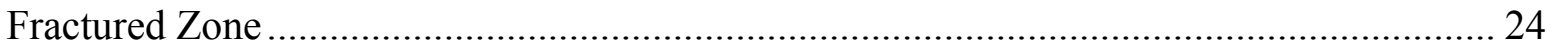

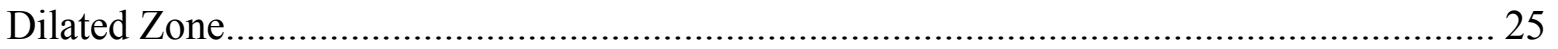

Bending or Constrained Strata Zone................................................................................... 25

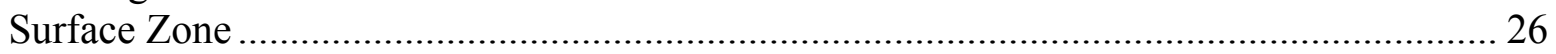

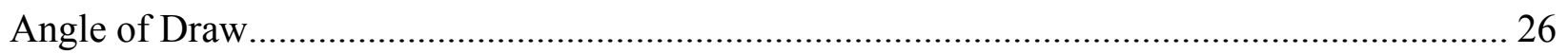

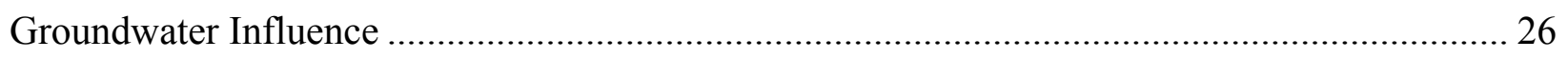

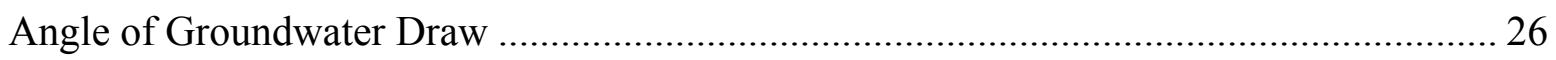

Geology

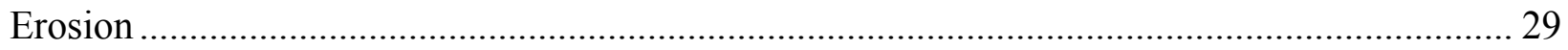

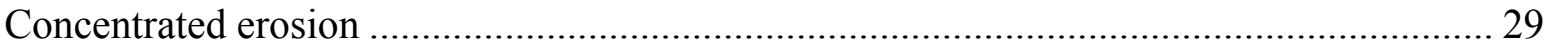

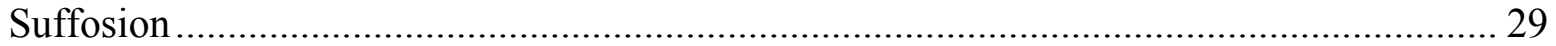

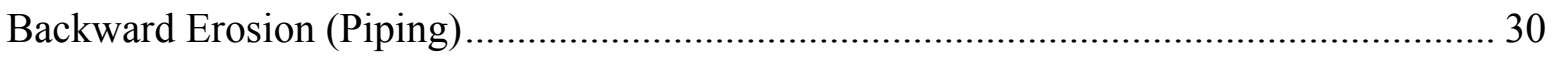

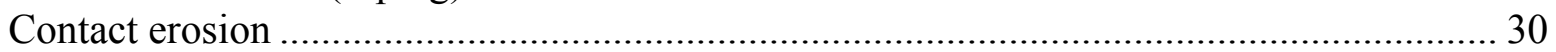

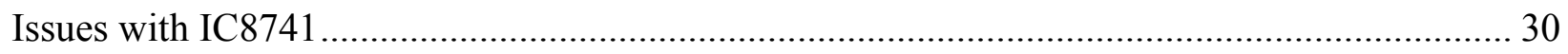

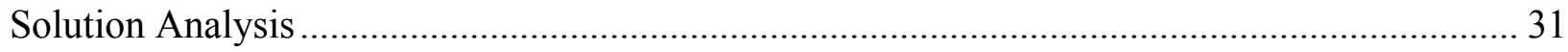

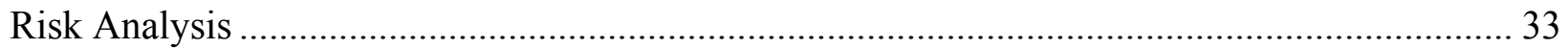

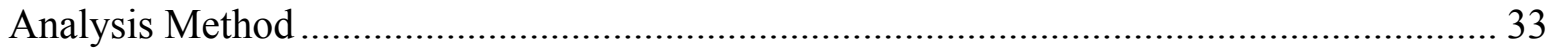

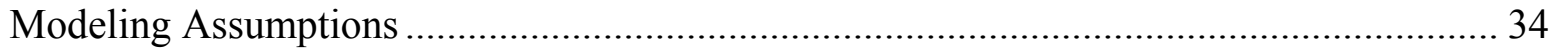

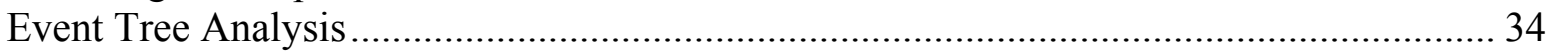

Development of Room and Pillar Event Tree............................................................................. 35

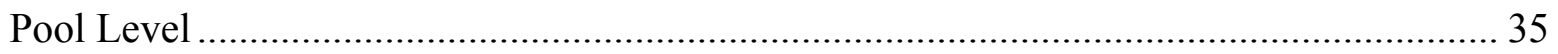

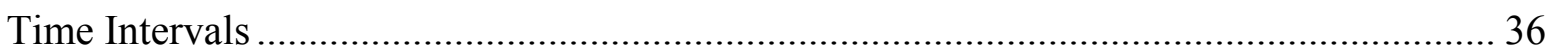

Terrain Type

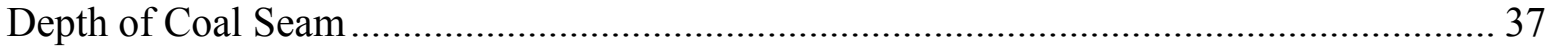

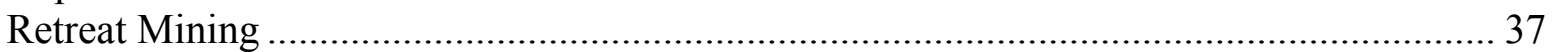

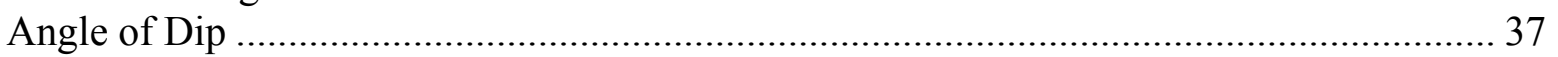

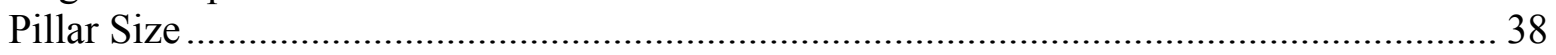

Geologic Makeup of Mine Roof or Floor ....................................................................... 38

Reservoir Event Tree for failure due to Longwall Mining ............................................................. 39

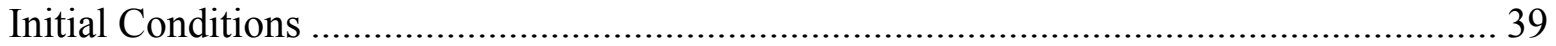

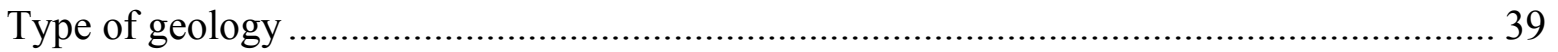

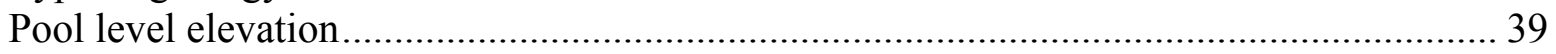

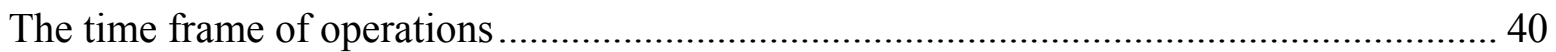

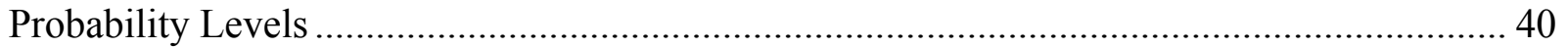

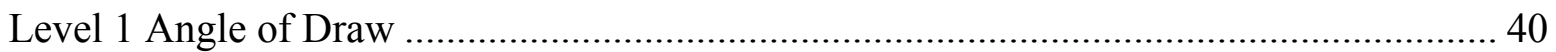




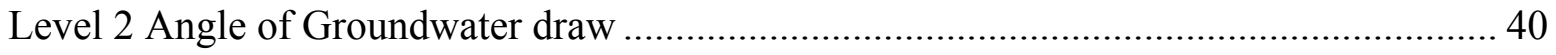

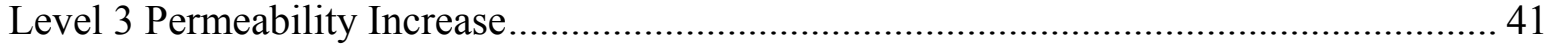

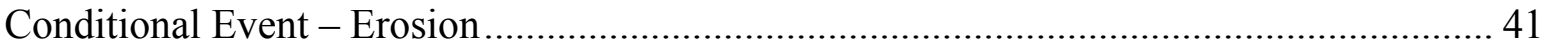

Qualifications for Sensitivity Analysis ..................................................................... 41

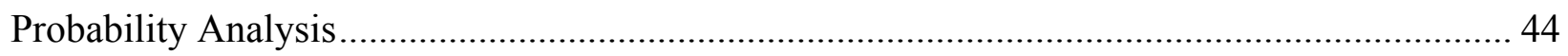

Probabilities Levels Using SME Handbook Ranges for Subsidence.................................... 47

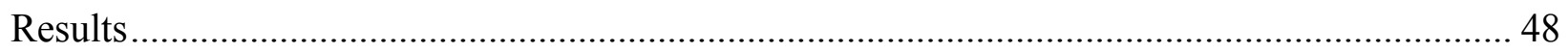

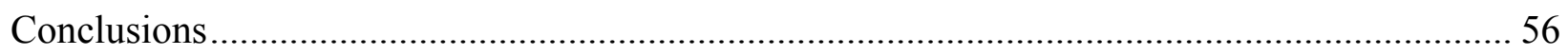

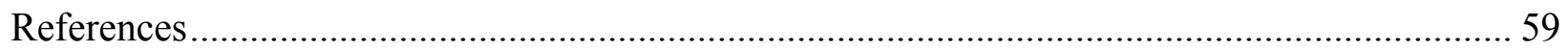




\section{LIST OF TABLES AND FIGURES}

Figure 1- Guidelines for Mining Under Surface Bodies of Water (After Babcock and Hooker 1977)

Figure 2 - Safety Zone Beneath Dam and Impounded Body of Surface Water (Babcock and

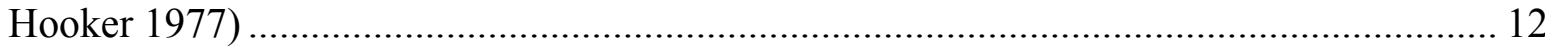

Figure 3- Subsidence curves for mining depth (Guo 2007)............................................. 13

Figure 4- Subsidence factors based on depth (Guo 2007) .................................................... 14

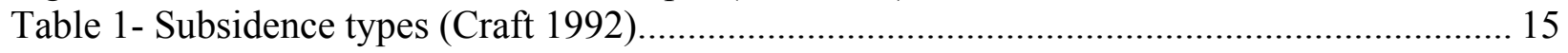

Figure 5- Duration of Subsidence (Singh 1992) ................................................................... 17

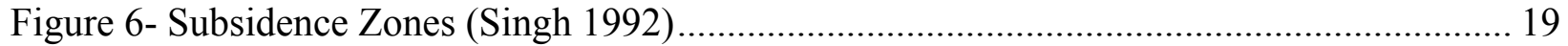

Figure 7- Compression Wave (Booth 2002) ......................................................................... 20

Figure 8- Zones of Overburden (After Karmis 1992) ........................................................... 20

Table 2- Strain Values in Appalachia (Dolinar 1999) ......................................................... 21

Figure 9- Subsidence Zones (Kendorski, 1979) ................................................................. 22

Figure 10- Subsidence Zones based on Chinese Literature (After Bai 1995) ........................... 22

Table 3- Strata Lithology Versus Strength of Rock.............................................................. 23

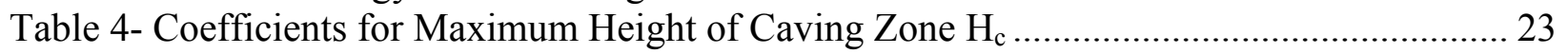

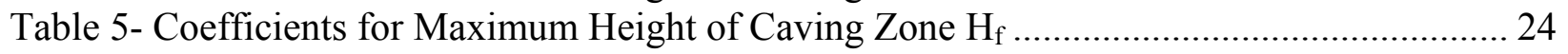

Figure 11- Subsidence Angle of Draw and Angle of Groundwater Influence ......................... 27

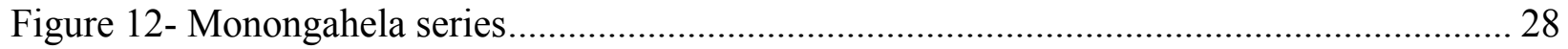

Figure 13- Allegheny Series ...................................................................................... 28

Figure 14- Generalized offset zones based on probability of erosion to occur .......................... 32

Figure 15- Generalized offset distances for a dam based on probability of erosion to occur....... 32

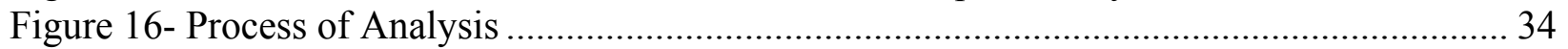

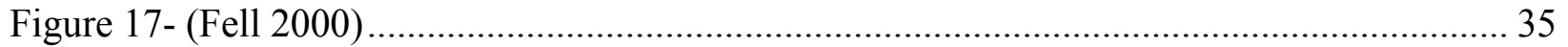

Table 6: Influence on Likelihood of Seepage Increase..................................................... 39

Figure 18- Generalized event tree for Longwall mining ................................................ 43

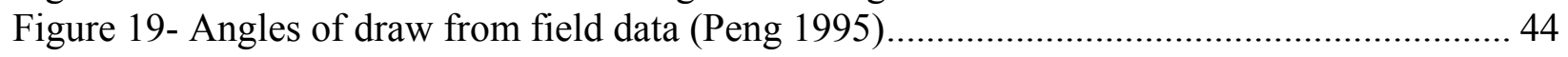

Table 7- Probability values for Ranges from SME Handbook ............................................. 44

Figure 20- Angles of draw values for longwall mining (Singh 1992) ...................................... 45

Figure 21-Mean values for data provided by SME Handbook .............................................. 45

Figure 22- R chart for data provided by SME Handbook..................................................... 46

Table 8 - Probability of groundwater draw based on angle of subsidence .............................. 47

Table 9- Changes in probability of permeability based on angle of groundwater draw .............. 48

Table 10 - Probability of Exceedance for $200 \mathrm{ft}(61.54 \mathrm{~m})$ offset .......................................... 49

Table 11 - Probability of Exceedance for $400 \mathrm{ft}(123.08 \mathrm{~m})$ offset ......................................... 49

Table 12 - Probability of Exceedance for $600 \mathrm{ft}(184.62 \mathrm{~m})$ offset ....................................... 49

Figure 23- Example path for event tree analysis ............................................................... 51

Figure 24- Partial event tree for 20 to 25 degree angle of subsidence.................................... 52

Figure 25- Example of one path for erosion probability analysis........................................ 53

Figure 26- Risk Analysis Methodology Appendix E, Version 2.52001 ................................. 53

Figure 27- Best estimate range of probability for initiation of erosion .................................... 54

Table 13 - Probability of Erosion at $200 \mathrm{ft}(61.54 \mathrm{~m})$ offset................................................. 55

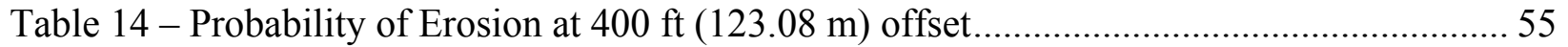

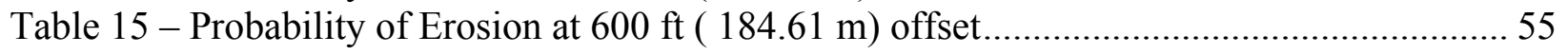


Figure 28: Probability of erosion based on offset distance using SME Handbook ranges of Subsidence..... 


\section{INTRODUCTION}

The need for energy both nationally and internationally often results in mineral and gas extraction encroaching near or beneath bodies of water. Since the early 1970's the former US Bureau of Mines performed studies to provide information for coal extraction beneath surface bodies of water (Babcock and Hooker 1977, Skelley and Loy 1976 and Wardell 1976). The proximity distances are limited by controlling the water inundation or seepage primarily for miners' safety. The extraction of underground coal reserves often extends into areas outside of traditional surface mine boundaries. In West Virginia, coal mining near and under coal waste impoundments occurs (MSHA and OSM 2003, OSM 2006) but in the past ten years there have been two sites where coal mining is proposed near US Army Corps of Engineers' dams and reservoirs. The first site was permitted by the West Virginia Department of Environmental Protection (WVDEP) in 2011 and is located near Tygart Lake in Taylor County, WV. The second site is currently being evaluated by the US Department of Interior, Bureau of Land Management prior to a federal coal sale at East Lynn Lake in Wayne County (WVDEP 2011, US Bureau of Land Management 2011).

Elsewhere in the region, other cases of coal mining near bodies of water have become news worthy. In Pennsylvania, USA, a mine company was sued by the State of Pennsylvania Department of Conservation and Natural Resources for compensatory damages in excess of $\$ 58$ million. The lawsuit claimed that the coal operator caused the failure of Ryerson Dam, necessitating the draining of Duke Lake, a popular recreation facility (Hopey 2008). In Ohio, the US Army Corps of Engineers and the US Department of Justice lost a federal lawsuit which would have stopped underground mining and tunneling underneath the east branch of Sunday Creek (Gray 2011).

This lawsuit has brought into question the ability to assess and quantify risk due to underground mining or gas extraction from beneath dams, reservoirs, and rivers. Conventional factor of safety analysis methods and empirical approaches to quantifying offset distances for mining under surface bodies of water appear to be in question for being able to adequately assess risks, which is essential to managing dams, flood systems, and projects (USACE 2008).

\section{PURPOSE}

The purpose of this research project is to investigate a probabilistic approach to quantify offset guidelines for mining operations that will ensure the protection of water bodies and dam structures in accordance with current US Army Corps of Engineers' risk based management approach. This will be performed using empirical and analytical techniques that will be used to develop tolerable risk guidelines for practical use in the field. Event tree analysis will be used to determine the probability of failure dependent on changes in the geologic profile due to mining. 
This report will detail the events for longwall and Room and Pillar mining and provide an analysis for longwall mining.

\section{SCOPE}

The specific aim of this research was to investigate risk factors at dam and reservoir sites due to changes in the spacial and mechanical characteristics of the subsurface environment resulting from mineral recovery of mined solid strata; coal or metal/nonmetal ore. Quantifying the risk factors may lead to a better understanding of the mining effects on such factors as seepage and foundation strength reduction.

The scope of the research was broken into three areas. The first area included a review and comparison of the historical design guidance documents which have, by default, become embraced by the regulatory and mining community. The second area identified critical issues in the methods and limitations of the guidelines. The third research area addressed development of a risk based approach with a sensitivity study based on data from literature.

This research will develop a step-by-step method to determine the potential risk to a dam or reservoir from longwall mining near its perimeter. It will approach this method by considering not only subsidence effects from the mine, but the effects through changes in permeability and groundwater flow that can propagate sub-surface erosion. It will then be linked to known probabilities for sub-surface erosion to occur to develop risk potential based on offset distance.

\section{TYPES OF MINING}

\section{$\underline{\text { Room and Pillar }}$}

Room and pillar mining is the most common method of mining in the United States. In the past, this form of mining constituted $90 \%$ of all coal extraction (Farmer 1992). The main benefit of room and pillar mining is the relative low cost compared to longwall mining (Farmer 1992). This method, called partial extraction, leaves pillars of coal in a checkerboard or grid fashion that supports the roof of the mine during operation (Singh 1992). This method is suitable for deposits ranging from horizontal up to 30 degrees of dip. However as the depth of the mine increases, the width of the support pillars must increase to support the increased load. Due to this effect, room and pillar mining is limit to shallower coal seams.

\section{Longwall}

The longwall mining method is full extraction of large panels of the coal seam. The method uses retreat mining of panels varying from 400 to $960 \mathrm{ft}$ wide and ranging from 3000 to $14000 \mathrm{ft}$ long (Peng and Chiang 1992). Multiple panels are excavated with chain pillars as separation. 
Longwall mining is considered much safer than room and pillar mining due to the retreat mining method. Subsidence from longwall mining is generally uniform and the duration is completed within several years of the mining operation

$\underline{\text { Panel and Pillar }}$

Panel and Pillar mining is generally used at greater depths than longwall mining. Like longwall this method excavates wide panels of the coal seam. However, between the excavated seams, a barrier pillar remains intact to support the weight of the overburden. It is not as efficient as longwall mining but allows for mining of deeper coal seams. This type of mining is not prevalent in the United States due to the presence of shallow deposits. However it is becoming more common overseas in England and China. As the need for coal increases, and shallower seams are depleted, the necessity to access deep coal deposits becomes more vital.

\section{LITERATURE REVIEW}

The coal mining industry has traditionally relied upon approaches for determining safety zones when mining under or near bodies of water that are principally based on US Bureau of Mines Information Circular(IC) 8741, Babcock and Hooker (1977), and reports by Wardell (1976), and Skelly and Loy (1976). These references determine offset distances for underground mining extents that are based upon both empirical relationships and analytical approaches using deterministic solutions. The proximity distances are limited by controlling the water inundation or seepage primarily for miners' safety (Babcock and Hooker 1977), (Skelly and Loy 1976).

The US Bureau of Mines Information Circular(IC) 8741, Babcock and Hooker (1977), hereafter referred to as IC8741, is the most widely referenced document providing barrier offset distance information for use in mines. The IC8741 guidance was based on empirical analysis and developed specifically to improve mines against water inundation, thus to protect miners from mine inundation. The guidance provides recommendations for mining near surface bodies of water and near dam structures.

\section{Guidelines for Mining Under Surface Water Phase III (Wardell)}

The objective of this research was to investigate guidelines for maximum coal extraction while avoiding potentials hazards. The hazards focus on mine flooding, environmental effects and public safety. The guidelines are to require little or no testing by the mine operator but recognize that additional coal may be extracted with this testing. This work focuses on total and partial coal extraction. However, the main focus is on total seam extraction due to maximizing the amount of coal to be mined. 


\section{$\underline{\text { Total Extraction }}$}

Total mine extraction has the most potential for failure due to collapse, fracturing and bedding slip. In this work, they detail that the height in which these effects may reach have been investigated by only 2 regions. The Former Soviet Union (now Russia). determined a height of 15 times the thickness of the seam with shale/mudstone strata. New South Wales determined a height of 35 times the thickness in a shale/sandstone environment. The determination of this work was that at a height of 30 times the seam thickness would be sufficient.

This work notes that fissures and cracks are observed in areas of convex ground curvature. None of these were observed at a depth of more than 50 feet. This still affects the strata permeability in which no empirical equation was formulated. This would require the relationship between depth and tensile strain for specific geology. In order to determine a safe extraction depth, the zone of increased permeability on the surface would need to be determined. The authors of this work determined this depth to be approximately $20 * t$ (where $t$ equals the thickness of the coal seam). This would make the actual safe working depth $50 *$ t.

There is evidence to suggest that the makeup of the strata can be a factor in determining the safe working zone of coal extraction. It is believed that the presence of shale or clays above the rockhead would inhibit the percolation of water into the mine working zone. There is currently no evidence to support that claim. There is evidence that the absence of these materials does not inhibit undersea mining.

Based on the findings above and subsidence observations they determined that in the United States the value of Smax would be lower than in Europe and Russia. This determination set the minimum depth of total extraction at $60 * \mathrm{t}$. In cases of multiple seam extraction, the maximum tensile strain shall not exceed $8.75 \mathrm{~mm} / \mathrm{m}$ beneath the surface water. In addition, there must be 60 times the coal seam thickness of strata between the two seams; as if the upper seam was a body of water.

\section{$\underline{\text { Partial Extraction }}$}

The minimum depth for partial extraction mining was determined based on the findings listed above. This was due to the fact that failure in a partially extracted mine would not be greater than in a totally extracted mine. Based on information taken from mines in New South Wales, the recommendation in this work is that the minimum thickness of strata be no less than 5 times the width or 10 times the height of the extraction room. In cases where there is only single rock member located somewhere in the strata, this figure could be reduced. The authors determined this minimum depth is based on the rock member's tensile strength. The determination is a member, such as sandstone, is present and is a minimum thickness of 1.75 times the entry width, then mining at lesser cover may be permissible. In addition, the same guidelines should be 
applied to tunnels or drifts unless permanently supported. Permanent support of pillar and room mines would be expensive and impractical so the guidelines for such cases have not been set.

\section{Pillar Width}

Determination of pillar width in these mines was based on the room width and the allowable pillar loading. The guidelines set are shown in tables provided in IC8741 (Babcock and Hooker, 1977). However in cases where the strength of the floor of roof beds is lower than the coal, those strengths should be used in determining the appropriate pillar width.

Panel and Pillar Mining

The guidelines for the panel and pillar mining state that there should be a minimum solid strata cover of $270 \mathrm{ft}$. The recommendation for the width of panels in the United States is they should not exceed one-third depth of mining. This was located under strata with sandstone beds. In the United Kingdom, the panel widths ranged from 0.1 to 0.3 times the depth with the general average being 0.25 times the depth and in New South Wales had panels that were 0.5 times the depth.The guidelines for the pillar width are 15 times their height or one-fifth the depth of mining, whichever is greater.

\section{Safety}

The recommendations for the safety of mines in this work are based on where restricted mining meets unrestricted mining. The concern is that a mine under a body of water could be impaired due to a total extraction mine in the unrestricted area. Their recommendations are that a safety zone be in place around the mine. Horizontally this zone is half the depth of the coal seam from the perimeter of the body of water. Where partial extraction mining is permitted, the safety zone shall extend an additional distance of two pillar widths for room and pillar, and one such width for panel and pillar (Wardell 1976).

The guidelines for safety zones around impoundments are different. No mining shall be allowed if the failure of such a structure by mining will cause an immediate hazard to the public. . The horizontal safety zone shall be 0.7 times the depth of cover to the seam. A zone of lesser distance can be allowed at the discretion of the regulatory agency.

The report states that there are additional hazards that are not covered under the guidelines. These include failure of dams and encroachment of water onto land. There is currently no way to determine the effects these will have on the mine site and therefore no formal guidelines were implemented. 


\section{Guidelines for Mining near Water Bodies (Skelly and Loy 1976)}

The research contract performed by Skelly and Loy (1976) determined results similar to those found by Wardell . A key difference is that their research expanded to where preliminary testing was conducted. The determination was that level I guidelines were generalized for all scenarios regardless of testing. If the proper data is obtained, mining within the offsets given in level I could be possible. This level (level II), was not included in IC8741.

\section{Level I Guidelines}

These guidelines require little or no surface or subsurface exploration. They are designed to ensure the integrity of the surface waters and prevent an inrush where water saturated alluvial deposits are known to occur (Skelley and Loy 1976) Three major categories are recognized in the guidelines;

1). Mining under continental surface waters

2). Mining near abandoned workings and natural subsurface hazards

3). General mine planning procedures

These guidelines are for partial and total extraction mining.

\section{Mining Under Continental Surface Waters}

The guidelines in this work regulate a distance of 200 feet horizontally from the high water mark of the body of water. Vertically the zone should extend 350 feet deep and continue downward at 25 degrees from vertical. This is shown as the zone of no extraction. The angle is designed to protect against subsidence inbreak due to roof falls and total extraction mining (longwall or pillar recovery). In one case $344 \mathrm{ft}$ of cover was not sufficient to prevent mine flooding which led to this regulation.

\section{Mining Near Abandoned Workings}

The guidelines stipulate that no mining should be permitted within 200 feet of any abandoned workings. If the abandoned workings can be inspected and verified to be safe, mining should be permitted up to a distance corresponding to the greater of a pillar width of 10:1 or a boundary pillar based on the equation:

$$
P_{b}=10+2 T+5 D
$$

$\mathrm{T}$ is the thickness of the seam and $\mathrm{d}$ is the depth of the seam in hundred foot increments. This should be utilized on both sides of the property line to create a distance of $2 \mathrm{~Pb}$. 


\section{$\underline{\text { Oil and Gas Wells }}$}

Barrier pillars of not less than 300 feet in diameter should be left around all oil and gas wells that penetrate the coal seam.

\section{Mining Near Shafts or Other Mine Openings}

When mining in an area near shafts, the guidelines stipulate that a barrier of 300 feet be left around the opening provided at least a $100 \mathrm{ft}$ radius of coal is left around the most extensive dimension. If these can be inspected to be safe and certified, a pillar of width to thickness ratio of 10:1 should be left around each opening.

\section{Mining Under Unconsolidated Deposits}

The guidelines for mining under unconsolidated deposits require minimum strata of 180 feet. If the reservoirs or deposits intersect the coal bed, a pillar of 200 feet should be left between the workings.

\section{$\underline{\text { General Guidelines }}$}

In addition to the guidelines given, there are general rules that must be adhered to. All mines must be kept well drained and free of water while occupied. They must also not allow workers in a portion of the mine where a body of water is held back at a higher elevation. There should also be maps and information pertaining to the mine at a fire safe location on the surface.

\section{Level II Guidelines}

The purpose of the level II guidelines is for when testing procedures are conducted, allowing for the greatest possible coal extraction while still promoting a safe environment. The guidelines are applicable for beds that are inclined less than 30 percent.

\section{$\underline{\text { Mining Under Continental Surface Waters }}$}

For partial extraction the cohesive rock must be at least 5 times the width of the mined rooms. For the strata to qualify as cohesive it must have a compressive strength of greater than 4,000 psi. Core samples must also be taken to determine permeability. Rock quality designation is also required to determine the maximum width a room can be. An RQD of 50\% will allow for a width of 20 to 40 feet without requiring additional heavy support. If the RQD is less than 50 percent, beams, support arches or cribbing is required. 
Pillar must be designed for stability based on the following formula;

$$
S=\frac{(K \times L)}{T}
$$

Where $\mathrm{S}$ is unit strength, $\mathrm{L}$ is the least width of the pillar and $\mathrm{T}$ is the pillar thickness. $\mathrm{K}$ is determined by the laboratory testing of the core sample. A factor of safety of 2 must be applied for the pillar thickness. Core samples should also be taken from the floor of the coal seam. The bearing strength of the pillar cannot exceed the load strength of the floor. When mining for the first time 2 headings should be kept as narrow as possible; not to exceed $15 \mathrm{ft}$.

For full extraction the tensile strain must not exceed 10 parts per thousand $(0.0010)$. The guidelines also stipulate that for every foot of seam thickness, there is 100 foot of strata. Full extraction should not be done less than 700 feet below the water body unless mircosiesmic monitoring is used, in which case the strata should be no less than 350 feet. The microseismic monitoring will detect and fractures in the strata and allow the mining to be halted before a hazardous situation occurs.

\section{Mining Near Abandoned Workings}

The best way to locate abandoned workings is through a borehole locator program. If it is able to be determined that the abandoned mine is dry, the guidelines set in Level I can be applied. If the mine is considered to be flooded, there are several options including drilling boreholes and draining the water. If this is not possible, a barrier pillar needs to be in place with a factor of safety of 4 . Water may be drained by drilling a bore hole through the barrier pillar and pumped through the active mine, however this can be hazardous. Property boundary barrier pillars should not be altered from Level I guidelines.

When mining under flooded abandoned workings, strata of no less than $100 \mathrm{ft}$ of cohesive material (as defined in guidelines for mining under continental surface waters) shall be maintained.

Oil and Gas Wells

Level II regulations are the same as Level I for oil and gas wells. The exception is when the well can be sealed. Once this occurs the barrier pillar can be mined through.

\section{Mining Near Shafts or Other Mine Openings}

Once a shaft or mine is abandoned, they can be mined through as in normal pillar recovery operations. However, the guidelines stipulate that they are first certified to be free of hazardous accumulations of water. If they cannot be inspected, borehole tests must be taken to determine if 
water is present. If water exists, it needs to be drained and verified that there is no further leakage. If leakage occurs, the opening of the mine or shaft should be plugged and then tested again. If no further leakage occurs, normal pillar recovery operations can be conducted.

\section{Mining Under Natural Subsurface Hazards}

For mining under natural subsurface hazards (as defined in Level I) there needs to be cohesive roof rock of no less than 5 times the width of the heading. The pillars are to be designed under the specifications given in Mining near Continental Surface Waters with a factor of safety of 2 used. Additionally, the bed floor of the seam needs to be evaluated to ensure the pillar load does not exceed the bearing capacity of the floor.

For full extraction, at least 100 feet of strata should exist for each foot of seam thickness. The maximum tensile strain on the floor of the water body must not exceed 10 parts per thousand. Full extraction should not be considered where overburden thickness is less than $700 \mathrm{ft}$ unless microseismic testing is monitored. A overburden depth of no less than 350 feet is then allowable.

\section{$\underline{\text { Future Research }}$}

Based on the conclusions of the report, future research and evaluations were determined to be needed when dealing with abandoned mines. There needs to be a reliable method to determine the location of these mines as well as determining potential water levels in the mines. In addition, future research was suggested be conducted on alternate methods of water drainage, and isolation of abandoned mines so they no longer present a hazard to future mines.

\section{Information Curricular 8741}

The two contracts afore mentioned were combined to create Information Curricular 8741 for the Bureau of Mines by Clarence Babcock and Verne Hooker (Babcock and Hooker 1977). When mining occurs near surface bodies of water the guidelines set by IC8741 require a minimum offset of $200 \mathrm{ft}$ from the high water mark for depths up to $350 \mathrm{ft}$. The high water mark is considered the probable maximum flood pool level. However there is no indication as to the time frame considered for the maximum flood. If a mined seam lies below the $350 \mathrm{ft}$ depth, and additional offset zone extending 65 degrees from horizontal is required.

Under the guidelines, mining is permitted below surface bodies of water under certain circumstances. They are determined based on the type of mining that occurs. The types considered are full extraction (longwall) mining and partial extraction (room and pillar and panel and pillar) mining. Room and pillar mining is only considered partial extraction if retreat mining does not occur. Retreat mining involves gob filling and removal of pillars, either fully or 
partially after initial mining has occurred. If retreat mining is performed, the mine is considered full extraction.

Panel and pillar mining is a hybrid of room and pillar and longwall mining. The extraction panels are much smaller in width than longwall mining. The width to depth ratio is key in this method so that the main strata can span the panels with little or no deflection. If the pillars are extracted, it will be considered full extraction. The guidelines for these methods are detailed in Figure 1.

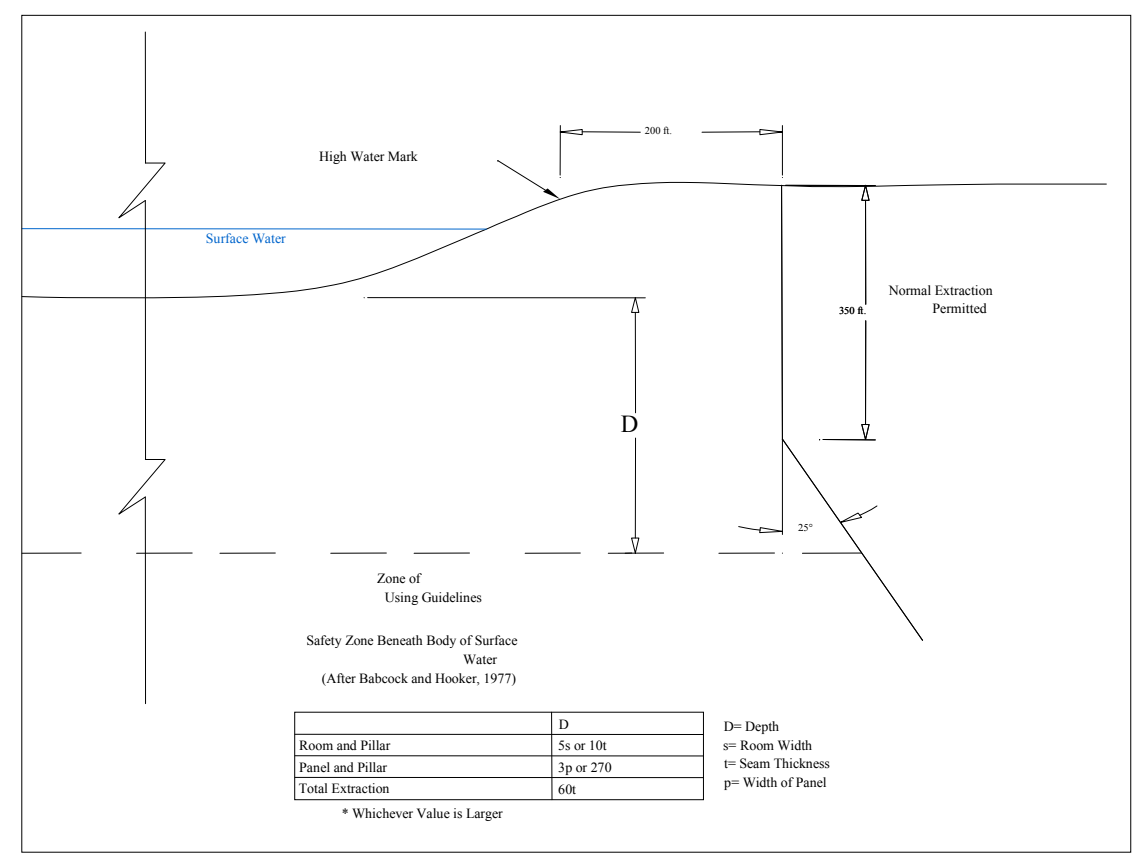

Figure 1- Guidelines for Mining Under Surface Bodies of Water (After Babcock and Hooker 1977)

\section{$\underline{\text { Total Extraction Mining }}$}

For total extraction mining, the guidelines determined that for each foot of coal extracted, a minimum of 60 feet of solid cover (rock) must be between the seam and the water body. If there are other materials located above the seam, they can be included in the 60 foot if proper permeability tests are performed. If they cannot be considered impermeable, that depth should be excluded. In cases where surface strain calculations can be made, the maximum tensile strain cannot exceed $8.75 \mathrm{~mm} / \mathrm{m}$. In cases of multiple seams, the lower seam should be partially extracted as if the upper seam was a water body. If a fault lies in the extraction zone that has a vertical displacement of over $10 \mathrm{ft}$, no seam should be totally extracted within $50 \mathrm{ft}$. There is no mention of partial extraction in this zone. 


\section{$\underline{\text { Partial Extraction Mining }}$}

\section{Room and Pillar}

The room and pillar mining method, in which pillars of coal are left to add support to the overlying surface, has stipulations based on the size of the room and the depth under the body of water. These guidelines state the strata must be no less than 5 times the entry width or 10 times the entry height, whichever is greater. If sandstone or a similar material with a width of at least 1.75 times the entry width is present, mining below these guidelines may be considered. There is no mention of how far below guidelines they can go. These guidelines apply to tunnels and drifts

as well, unless permanently supported; in which case the strata cover should be no less than 1.75 times the tunnel width.

This work lists multiple tables which determine the minimum thickness the pillars must meet. This is determined based on the depth of the seam, height of the pillar and the width of the room. If the height of the pillars is not listed in the charts, a formula for determining the width is given.

\section{Panel and Pillar}

The guidelines set for panel and pillar mining are set where there is minimal deflection by the overlying strata. This states that the strata cover must be $270 \mathrm{ft}$ or 3 times the width of the panel, whichever is greater. In addition the widths of these panels should not exceed one-third the mining depth. The pillar widths should be 15 times their height or one-fifth the mining depth, whichever is greater. When multiple seams are mined, the pillar widths should be determined by the thickest or deepest seam, whichever will give the greater pillar width.

\section{Mining near Surface Structures}

IC8741 considers risk to a surface structure if its failure would cause "loss of life, property damage, or damage to water supplies needed for the public welfare." It recommends that the offset perimeter be designed by those who are in charge of maintaining the integrity of the structure itself. However it has developed guidelines for these zones. Similar to mining under surface bodies of water, the offset zones for mining near a dam require a horizontal barrier of $200 \mathrm{ft}$ for depths up to $350 \mathrm{ft}$. For depths greater than $350 \mathrm{ft}$, and additional offset extending 65 degrees from horizontal is required. The difference for surface structures is that IC8741 does not allow mining to occur within this zone under any condition. These zones are detailed in Figure 2. 


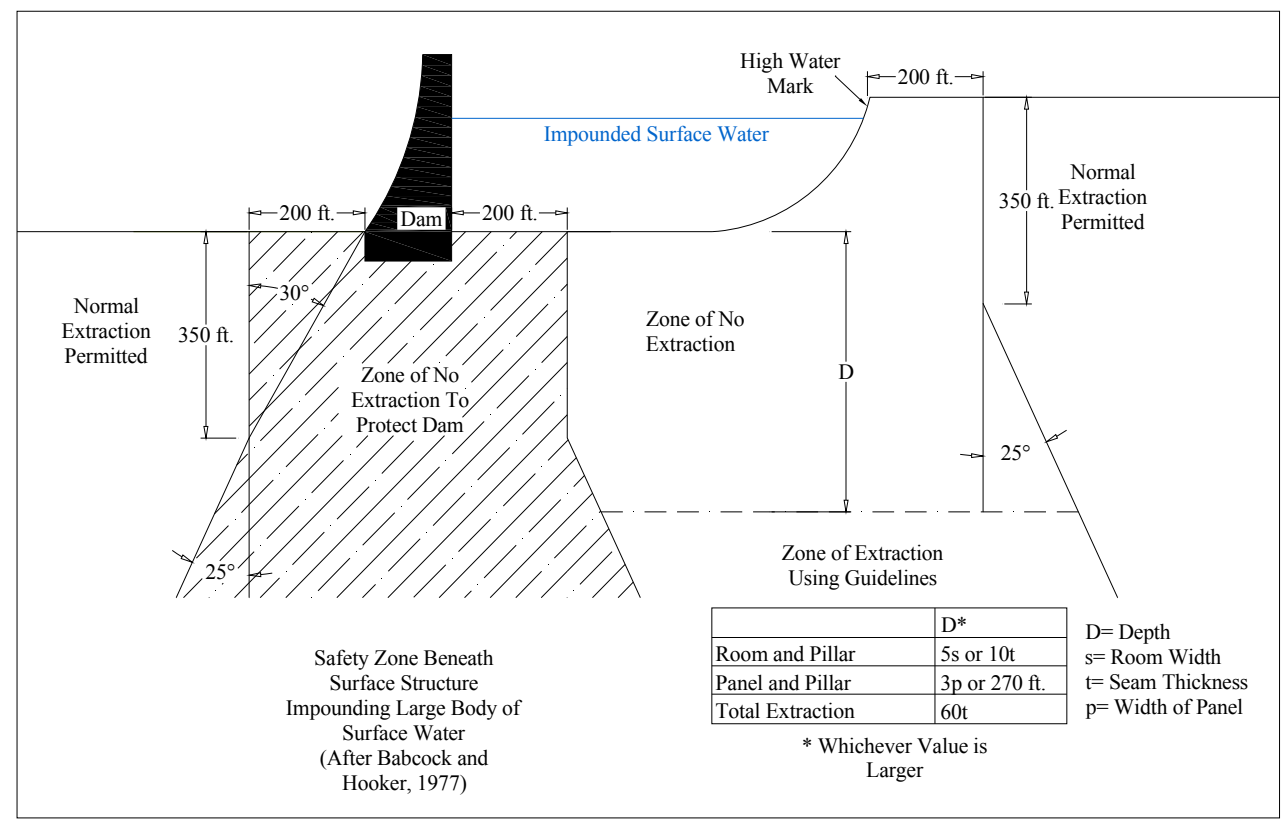

Figure 2 - Safety Zone Beneath Dam and Impounded Body of Surface Water (Babcock and Hooker 1977)

\section{MINING DEPTH}

Mining depth plays a key role in determining the horizontal distance affected by subsidence and groundwater changes. The angles of subsidence and groundwater draw extend outwards from the edge of the mine to the surface. In general, the greater the depth of the mine, the greater surface area affected. However the extent of these changes is also affected with mining depth. Using field and empirical data

Mining depth was researched by Wenbing Guo, Khaled Morsy and Syd Peng for the $26^{\text {th }}$ International Conference on Ground Control in Mining. The author's discuss how surface subsidence is directly affected by the depth of the mine. There have been conflicting reports as to whether the depth of a mine actually increases or decreases surface subsidence. In this report they used six different models for strip pillar mining to analyze the affects of subsidence based on the depth of the mine, panel width, pillar width, thickness, recovery ratio, mining method along with other factors. Their determination is that mining depth is the most important factor when dealing with subsidence.

The elastic modulus of the strata was reduced to $1 / 4$ of the actual figure for intact rock to determine the fractured rocks properties. Additionally the mined area is large to induce full caving. The gob is solidly recompressed to allow for some additional support to the overburden. The gob has shown that as it is compressed the modulus of elasticity increases. This is determined by using the following equation; 


$$
\sigma=\frac{R_{o} \times E_{i}}{a} \times\left(e^{\epsilon \times a}-1\right)
$$

$\sigma$ is the vertical stress

$C$ is the vertical strain

The depths of the models were from $300 \mathrm{~m}$ to $800 \mathrm{~m}$ increasing in increments of $100 \mathrm{~m}$. The average mine height was $4 \mathrm{~m}$. The width was $60 \mathrm{~m}$ and the amount of extraction was $50 \%$. There were 6 mining strips with 5 pillars in each model. The 2 side pillars varied from $1,100 \mathrm{~m}$ to $2,300 \mathrm{~m}$. The following figures show the surface subsidence results from the models;

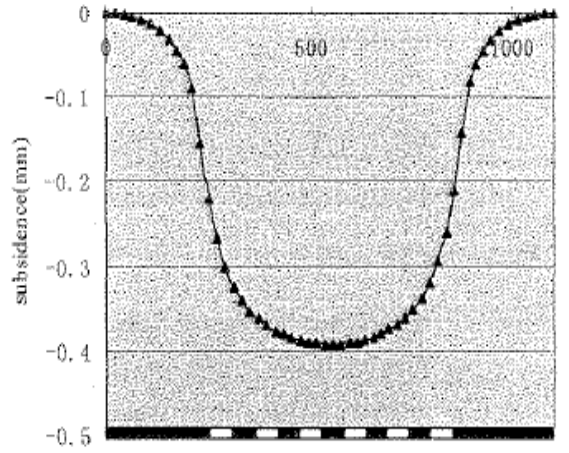

Figure 1 Subsidence curve for model No. 1 (mining depth is $300 \mathrm{~m}$ )

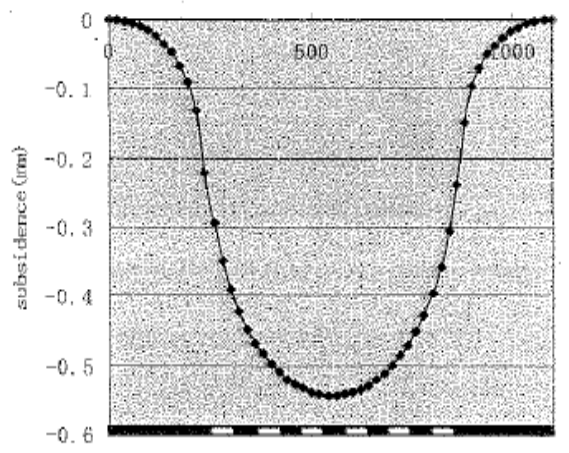

Figure 2 Subsidence curve for model $\mathrm{No}, 2$ (mining depth is $400 \mathrm{~m}$ )

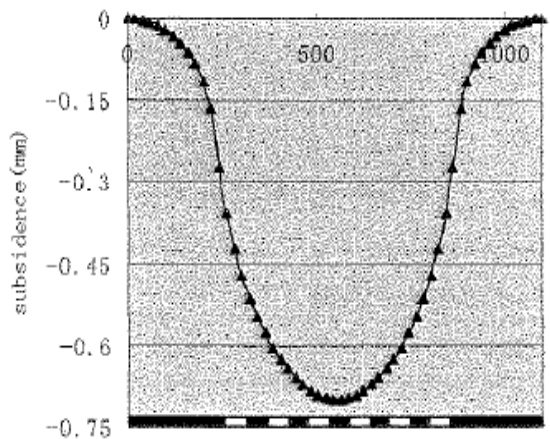

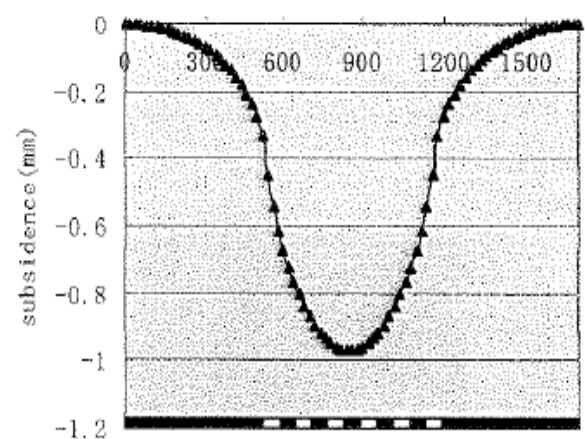

Figure 4 Subsidence curve for model No. 4 (mining depth is $600 \mathrm{~m}$ )

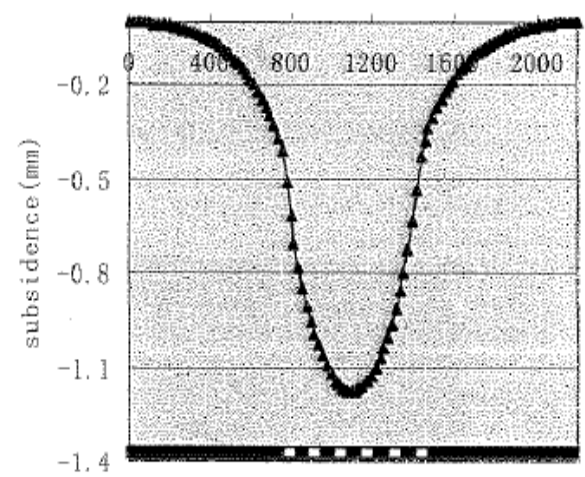

Figure 5 Subsidence curve for model No. 5 (mining depth is $700 \mathrm{~m}$ )

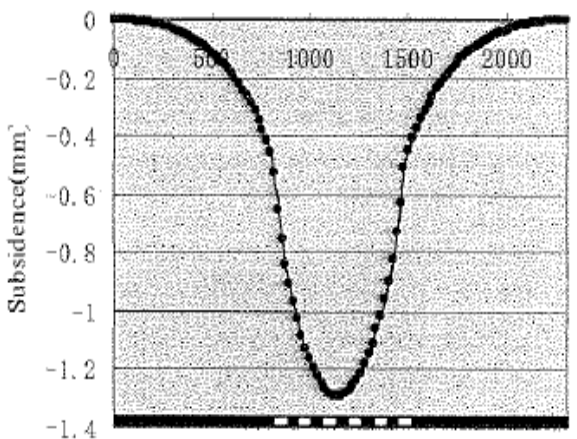

Figure 6 Subsidence curve for model No. 6 (mining depth is $809 \mathrm{~m}$ ) depth (Guo 2007)

Figure 3- Subsidence curves for mining depth (Guo 2007) 
The results show that the strip pillar mining is similar to full extraction mining at shallower depths (figures 1 and 2). Maximum subsidence occurs in the center of the surface vertically above the center of the gob. In greater depths the strip pillar mining changes to subcritical mining subsidence. Due to this, the critical subsidence factor needed to be calculated in order to compare the results. The following equations were used to determine this;

$$
q=\frac{W_{\max }}{\left(m \times \cos \alpha \times n_{1} \times n_{3}\right)}
$$

$\mathrm{q}$ is the subsidence factor

$\mathrm{W}_{\max }$ is the maximum surface subsidence

$\mathrm{M}$ is the mining height

A is the friction angle of coal seam

$\mathrm{n}_{1}$ and $\mathrm{n}_{3}$ are factors of mining extent based on the following equations;

$$
\mathrm{n}_{1}=\mathrm{K}_{1} * \mathrm{D}_{1} / \mathrm{H} \quad \mathrm{n}_{3}=\mathrm{K}_{3} * \mathrm{D}_{3} / \mathrm{H}
$$

$\mathrm{K}_{1}$ and $\mathrm{K}_{3}$ are constants usually equal to 0.8

$\mathrm{H}$ is the mining depth

If $n_{1}$ or $n_{3}$ is greater than 1 , the value is 1

As a result, the following equations were created for determining the maximum subsidence value and the surface subsidence factor;

$$
\begin{gathered}
\mathrm{W}_{\max }=0.9904 \ln (\mathrm{H})-5.2866 \\
\mathrm{q}=0.2936 \ln (\mathrm{H})-1.5934
\end{gathered}
$$

These equations show the relationships of mining depth and maximum surface subsidence and the subsidence factor in Figure 4

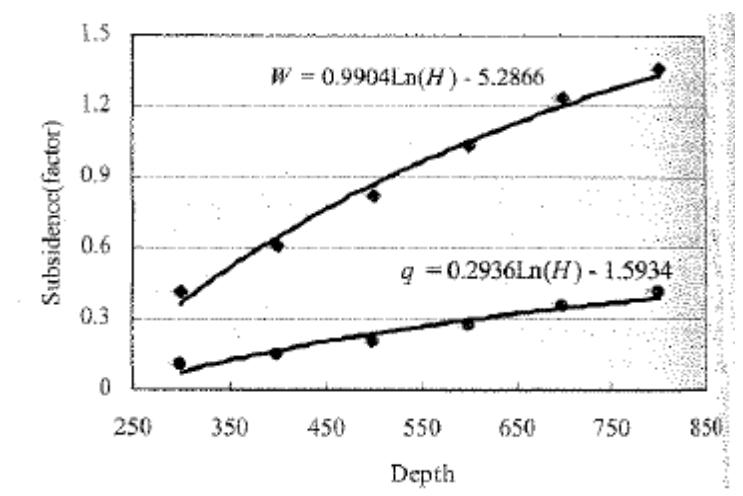

Figure 4- Subsidence factors based on depth (Guo 2007)

The results show that the maximum surface subsidence in strip pillar mining increases with mining depth. This is due to an increased load on the pillars and gob within the mine. As these 
become more compressed, the subsidence factor and value increase. However in a full extraction mine the opposite is true. According to the authors, both theoretical and field data show that less strata subsidence will transmit to the surface. As the mine depth increases, the voids and separations in the strata also increases. While the characteristics of the subsidence at the surface are similar for each method, the amount is different.

\section{SUBSIDENCE}

\section{Types of Subsidence}

Subsidence is the vertical displacement of surface soils caused by a void in the underlying strata. For the purpose of this report, the voids discussed are developed due to mining operations, either longwall or room and pillar. As a mine is formed, the overlying strata bend and fracture, creating vertical movement at the ground surface. This movement is critical in determining the effects of mining because it not only can cause damage to surface structures but creates strain in bed layers, both vertically and horizontally. Increased strain is the determining factor that leads to increased hydraulic conductivity and seepage erosion progression.

There are 4 types of subsidence due to underground mining (Craft 1992). These are pit subsidence, room subsidence, sag subsidence and beam subsidence. Each type of subsidence develops based on the geological setting around the mine itself. The key factors in determining the subsidence are depth of mine, overburden and the topography.

\begin{tabular}{|c|c|c|c|c|c|c|}
\hline \multirow{2}{*}{$\begin{array}{l}\max \text { or } \\
\text { sinstoses }\end{array}$} & \multirow{2}{*}{\multicolumn{2}{|c|}{ PIT }} & \multirow{3}{*}{ 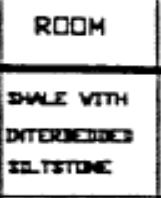 } & \multirow{3}{*}{ 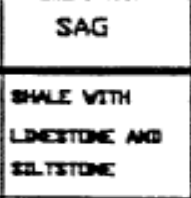 } & \multicolumn{2}{|c|}{ BEAM } \\
\hline & & & & & \multirow{2}{*}{ 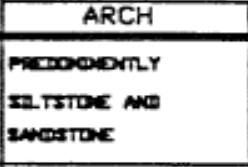 } & \multirow{2}{*}{ 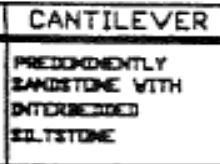 } \\
\hline QVERBURDEN & 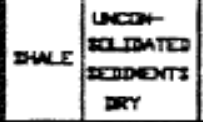 & 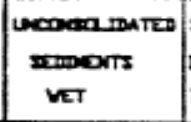 & & & & \\
\hline TDPQGRAPHY & 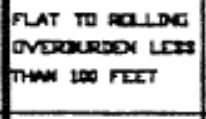 & 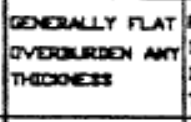 & 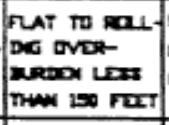 & 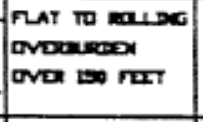 & 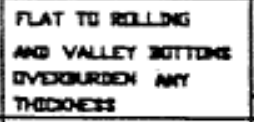 & 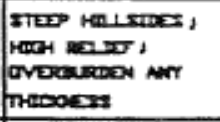 \\
\hline $\begin{array}{l}\text { SURFACE } \\
\text { EXPRESSIDN }\end{array}$ & 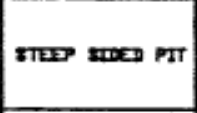 & $\begin{array}{l}\operatorname{mes} \\
\operatorname{mos} \\
\operatorname{mox}\end{array}$ & 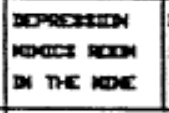 & 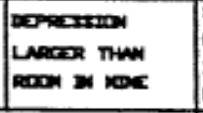 & 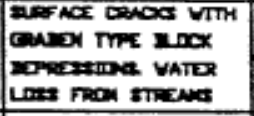 & 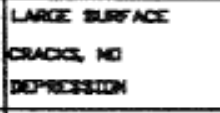 \\
\hline DEPTH & 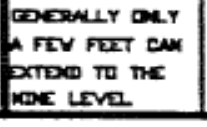 & 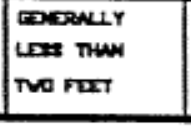 & \multicolumn{2}{|c|}{ 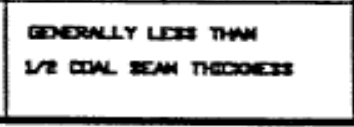 } & 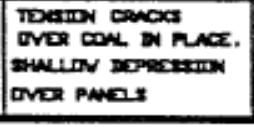 & 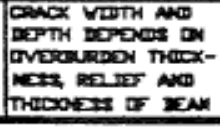 \\
\hline \multicolumn{7}{|c|}{ REMEDIAL MEASURES } \\
\hline EMERGENCY & 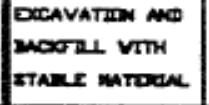 & \multicolumn{4}{|c|}{ 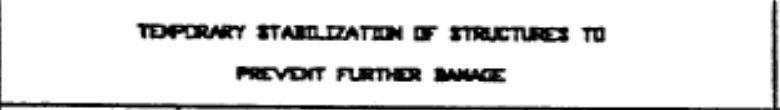 } & 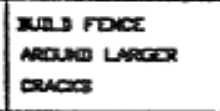 \\
\hline $\begin{array}{l}\text { LDNG } \\
\text { TERM }\end{array}$ & 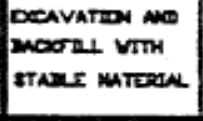 & 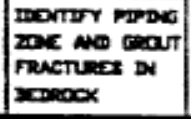 & 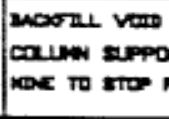 & 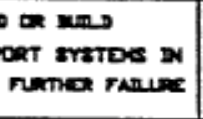 & 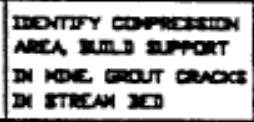 & morest \\
\hline
\end{tabular}

Table 1- Subsidence types (Craft 1992) 


\section{$\underline{\text { Pit Subsidence }}$}

Pit subsidence is the initiation of a small surface depression directly above the mine that extends varying depths towards the mine. Maximum subsidence generally occurs directly over the mine itself with easing effects extending outwards in all directions. This type of subsidence occurs when mining induces fracturing in the overburden or where the operation disturbs existing fractures. In this instance a steep sided pit is formed. The actual size and shape of the pit is determined by the composition of the overburden and presence of a water table. If the overburden contains continuous layers of solid rock such as shale, the fractures will extend through the broken (fractured) zone to the surface due to local caving effects from the mine. If unconsolidated material is present, fracturing will cease at the contact point. However the unconsolidated material may be susceptible to hydraulic transport into the mine void or other types of erosion due to strain effects. The three typical settings for this type of subsidence to occur are where; 1) thin-bedded shale is present, 2) a perched water table with unconsolidated material exists or 3) in areas of a seasonal water table.

When either water table type is present the sediment may travel through the fractured material into the mine void. If the fractured zone lies in contact with unconsolidated material, hydraulic transport of fines can occur. This will in effect lower the water table and draw water from outlying areas not directly influenced by subsidence.

\section{$\underline{\text { Room Subsidence }}$}

Room subsidence occurs in overburden directly over the mined region extending upwards in converging towards directly above the center of the mine void. Due to this, the area affected is generally less than or equal to the area of the mine. This type of subsidence occurs in shallow mines generally less than $100 \mathrm{ft}$ deep and in predominately shale. According to Craft (1992), the maximum vertical displacement of this type of subsidence is less than half the thickness of the original mine void and occurs very rapidly. After such an instance occurs, there is minimal movement at the edges of the depression.

\section{$\underline{\text { Sag Subsidence }}$}

This type of subsidence is limited to partial extraction mining where the pillars fail from crushing causing roof failure. It occurs in areas where overburden consists of limestone, shale and siltstone at depths greater than $150 \mathrm{ft}$. Although the surface cracks are generally small (several inches) the angle of draw diverges towards the surface extending past the mined seam. When the pillars begin to fail subsidence occurs rapidly and will continue to occur over a long period of time. Surface structural damage is common with this type of subsidence, especially at the edge of the subsiding area. 


\section{Beam Subsidence}

Beam subsidence can occur in two ways: cantilever and arch beam failure. Cantilever beam subsidence occurs when a layer of hard rock lies above a coal seam but outcrops overtop of the coal seam. For full extraction mining the entire weight of the remaining overburden is placed on this seam. If pillars are left as in partial extraction, the weight extends to them. As the pillars fail, the overburden acts on the cantilever beam dropping the opposite end of the beam. This type of subsidence causes a large fissure in the overburden directly above the support structure on the supported side of the beam. This type of subsidence occurs in areas of steep terrain.

Arch beam failure occurs when a large area of coal is left between two room and pillar areas. This potentially may occur between longwall mining. Over time the pillars will slowly crush or fracture causing settling directly above the mined areas. As both sides settle, the overburden in the middle will arch creating high zones of tension directly above the untouched coal extending outward to the mined sections. This type of subsidence will occur slowly and under all types of terrain.

\section{$\underline{\text { Duration of Subsidence }}$}

The timeline for subsidence to occur is directly dependent on the type of mining that occurs. Full extraction such as longwall mining occurs almost instantaneously and can continue for several years after initial mining takes place. Table 4 shows estimated timeframes for longwall mining (Singh 1992).

\begin{tabular}{|c|c|c|}
\hline Reference & $\begin{array}{l}\text { Country/ } \\
\text { Coalfield }\end{array}$ & $\begin{array}{c}\text { Residual Subsidence } \\
\text { Duration }\end{array}$ \\
\hline $\begin{array}{l}\text { Institution of Municipal } \\
\text { Engineers (Anon., } \\
\text { 1947) }\end{array}$ & UK & 2 to 10 years \\
\hline Orchard \& Allen (1974) & UK & $\begin{array}{l}\text { Several months to } 3 \text { to } \\
6 \text { years (strong } \\
\text { overburden) }\end{array}$ \\
\hline Collins (1977) & UK & 2 to 4.5 years \\
\hline Grard (1969) & France & 6 to 12 months \\
\hline Bratuer (1973) & Germany & $\begin{array}{l}1 \text { year (Cretaceous } \\
\text { overburden) } \\
2 \text { years (sandstone } \\
\text { overburden) }\end{array}$ \\
\hline Brauner (1973) & USSR & $\begin{array}{l}2 \text { years (shallow } \\
\text { mines) } \\
4 \text { to } 5 \text { years (deep } \\
\text { mines, }>1300 \mathrm{ft} \text { or } \\
400 \mathrm{~m} \text { ) }\end{array}$ \\
\hline $\begin{array}{l}\text { Shadrin and Zamotin } \\
(1977)\end{array}$ & USSR & 2 to 25 months \\
\hline Gray et al. (1977) & US/Appalachian & $\begin{array}{l}\text { Few months to few } \\
\text { years }\end{array}$ \\
\hline Hood ef al. (1981) & US/Illinois & 12 months \\
\hline
\end{tabular}


In general, initial subsidence occurs when a void is created in the subsurface. As the overburden begins to fracture and sag, the subsidence effects will continue to increase. As long as the overburden cannot support itself, the effects will continue.

Duration time for subsidence due to room and pillar mining is much more complicated to predict. Unlike full extraction mining, the pillars will support the overburden as long as they are intact. Some initial subsidence will occur but generally in localized areas and only minimal effects will be seen. Overtime, the pillars will begin to fail. Once one begins to crush or fracture, the weight supported by that pillar will be transferred to the other surrounding pillars. With additional weight placed upon them, these pillars will begin to fail as a faster rate creating a domino effect.

The initial failure event for pillars is dependent on multiple factors. The depth of the coal seam affects the overall weight needed to be supported. The width of the pillars and placement affects how much each one is designed to support. The terrain and the dip of the coal seam affects how much overburden each pillar is designed to support and the type of strata dictates how a pillar is likely to fail. Because of all the unknown factors in pillar design and overburden, it is hard to predict the timeframe when subsidence will occur. What is known is that failure will eventually occur and it will be relatively quick when it does (citation needed). Over a long period of time, room and pillar mining will have the same subsidence effect on the surface as full extraction mining would.

\section{Effects of subsidence}

Longwall mining causes subsidence to occur quickly, which affects the overburden. These changes occur in the form of fracturing and bed separation. At the surface, subsidence can be up to 60-90 percent of the thickness of the coal seam (Booth 2000). As this occurs, groundwater flow and aquifers can be altered due to changes in hydraulic properties. Over time the overburden will recover to an extent, however in most cases there is permanent increase in the soil hydraulic conductivity.

Maximum subsidence generally occurs directly above the mine (Singh 1992). The amount of subsidence is dependent on the width of mine (Singh 1992). This would be the size of the room for partial extraction or the width of the longwall for full extraction. The critical width is the distance necessary for full subsidence to occur. If this width is not reached, subsidence will occur albeit at a lesser rate. Figure 6 shows how the room width of the extraction seam can affect the amount of subsidence occurring. 


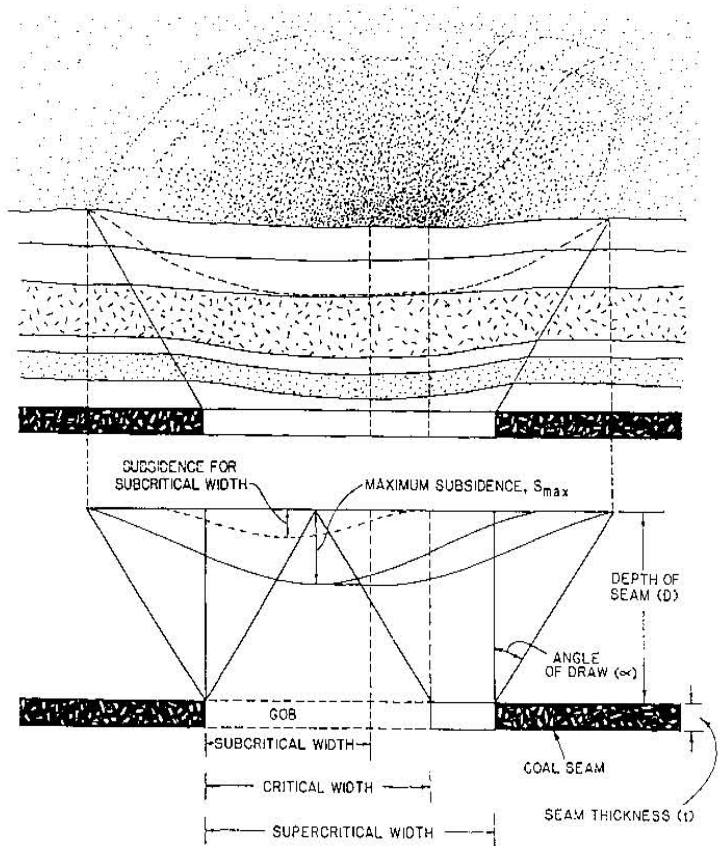

Figure 6- Subsidence Zones (Singh 1992)

Longwall mining creates rapid subsidence, generally within several weeks because of the full extraction method (Booth 2000). As the mine face advances it creates what is known as a "subsidence wave". This is shown in figure 7. The subsidence wave creates zones of tension and compression that create fracturing and separation of the bed layers. The rapid changes are expressed in stages (Booth 2000). The initial response is lowering of groundwater head outside of the mining zone. This is known as the angle of groundwater draw. The lateral distance affected is dependent on the transmissivity of the overburden. Recovery of the water levels can occur after mining but timeframe is hard to predict. In several cases water levels recovered within several months. In another case study, only 1 out of 19 had any significant recovery (Booth 2002).

\section{STRAIN EFFECTS}

Generally subsidence creates zones of compression directly above the extracted coal seam with areas of tension beginning near edges and extending outwards. The zones of tension and compression are shown in figure 8 with the inflection point of where the change between the two occurs. Heavy fracturing and compression occur directly above the mine where tensional strains occur past the inflection point outwards to the extent of where the rock is undisturbed. This correlates with the angle of subsidence. 


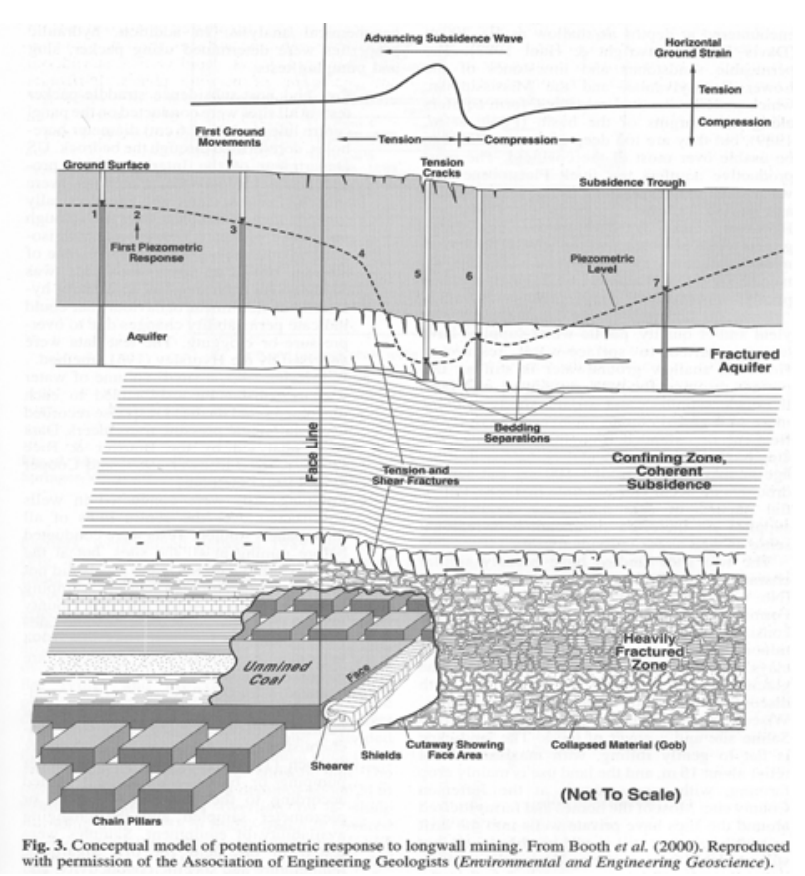

Figure 7- Compression Wave (Booth 2002)

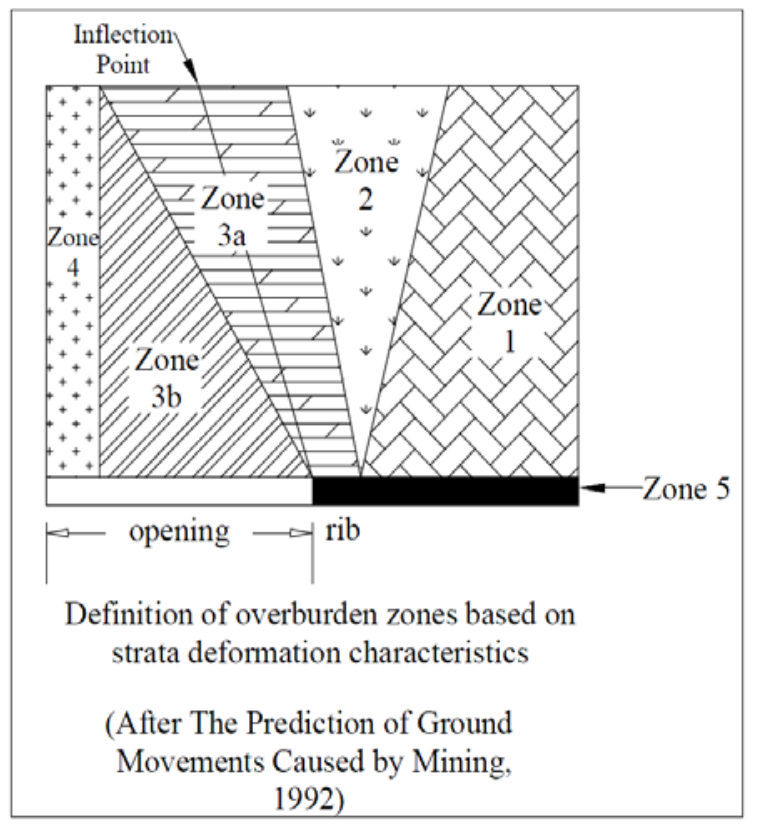

- Zone 1 or Intact Zone- Includes the strata below the seam and the undlsturbed rock outside of the influence area

- Zone 2 ar Intermediate Zone- Extends between the outermost boundary of Zone 3 and the boundary of Zone 1, over the rlb or the excavatlon. The angel of fracture, when available, is also used to define the right boundary of this zone.

- Zone 3 or Fractured Zone- Includes the high shear area around the inflection point

- Zone 4 or Affected Zone- Extends from the innermost boundary of Zone 3 to the center-line of the panel. In this zone, the strata is assumed to be primarly subject to translation, without being exposed to high stresses assoclated with the high shear zone.

- Zone 5 or Extraction Zone- Represents the coal seam

Figure 8- Zones of Overburden (After Karmis 1992)

The recommended tolerable strain for groundwater aquifers and surface bodies of water is 0.005 (Singh 1992). However, research has shown that increased permeability can occur with extensional strains of 0.001 (Bai 1995). This is 5 times less than the recommended guidelines. IC 8741 recommends strains not to exceed 0.00875 which is far greater than both of these values. 
Field data from the eastern United States shows a range of 300 to 970 micro strains (Dolinar 1999). These values are shown in table 2. For the 36 sites examined, all showed maximum strain values above what can initiate increased permeability based on Bai (1995).

Table 1. Average excess applied horizontal strain by region for the eastern United States.

\begin{tabular}{lccccccc}
\hline \multicolumn{1}{c}{ Region } & $\begin{array}{c}\text { Number of } \\
\text { Sites }\end{array}$ & $\begin{array}{c}\text { Maximum } \\
\text { Strain Micro } \\
\text { strain }\end{array}$ & $\begin{array}{c}\text { Standard } \\
\text { Deviation }\end{array}$ & $\begin{array}{c}\text { Range of Site } \\
\text { Maximum Strain } \\
\text { Microstrain }\end{array}$ & $\begin{array}{c}\text { Minimum } \\
\text { Strain Micro } \\
\text { strain }\end{array}$ & $\begin{array}{c}\text { Standard } \\
\text { Deviation }\end{array}$ & $\begin{array}{c}\text { Strain Ratio } \\
\text { Max/Min }\end{array}$ \\
\hline $\begin{array}{l}\text { Northern Appalachian } \\
\text { Central Appalachian }\end{array}$ & 7 & 440 & 90 & $300-540$ & 260 & 70 & 1.69 \\
$\quad$ Low Strain Zone & 7 & 370 & 60 & $300-480$ & 170 & 70 & 2.17 \\
$\quad$ High Strain Zone & 12 & 760 & 130 & $550-970$ & 410 & 130 & 1.85 \\
Eastern Mid-Continent & 10 & 370 & 90 & $240-530$ & 80 & 90 & 4.6 \\
\hline
\end{tabular}

Table 2- Strain Values in Appalachia (Dolinar 1999)

\section{STRATA RESPONSE}

Strata response due to mining has been specifically detailed for the $14^{\text {th }}$ Conference on Ground Control in Mining with Mao Bai, Francis Kendorski and Danny Van Roosendaal titled Chinese and North American High Extraction Underground Coal Mining Strata Behavior and Water Protection Experience and Guidelines. This is an extension on the strata zones that were discussed in a report written in 1979 titled Criteria for Determining When a Body of Surface Water Constitutes a Hazard to Mining for the U.S. Bureau of Mines. This report was written shortly after the IC 8741 report was available. In the overburden layers, the rock will lose strength from either tension or compression. The loss of strength results in fracturing and allows for increased permeability. These reports break down the strata layers from the mine to the ground surface into 5 separate layers. These layers are;

1.) Caved Zone

2.) Fractured Zone

3.) Dilated Zone

4.) Constrained Zone

5.) Surface Fracture Zone 
Figure 9 shows the zones and the approximate depth of each layer above a mine.

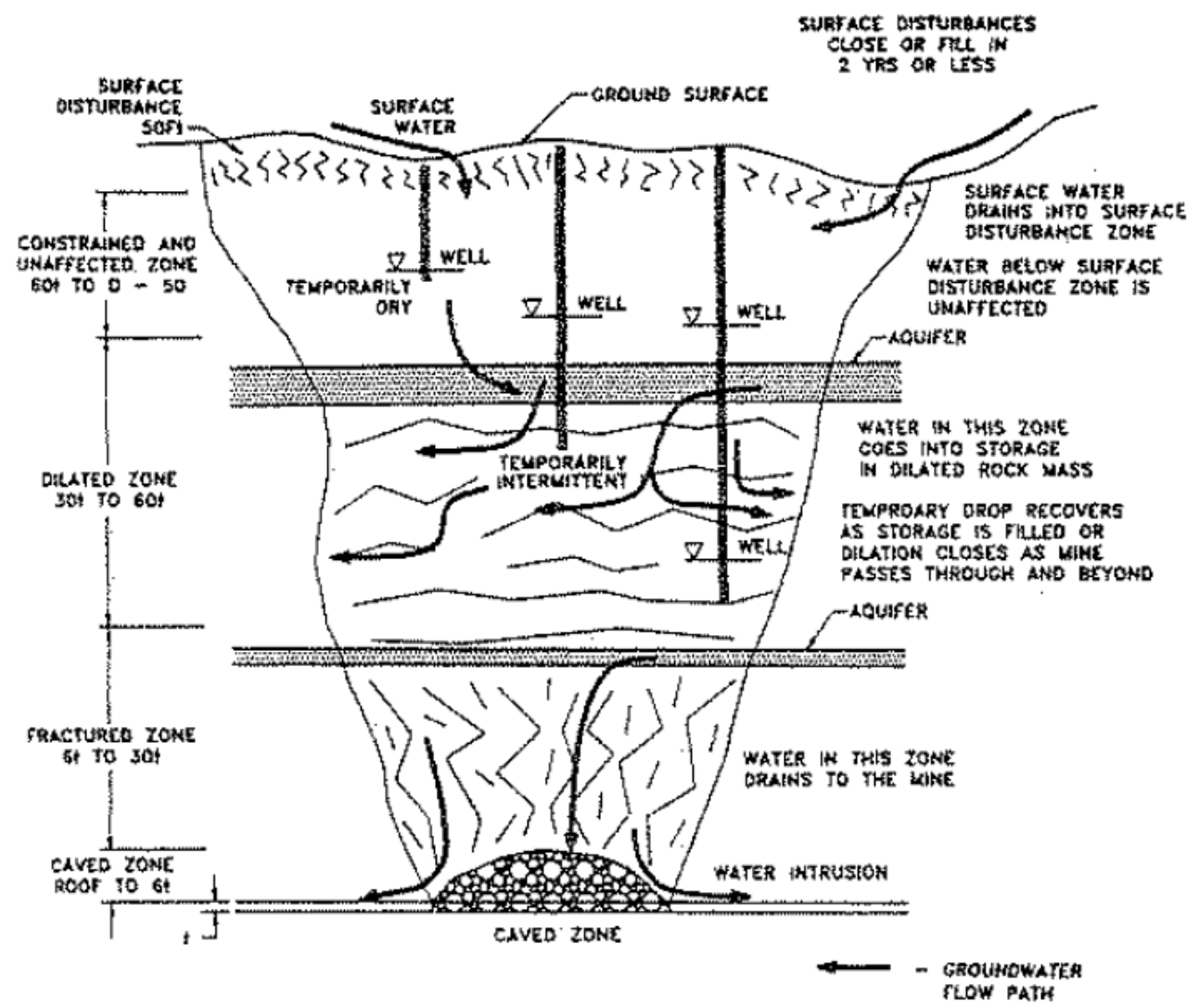

Figure 9- Subsidence Zones (Kendorski, 1979)

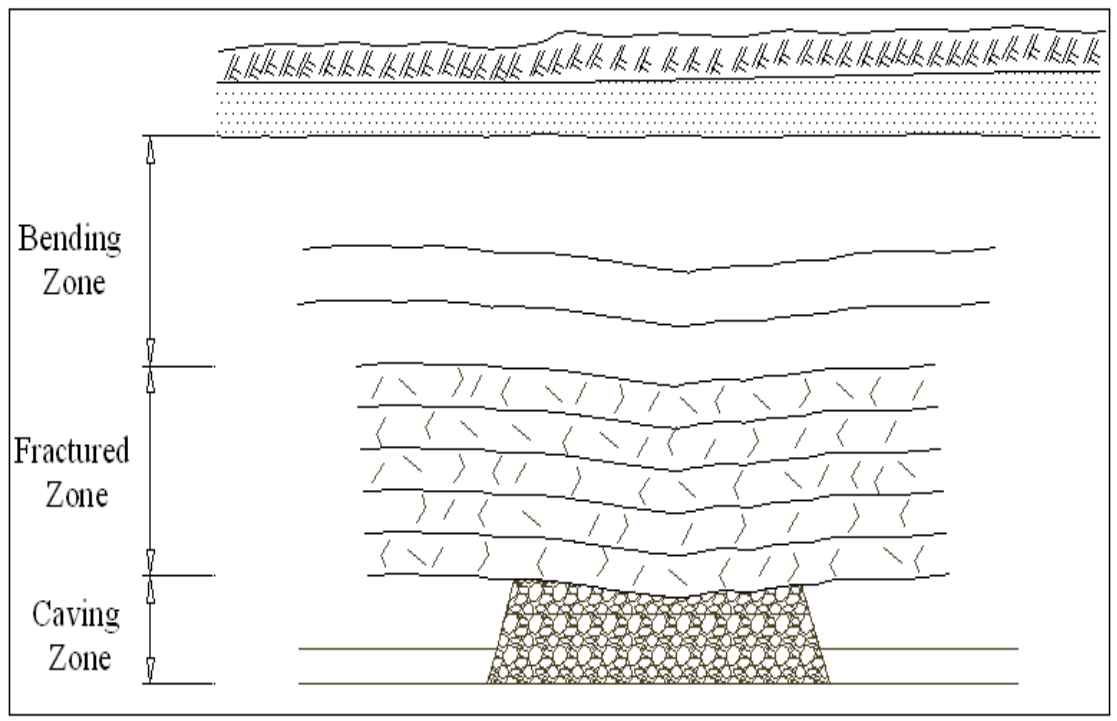

Figure 10- Subsidence Zones based on Chinese Literature (After Bai 1995) 


\section{Caved Zone}

The caved zone exists from the roof of the mine to approximately 6 times the thickness of the mine according to the reports. The amount of fracturing or caving in this zone is dependent on the rock dilation. This differs depending on the type of rock that is present in this zone. The average coefficient for rock dilation is usually less than 1.5 and decreases under multiple seams due to repeated compression. The report lists a table of these approximate coefficients. The Chinese have developed a formula for determining the extent of this zone.

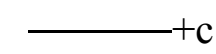

or is the extent of the caving zone in total height

$\mathrm{M}$ is the coal seam thickness

$\mathrm{a}$ and $\mathrm{b}$ are the coefficients of rock dilation (listed below)

$\mathrm{c}$ is the mean square deviation (listed below)

\begin{tabular}{|l|c|}
\hline Strata Lithology & Uniaxial Compressive Strength \\
\hline Strong & $>40 \mathrm{Mpa}(5,800 \mathrm{psi})$ \\
\hline Medium Strong & 20 to $40 \mathrm{Mpa}(2,900$ to $5800 \mathrm{psi})$ \\
\hline Weak & $<20 \mathrm{Mpa}(2,900 \mathrm{psi})$ \\
\hline
\end{tabular}

Table 3- Strata Lithology Versus Strength of Rock

\begin{tabular}{|l|c|c|c|}
\hline Strata Lithology & $a$ & $b$ & $c$ \\
\hline Strong & 2.1 & 16 & 2.5 \\
\hline Medium Strong & 4.7 & 19 & 2.2 \\
\hline Weak & 6.2 & 32 & 1.5 \\
\hline Weathered & 7.0 & 63 & 1.2 \\
\hline
\end{tabular}

Table 4- Coefficients for Maximum Height of Caving Zone $\mathbf{H}_{c}$ 


\begin{tabular}{|l|c|c|c|}
\hline Strata Lithology & $\mathrm{a}$ & $\mathrm{b}$ & $\mathrm{c}$ \\
\hline Strong & 1.2 & 2.0 & 8.9 \\
\hline Medium Strong & 1.6 & 3.6 & 5.6 \\
\hline Weak & 3.1 & 5.0 & 4.0 \\
\hline Weathered & 5.0 & $\mathbf{8 . 0}$ & 3.0 \\
\hline
\end{tabular}

Table 5- Coefficients for Maximum Height of Caving Zone $\mathbf{H}_{\mathrm{f}}$

Field tests have shown that the caved zone does fall into the criteria of the report. The studies have shown that the caving zones fell between 2 and 10 times the seam height. The field tests also have shown that weaker strata actually cave less than stronger strata. This is because the weaker strata will sag rather than break apart. The Chinese guidelines follow this pattern.

\section{Fractured Zone}

The fractured zone consists of the area above the caving zone to an aquifer layer. This zone ranges from $6 \mathrm{t}$ to up to $30 \mathrm{t}$ (where $\mathrm{t}$ is the seam thickness) depending on the geologic profile of the overburden. Within this region, the ground water will eventually drain into the mine. There are several types of fractured zones according to Chinese reports (Bai 1995). The severely fractured zone consists of large separation of the strata with flow rates greater than $1 \mathrm{liter} / \mathrm{sec} / \mathrm{m}$. The moderately fractured zone has only partial separation with ground flows ranging from 0.1 to 1 liter/sec/m. The slightly fractured zone has only small fractures. The flow rates in this region are less than 0.1 liter $/ \mathrm{sec} / \mathrm{m}$.

The following equation can be used for determining the height of this zone. This also includes the caved zone;

$a, b$ and $c$ are coefficients of the strata

$\mathrm{n}$ is the number of lifts

As with the caved zone, weaker strata have a smaller fractured zone. In North America the fractured zone is approximately $24 \mathrm{t}$ for strong strata and decreases to $19-20 \mathrm{t}$ for weaker strata and even down to $10 \mathrm{t}$ in certain instances (Bai 1995).

The fractured zone does not remain constant. According to the report, the fractured zone will reconsolidate over time (Bai 1995). The length of time is also a function of the type of overburden. Stronger strata will remain constant for a least a month and remain up to 20 years before reconsolidation occurs. Weak strata will remain for only 6 months to 17 months. At this 
point the zone will decrease at an average rate of $0.4 \mathrm{~m}$ per month. Field experience has shown that the fractured zone will also from a saddle shape due to compaction.

\section{Dilated Zone}

The dilated zone reaches from approximately 30 times to 60 times the coal seam thickness above the mine. This zone is not recognized in the Chinese empirical zones (Bai 1995). The strata in this area acts as multiple thin beams that bend which ultimately cause surface fracturing. There is little fracturing in this zone because the rock beds act differently under stresses and tend to separate. This does however increase the water storage volume of this zone. The bending causes tension on the lower portion of the beams and compression on the upper portions. This can be a result of the saddle formation in the lower zones. Due to the different stiffness of the beams, there is considerable shear present in the dilated zone. This will cause larger deformations in the zone but will not increase (actually lower) the vertical transmission of groundwater. In three layer subsidence, this zone is included in the fractured zone. However in this report it is a separate zone due to its minimal vertical flow. It lies above an aquifer zone and therefore cannot increase the volume of water flowing into the mine.

\section{Bending or Constrained Strata Zone}

This zone lies between the dilated and surface zones. It lies above an aquifer zone and does not allow additional water to flow into the fractured zone and ultimately into the mined area. According to Bai (1995), this zone is a barrier that provides a measure of safety for the water bodies above.

This zone only exists when the mine lies deeper than the combination of the surface and fractured zones. It is characterized by having tensile strains less than $1 \mathrm{~mm} / \mathrm{m}$ where there is no increased permeability. However Bai (1995) expresses that localized excessive strains may occur in this zone. The report by Kendorski (1979) also determines that this zone should be comprised of shale to limit fracturing and become "self-healing".

The Chinese have a similar aquiclude zone that allows for clays, shale, and crystalline rocks. Their equation for the thickness of this zone is;

$$
H_{p}=d\left(\frac{M}{n}\right)
$$

Where:

$\mathrm{M}$ is the seam thickness

$\mathrm{n}$ is the number of lifts

$\mathrm{d}$ is the coefficient for thickness of the protective layer 
The coefficient is based on the presence of clay material at the bottom of unconsolidated layer. The amount present dictates the coefficient used.

Surface Zone

There is no real data to express the depth of this zone. In figure 9, Kendorski (1979) lists the extent of surface subsidence to $50 \mathrm{ft}$. However the actual depth is reliant on the type of properties in the strata. Soils are plastic in nature and will show very little fracturing but will show subsidence. Rock layers in this zone will show fracturing but natural fractures already exist in this zone. This will not cause any additional effects. The fractures in this zone are not expected to cause any additional water transfer into the fractured zone except in shallow mined areas.

\section{ANGLE OF DRAW}

Subsidence reaches its maximum displacement directly above a mine. However it extends horizontally past the mine void in a range called the angle of draw. In the United States the average angle of draw is expected to be less than 35 degrees in coal fields (Singh 1992).

Data for the Appalachian coal fields indicate that the subsidence angle of draw can extend more than 40 degrees. The Mining Engineering Handbook listed typical values of angle of draw ranging between 10 to 38 degrees for the eastern United States (Singh 1992). For case history data the range for Appalachia and Illinois subsidence generally falls between 20 to 40 degrees (Booth 2006). Peng discussed that the range of angle of draw has been reported to be between 4 to 45 degrees. However, in the development of a database for subsidence from longwall mining, Peng found the maximum angle of draw for 110 cases was 24 degrees. In $95 \%$ of these cases the subsidence was reported to be less than 20 degrees (Peng, et al. 1995).

\section{GROUNDWATER INFLUENCE}

Subsidence can affect permeability in the subsurface in multiple ways. It can create an area of compression above the mine causing an area of pooling. In areas of tension located within the area of draw, strain values will increase permeability. Both of these instances will allow for changes on subsurface water flows outside the angle of draw. The area affected is called the angle of groundwater influence. Like the angle of draw. This range develops at an angle extending outwards from the extents of the mine.

\section{Angle of Groundwater Draw}

The angle of groundwater draw is the region where permeability changes or head loss occurs due to subsidence affects. While related to angle of draw, it is not directly correlated to this. The angle of draw only shows the areas where fracturing causes hydrologic responses. The 
groundwater changes can extend much farther past this zone. The angle of groundwater influence correspondingly ranges from 16 to 60 degrees (Booth 2006). Generally groundwater influence is within 40 degrees unless in areas of steep terrain. However, in one case study, the range of groundwater or "dewatering" influence reached $70(60 \pm 20)$ degrees (Reed and Rauch 2001).

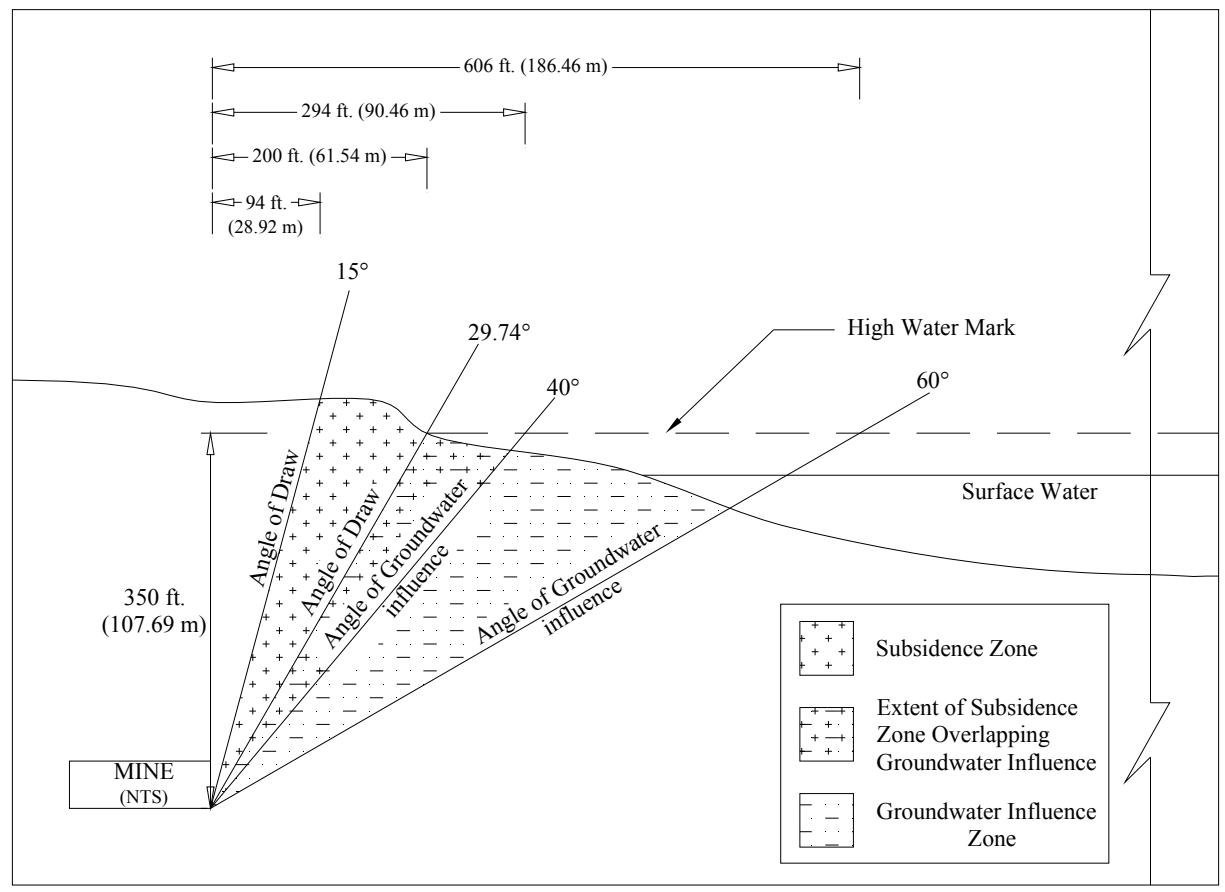

Figure 11- Subsidence Angle of Draw and Angle of Groundwater Influence

There is an interrelationship of these two effects, specifically the subsidence strain causing surface deformation changing strata permeability. Figure 1 illustrates that at an approximately $200 \mathrm{ft}(61.54 \mathrm{~m})$ offset, the angle of groundwater influence will extend into the surface water reservoir at the high water mark elevation for the full range of influence.

Kendorski identified that the subsurface strata permeability increases when strains due to mining are greater than $0.001 \mathrm{in} / \mathrm{in}$, or $0.1 \%$. Ground surface cracking develops parallel to mine edges directly above the mine with extensional strains ranging 0.006 to $0.009 \mathrm{in} / \mathrm{in}$. Field measurements indicate maximum tensile strains of 0.0134 and 0.021 (Kelleher 1991).

From the hydrogeology perspective, Booth presented research on the effects of mine subsidence related to issues including the advance of the subsidence wave which induces tension and compression strains leading to zones of subsidence extension, compression, and fractured zone (Booth, Curtiss et al. 2000). The overburden strata strain effects culminate to permeability changes occurring in the near surface soils. The changes occurring during mining are the highest. Booth reports that reductions in the subsidence compression have been shown at 
approximately $-10 x$. While the permeability increases in the extension (dilation) zones range from $+10 \mathrm{x}$ to $+1,000 \mathrm{x}$. These changes have permanent effects on the groundwater system.

\section{GEOLOGY}

The following figure shows typical geologic profiles for the Appalachian mountain range. The most common rock types found near coal seams are sandstone, shale, limestone and clays. The location of these layers is critical in determining the changes in hydraulic conductivity above a mine. Sandstone is a very hard rock with low transmissivity (thickness times hydraulic conductivity). However it is more susceptible to fracturing and is generally not self healing. Figure 13 shows that in the Kittaning coal seams there is an underclay and a sandstone located directly above the coal seam. In figure 12 there are limestone deposits located abover or below the coal seams. These are also present in the overburden layers which would be part of the fractured or constrained zones should mining occur.

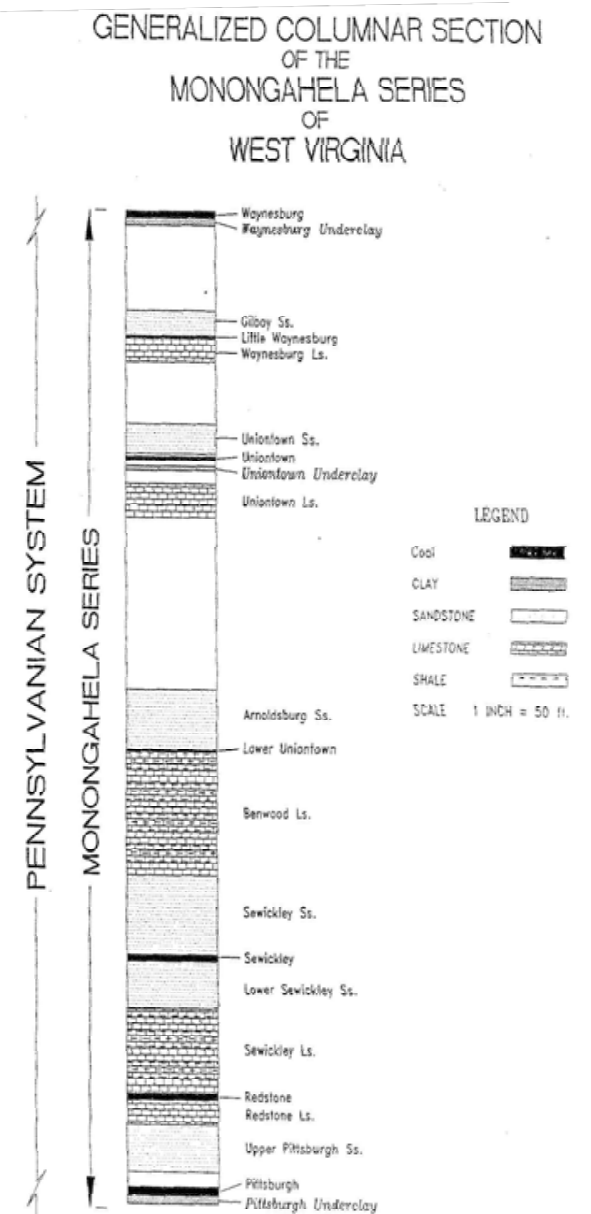

Figure 12- Monongahela Series

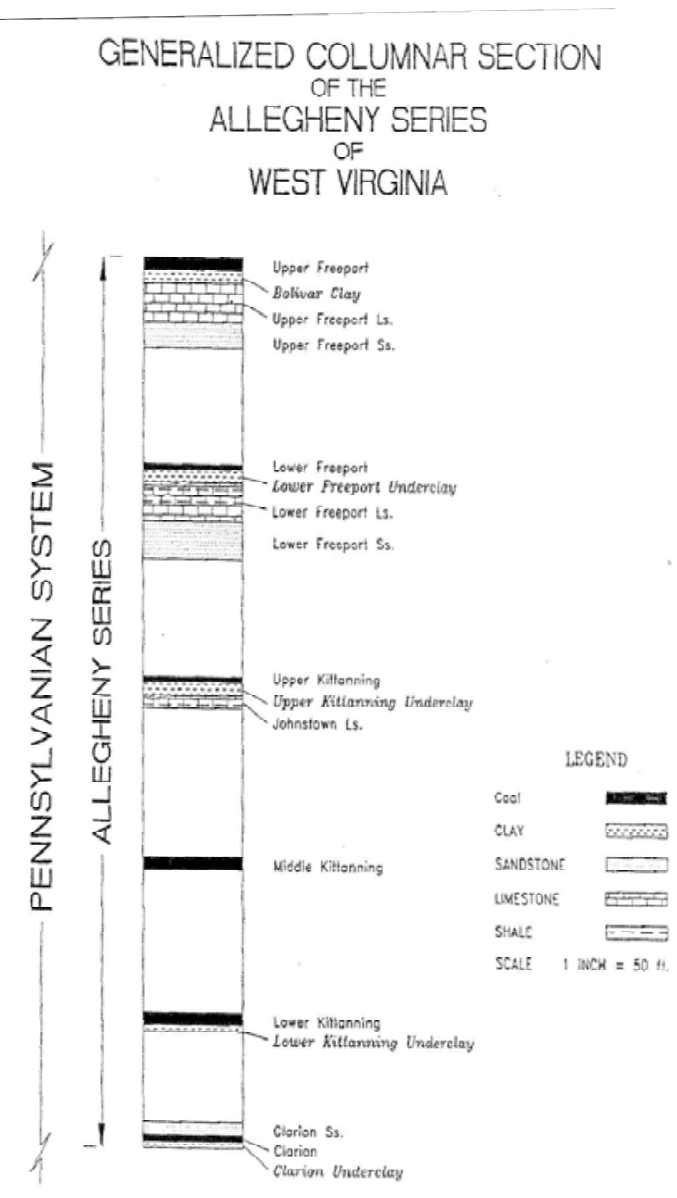

Figure 13- Allegheny series 


\section{EROSION}

Internal erosion is a progressive event in the failure mode process. It connects the physical changes in the soil structure and the final events that lead to failure. The erosion process occurs when subsidence and changes in groundwater flow cause the particles in the strata to begin to move. There are 4 types of internal erosion; concentrated, suffusion, backward erosion and contact erosion (Brown 2008).

\section{Concentrated erosion}

Concentrated erosion occurs within cohesive soils that can contain open cracks or a continuous voids either horizontally or vertically. For erosion to occur, the shear stress of the soil must be exceeded by the shear stress of the water flow. The shear stress in soils varies in several orders of magnitude(Brown 2008), generally from 0 to $150 \mathrm{~Pa}$. The rate of erosion will also vary by several orders of magnitude. The sides of the opening will erode creating larger fractures and increased voids. As the openings increase, there will be an increase in permeability within the strata.

The shear stress and the flow velocity can be determined by using the formula;

$$
\tau=\gamma R i
$$

where;

$\tau=$ shear stress

$\gamma=$ specific weight of water $\left(9.8 \mathrm{kN} / \mathrm{M}^{3}\right)$

$\mathrm{R}=$ hydraulic radius

$\mathrm{i}=$ Hydraulic gradient

Concentrated erosion will likely occur in the failure mode identification when permeability changes allow for increased transmissivity and hydraulic conductivity. For this type of erosion to occur the soil must have cohesion that can withstand fracturing. In the surface fracture zone (Bai, Kendorski et al. 1995) this will occur when clays and mudstones are present. However, this type of erosion is more likely to occur in the dilated zone where strains are greater than 0.001 . The common geologic profile for this region above a mining operation is limestone and sandstones. However shale, mudstone and clay materials are also prevalent in this region making the potential for erosion likely in the dilated zone.

\section{$\underline{\text { Suffosion }}$}

Suffosion is the process where flow velocity is sufficient to transport finer particles between the larger particles. As the finer particles as removed the void ratio and permeability of the soil increases. This increase will cause further particles to be removed in the soils. This type of erosion occurs in soils that are internally unstable making fracturing within the soil unlikely and found in the surface fracture zone rather than the dilated zone. The loss of fines within the layers 
will cause an increase in transmissivity both vertically and horizontally. Vertically the increased seepage will allow water to infiltrate the underlying strata layers and allow for conditions causing increased head and pore pressure. According to Brown, the mean pore velocity $\left(\mathrm{V}_{\text {pav }}\right)$ due to seepage can be determined by the following equation;

$\mathrm{n}=$ porosity

$$
V_{p a v}=\frac{V}{n T}
$$

$\mathrm{T}=$ tortuosity $(2 / \pi$ or 0.64$)$

\section{Backward Erosion (Piping)}

Backward erosion results from pore pressures within the strata. As the water flows through the soil it releases at an exit point where there is little pore pressure. If the soil is cohesive, a "pipe" will begin to form and transmit back against the groundwater flow. This type of erosion occurs when the seepage gradient exceeds the floatation gradient of the soil. The critical average gradients are $0.34,0.28,0.24$ and 0.14 for gravel, coarse medium and fine sand all with a uniform coefficient of 3(Brown 2008).

\section{$\underline{\text { Contact erosion }}$}

Contact erosion is where fine soils are washed into a coarse soil due to horizontal flow. The methodology for this is similar to concentrated erosion with adjustment for pore size and crack width. Time for Development of Internal Erosion and Piping in Embankment Dams;

- Backward erosion will be rapid with a concentrated leak and slow in a non concentrated leak.

- Crack/hydraulic fracture will be rapid and occurs when the reservoir level reaches the crack or a point in which a hydraulic fracture is induced

- High permeability -process will occur rapidly once the reservoir reaches an area of high permeability and or other critical gradients to initiate erosion

- Suffosion occurs slowly.

\section{ISSUES WITH IC8741}

IC8741 was an empirical approach to for mine safety during the duration of the mine. Its intention was to protect the miners from water inundation. It however did not approach the effects of mining on surface structures and bodies of water. The approach, as detailed previously, recommends an offset of $200 \mathrm{ft}$ from the high water mark of a reservoir at depths up to $350 \mathrm{ft}$ vertically. Beyond this depth the recommendation is an additional 25 degree offset as detailed in Figure 1. 
Research has shown the angle of subsidence in Appalachia can extend upwards of 40 degrees (Booth 2006). At a depth of $350 \mathrm{ft}$., the offset distance would be $294 \mathrm{ft}$. for a subsidence angle of 40 degrees. In addition the report fails to identify changes in the seepage and groundwater as a result of the subsidence created by mining. While groundwater may not penetrate into the mine itself, changes in gradient and hydraulic conductivity can permanently affect groundwater flow within the upper 4 layers of the subsided strata. Increased flow can create conditions that initiate erosion and lead to loss of ability to control pool levels or failure of a dam or surface structure. These conditions exceed beyond the angles of subsidence and can extend up to 70 degrees (Reed and Rauch 2001). This lies well beyond the 29.74 degree angle recommended by IC 8741 for depths up to $350 \mathrm{ft}$.

The offset distances recommended by IC8741 are a generalized approach applicable to all conditions when mining near surface bodies of water. However it allows for these offsets to be encroached if proper testing is performed. The type of tests and data required to determine the new offset distance is not covered.

The report recommends the offset perimeter should be established around structures by those responsible for its protection when the threat of loss of life occurs. However it does not explicitly give authority to the owners or personnel to determine the offset distance.

In addition to offset distances, IC8741 recommends a maximum tensile strain in the overburden as $0.00875 \mathrm{in} / \mathrm{in}$. Research has detailed strain values above $0.001 \mathrm{in} / \mathrm{in}$ create an increase in permeability within the strata (Kendorski 1993). The recommendation of the report is 8.75 times this value. In areas of low strain localized areas of high strain can occur due to faults and other abnormalities within the strata (Kendorski 1993). These localized areas could result in the progression of erosion through piping or suffusion.

IC8741 was designed to protect mine workers during the lifespan of the mine only. It does not approach conditions of the overburden after the mine has been abandoned. Over time, pillars in partial extraction mines will begin to erode and fail. This will cause fracturing and caving within the strata similar to full extraction mining. As time progresses, the subsidence zone will reach its maximum. For longwall mining this occurs between 2 to 3 years (Singh 1992). For partial extraction mining, the time frame for pillar failure is difficult to determine and may fail gradually over a few years to several decades. Because IC8741 was not designed to investigate conditions created after mining, this issue was not addressed.

\section{SOLUTION ANALYSIS}

The solution approach for this sensitivity study is to determine offset distances based on probability of erosion to occur. Using data from literature or from the field, the probability can 
be determined. These ranges are based on the potential angles of groundwater influence seen in Appalachia and the likelihood of erosion based on strain values in the overburden. Figure 14 shows a generalized view of how the probability would affect the allowable proximity of a mine to a reservoir. The probability of erosion is based on distance and depth. The closer the mine is to a reservoir, the greater the risk when all other parameters remain constant.

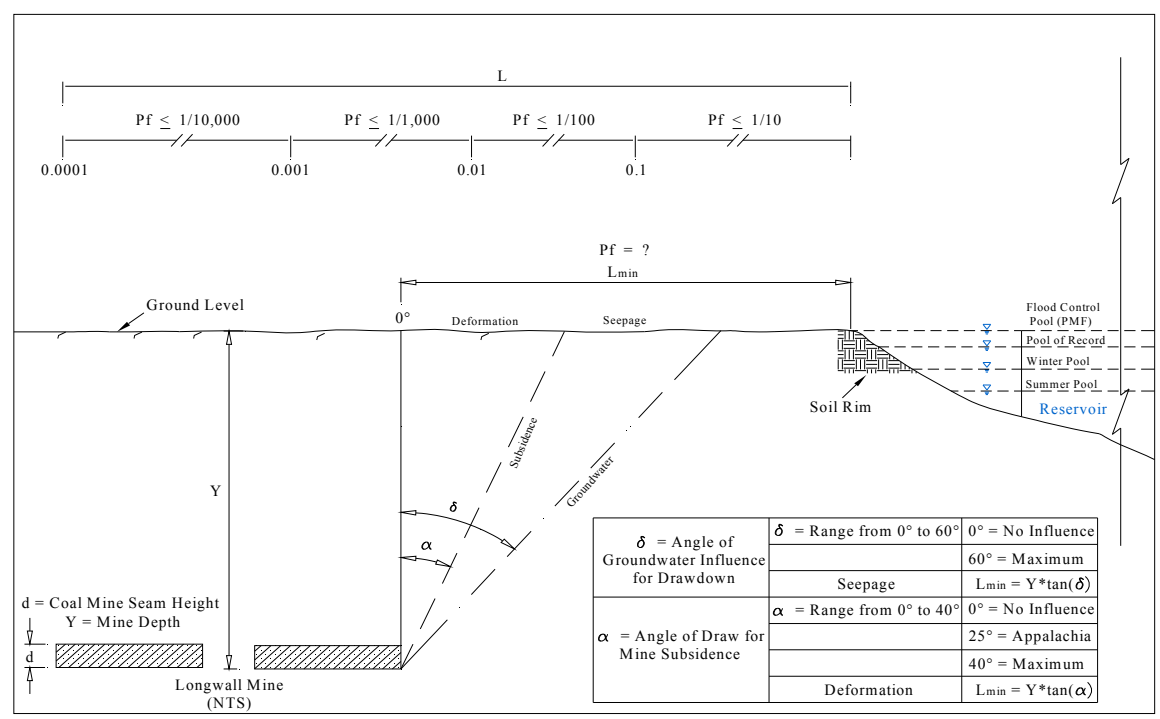

Figure 14- Generalized offset zones based on probability of erosion to occur

Figure 15 shows the generalized offset distances based on probability for mining near a dam. The potential for erosion would be similar to that of a reservoir. In this circumstance, strain values and deformation would have to be much more closely detailed. Erosion may not occur at the extents of the angle of groundwater draw but increased strain within it could still pose a threat to the integrity of the dam.

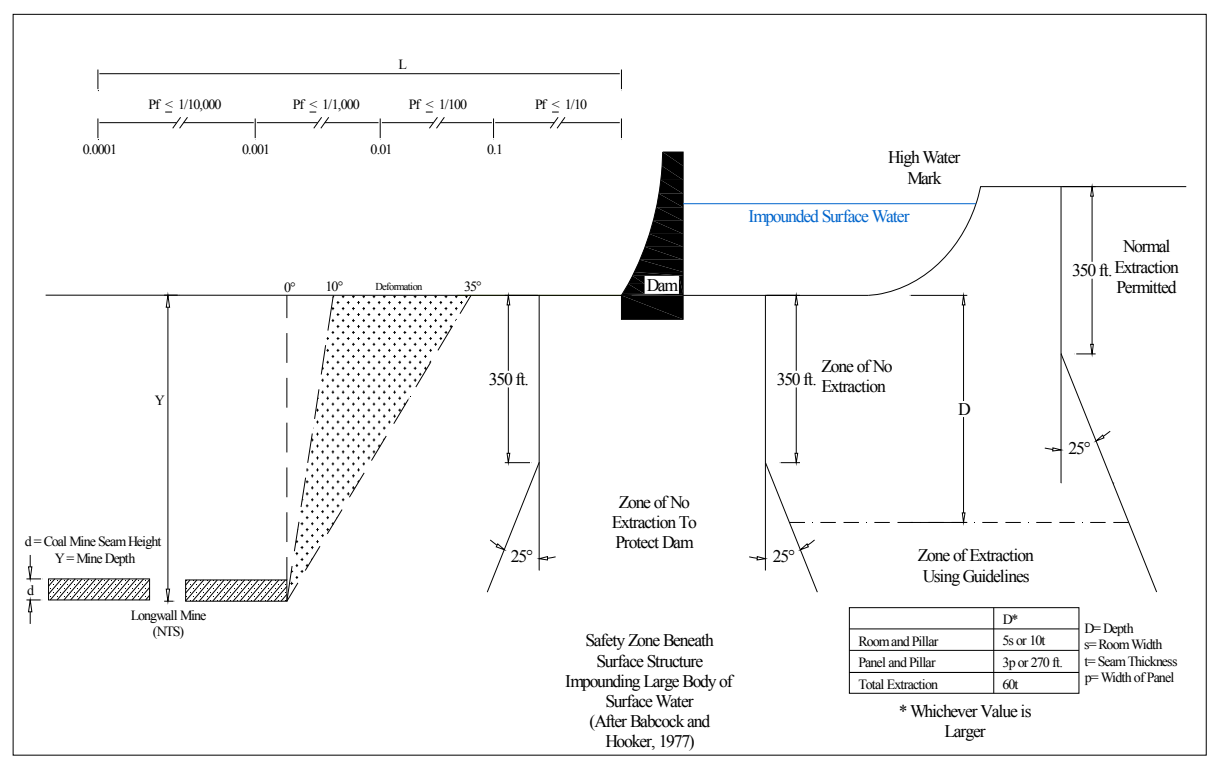

Figure 15- Generalized offset distances for a dam based on probability of erosion to occur 


\section{RISK ANALYSIS}

The US Bureau of Reclamation (USBR) and the US Army Corps of Engineers (USACE) incorporate risk analysis as the primary dam safety decision making tool and have noted the continued need for development of dam safety analysis, guidelines, and procedures (USACE 2008). These organizations define and estimate risk based on understanding and documenting what the major contributors are in initiating a dam failure and why they occur. While the USBR and the USACE have been performing multiple levels of risk analysis for over fifteen years, the need for continued development and tracking of conditions which influence risk is still needed (RECLAMATION 2011).

\section{Analysis Method}

The analysis performed in this research is dedicated to development of an alternative risk based analysis approach for determining offset distances at USACE reservoirs due to underground coal mining. The important problem is that underground mining for energy extraction near or under bodies of water at USACE and the USBR projects may raise the risk to that dam or reservoir. The USACE methodology involves fully describing and evaluating site specific Potential Failure Modes (PFM) then applying event trees for a site-specific analysis.

The method advanced involves the following steps is illustrated in Figure 16:

\section{Modeling method and scope}

1. Perform Failure Mode Identification of seepage effects due to a full extraction longwall mining event initiated near a reservoir rim.

2. Apply verbal probability transforms for categorizing risk based on likelihood of occurrence (Vick 2000)

3. Perform sensitivity analysis on Event Tree probabilities using verbal transforms linked with published USBR risk values. Incorporate the probability of occurrence for the angle of subsidence draw and angle of groundwater influence to permeability increases due to extension of overburden strata.

4. Identify Tolerable Risk $\left(\mathrm{P}_{\mathrm{f}}\right)$ leading to determination of total probability of failure (PFMA) correlated to a minimum offset distance $\mathrm{L}$.

5. Compute the tolerable risk (total) to the reservoir undergoing an increase in overburden soil seepage above a threshold value. 


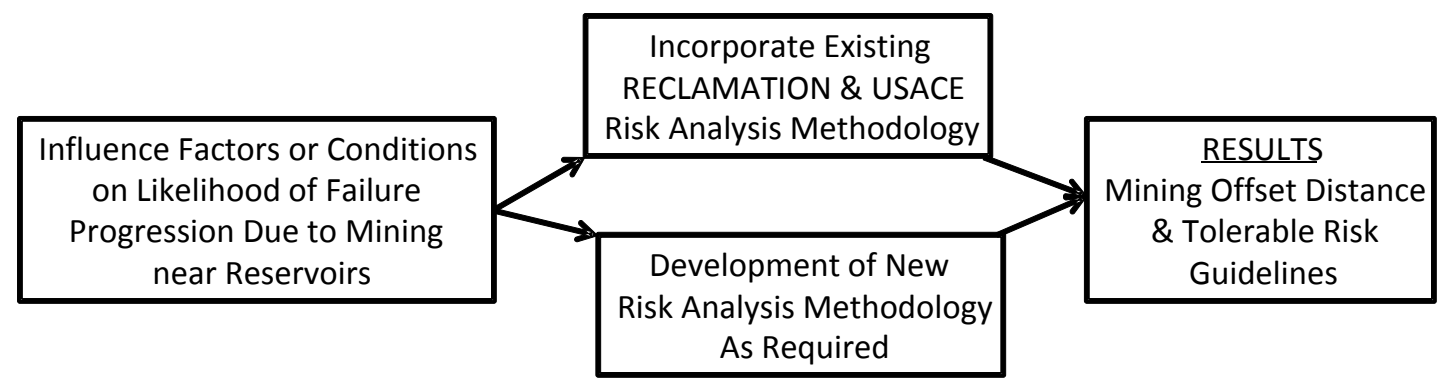

Figure 16- Process of Analysis

\section{$\underline{\text { Modeling Assumptions }}$}

The following assumptions were made to define the analysis.

1. The type of mining method studied is the longwall, full extraction versus the room and pillar mining method. The analysis for a longwall method is advanced because the mining approach has been permitted at locations near the Tygart Lake Dam and Reservoir, Taylor County, West Virginia (WVDEP 2011) and may approach worse case condition. This mining method was also selected based on literature data availability in order to assess frequency of occurrence relationships to develop probability factors.

2. The mine depth is $350 \mathrm{ft}(107.69 \mathrm{~m})$ below ground level, comparable with IC 8741 requirements.

3. The reservoir pool elevation is the Flood Control Pool - Probable Maximum Flood (PMF) level.

\section{$\underline{\text { Event Tree Analysis }}$}

Event tree analysis was designed based on Quantitative Risk Assessment (QRA) to estimate the probability of failure (Fell 2000). Quantitative Risk Assessment is used for determining failure mode identification, analysis for probability of failure and calculation of losses that would occur in case of failure. For this research the event tree analysis is only concerned with the likelihood of failure. Potential damages and loss of life are not considered given they are on a case by case study and outside the scope of this paper. For example, a reservoir located in a highly populated zone would have higher risk for loss of life while the risk to life loss in a sparsely populated zone would be lower. However the potential for failure for either reservoir may be similar. This analysis is designed to estimate the potential for such failure.

The event tree is designed based on initial conditions governing the mine. The initiating event is considered to be what begins the potential for erosion to occur. This is shown in columns labeled levels. An example is shown in figure 17. Each level has a predetermined probability of 
occurrence based on that event. The probabilities for each level are multiples for each possible path. Failure is tallied at the end for only the paths that affect the last level. Such that an event that causes an occurrence of one level would not necessarily cause the failure in the last level.

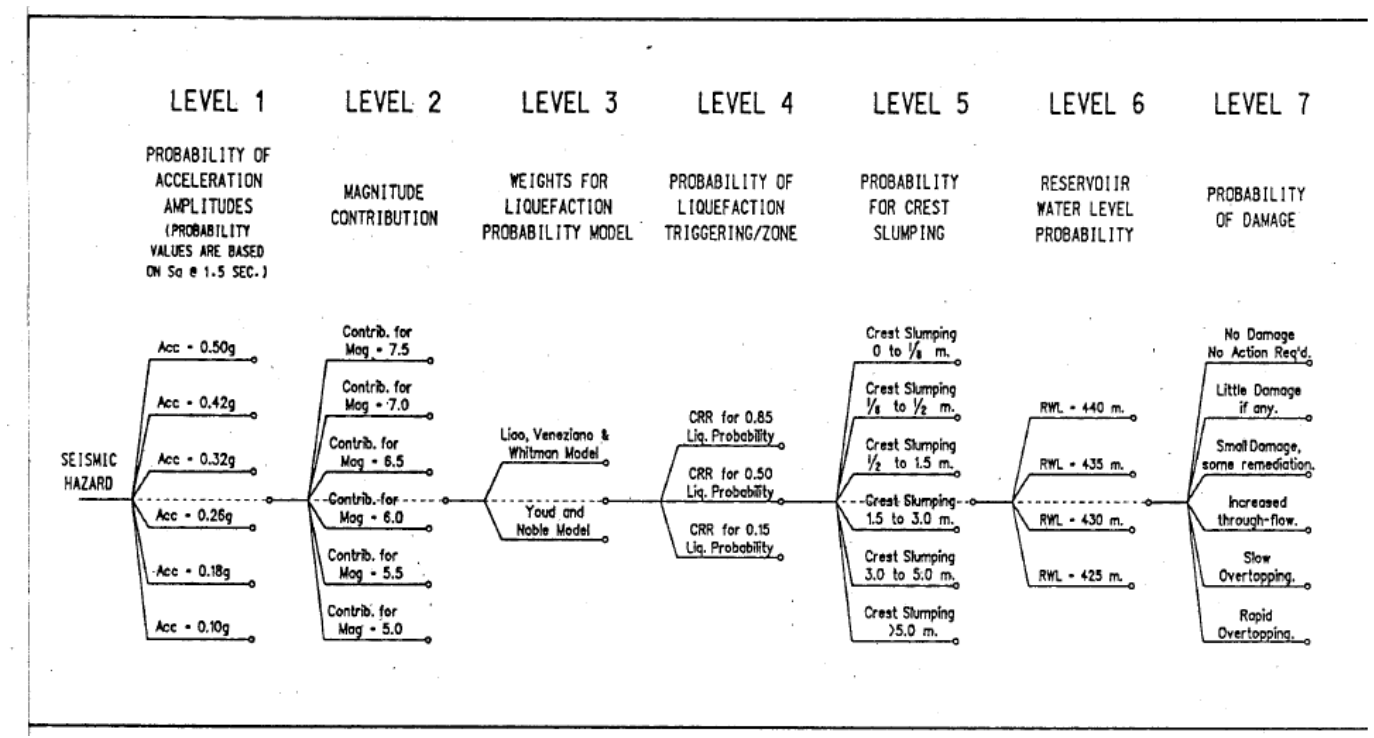

Figure 17- (Fell 2000)

For this analysis the factors affecting the initiating influence are on a case by case study. For room and pillar mining, full subsidence only occurs when the pillars fail while subsidence occurs almost immediately with longwall mining. The factors affecting the angle of draw include depth, geologic profile and other site specific factors. Unlike the event tree example previously shown, the probabilities for each level in erosion assessment can change based on previous levels. The initiating event is subsidence due to mining. The angle of draw, while not directly linked to groundwater draw, will have an influence on the probability of increased hydraulic conductivity.

\section{DEVELOPMENT OF ROOM AND PILLAR EVENT TREE}

Room and Pillar mining progressive failure event tree is similar in nature to longwall mining for probability. However, there are more initial conditions that determine the path an event will follow. These initial conditions are much more dependent on the strata and overall type of terrain where mining takes place. Maximum subsidence in room and pillar mining is similar to longwall mining. The key difference is in room and pillar this only occurs when the pillars designed to support the roof fail. The parameters leading to pillar failure are detailed below and listed as conditional decisions on the progressive failure tree.

\section{$\underline{\text { Pool Level }}$}

The pool level of a reservoir is important in determining the risk of erosion occurrence. There are three typical pool levels considered: summer, winter and maximum pool level. Summer pool 
level, also known as sunny day, is most common for determining risk because it is the lowest normal conditions. However, for this analysis, the maximum pool level should be considered because it generates the greatest potential for failure due to erosion as this condition produces the highest hydraulic head. The maximum pool level is the highest peak level a reservoir is expected to reach over its lifespan. However for specific locations, the maximum pool level could be deemed to be caused by a 100 year, 500 year or 1000 year storm, depending on the severity of the effects and expected outcome. The analysis would not consider the probability of the flood event occurrence only that it could occur during the lifespan of the reservoir. While this provides the greatest chance of seepage failure, summer and winter pool conditions need to be recognized as a constant since these are general conditions. The sunny day analysis would provide the everyday risk to the reservoir while the probable maximum flood would give the maximum risk to the reservoir. These can both be used in considering potential risk at specific locations.

\section{$\underline{\text { Time Intervals }}$}

Unlike longwall mining, where subsidence is expected to occur almost immediately, room and pillar subsidence can occur over long periods of time. There is limited initial subsidence during the mining operation but as long as the pillars remain intact there will not be significant surface subsidence. Eventually after a few pillars begin to fail there will be a domino effect creating subsidence similar to full extraction mining. When this occurs it will affect the likelihood of failure to a reservoir. While the pillars remain intact, changes in the hydrogeology of the strata will remain close to original conditions. If a flood event occurs during this time, the potential for failure due to erosion will be less than under conditions when the pillars had already failed.

Additionally, pillars will lose strength over time. Flood conditions could add additional stress to the pillars causing them to fail more rapidly than under sunny day conditions. This could create full subsidence conditions during the event or could speed up the failure rate of the pillars. In many room and pillar mining operations, retreat mining of pillars is common. In this analysis, retreat mining above $70 \%$ of the total coal seam would create full extraction conditions because the pillars would no longer be able to withstand the weight of the overburden. This scenario would follow the event tree path similar to longwall mining.

\section{Terrain Type}

The surface terrain directly above a room and pillar mine is important to determine the total stress on an individual pillar. In pillar design, stress is assumed to be evenly distributed throughout the mine plan (Farmer 1992). However this assumption is based on level surface and does not consider steep terrain. In locations, such as the Appalachian mountain chain, there are significant elevation changes within mine locations. Stress on one pillar in a valley may be doubled on a pillar located under a hilltop or plateau. Unless the maximum possible stress is considered for each pillar, there is a potential for underestimation and faster occurrence of pillar 
failure. Pillar failure occurs when the stress exceeds the compressive strength of the pillar. Reliable measurements of average stress are rare because of the difficulty to obtain them (Farmer 1992).

\section{Depth of Coal Seam}

The depth of the extracted coal seam has a direct effect on the angles of subsidence and accordingly the angle of groundwater draw. Hence: the deeper the mine the greater the affected area. In room and pillar mining it also has an effect on the pillars designed to support the roof. This has two effects on the potential failure of a pillar; the total weight a pillar must be designed to withstand and the total stress where the pillars contact the floor and roof of the mine. Pillars are designed to withstand the weight of the overburden for the lifetime of the mine for the protection of mine workers. Once they begin to fail, greater weight will be required to be supported by the pillars that remain intact. In deeper mines this weight will be more evenly distributed throughout the mine and into the untouched areas outside of the mine. In shallower mines, such as found in the Appalachians, failure of one pillar will have a greater affect on the surrounding pillars. For depth, the strength of these layers needs to be able to withstand the stresses applied by the overburden. Failure of pillars can occur regardless of their strength if the contact layers cannot equal the stress applied. Depth of the coal seam should not be less than 100 $\mathrm{ft}$.

\section{Retreat Mining}

Retreat mining is a common method used to extract maximum amount of coal in a room and pillar mine. Once a mine has been excavated through traditional room and pillar methods, the pillars are then harvested, either partially or fully. The percentage of total coal mined dictates how subsidence will occur. Room and pillar mining generally extracts $50 \%$ of the total coal. If the percentage exceeds $70 \%$ through pillar recovery, subsidence will occur almost immediately similar to longwall mining. If the percentage is less than $70 \%$, the pillars can withstand the overburden for a period of time before the maximum subsidence occurs. For this analysis, any extraction above $70 \%$ will be considered full extraction mining. Any partial recovery of a pillar will determine the overall strength of a pillar and type of failure likely to occur.

\section{Angle of Dip}

The angle of dip is the angle in which a coal seam rises or falls with respect to horizontal. Room and pillar mining is not recommended above angles greater than 30 degrees. In the Appalachian mountain range, the angles of dip generally fall less than 10 degrees. The importance of angle of dip when considering the potential for failure is the stress that is placed on individual pillars. In areas of constant surface elevation and no dip in the coal seam, the stress in pillars will be evenly distributed. As previously discussed, changes in surface elevation will affect how much stress each pillar is required to withstand. Likewise the angle of dip will have the same effect. If a coal 
seam dips over the course of the extraction site, more overburden will be above one end of the mine than the other causing additional stress. If the seam dips under an area where the surface terrain rises, extreme conditions compared to normal expectation can occur causing the rapid failure of the mine.

\section{$\underline{\text { Pillar Size }}$}

The height-to-width ratio of pillars affects the likeliness of how the pillars fail. IC8741 has specific guidelines for pillar design based on depth, height of coal seam and room width. This only applies for the safety of the workers during the operation of mine. Studies have shown that pillars with a height to width ratio less than one-third behave in more of a yielding fashion. This means they are prone to compression creating a sagging effect on the roof. This type of failure occurs more slowly than fracturing of a pillar. However, in this type of yielding, the pillars could also push or "punch" through the roof or floor creating a localized zone of vertical and horizontal fracturing. This fracturing diminishes the integrity of the roof layer and its ability to support the overburden. Fracturing in this instance could cause a greater zone of caving and fracturing above the levels investigated in literature. Pillars with height-to-width ratios greater than one-third tend to be more brittle in nature. These ratios mean the pillars are more elongated and have a smaller cross sectional area causing them to crack. The effect is a more rapid failure of the pillar and subsidence effect. This type of failure may not manifest for a long period after mining but will occur almost without warning.

\section{$\underline{\text { Geologic Makeup of Mine Roof or Floor }}$}

The type of rock found directly above or below a mine seam will impact the ability for support structures to function properly. Pillar design requires that the pillar stress does not exceed the maximum stress capacity of the rock it is in contact with. However, this is determined while all pillars are assumed to be intact. Once pillars begin to fail, the stress on other pillars and their contact with strata increases. If the maximum stress level on the roof is exceeded, the roof will fracture around the pillar creating a punching effect. This leads to vertical fracturing and additional stresses on other pillars creating an immediate domino effect and subsidence zone.

The conditional decisions discussed will lead into the probability levels detailed after longwall mining. 


\section{RESERVOIR EVENT TREE FOR FAILURE DUE TO LONGWALL MINING}

\section{$\underline{\text { Initial Conditions }}$}

The initial conditions for potential reservoir failure are predetermined based on the following;

\section{Type of geology}

The type of soils and strata located around the reservoir determines the depth location of any aquifers in the region. It also has a direct affect on the increase of permeability and type or erosion expected. For example sandstone typically increases one order of magnitude for permeability while shale increases by a magnitude of 2-3. Shale will also tend to recompress over time.

Table 6 presents the influence factors on the likelihood of progression of a reservoir rim foundation erosion condition. This is caused by an increase in overburden soil permeability resulting from full extraction longwall mining subsidence occurring parallel to the reservoir.

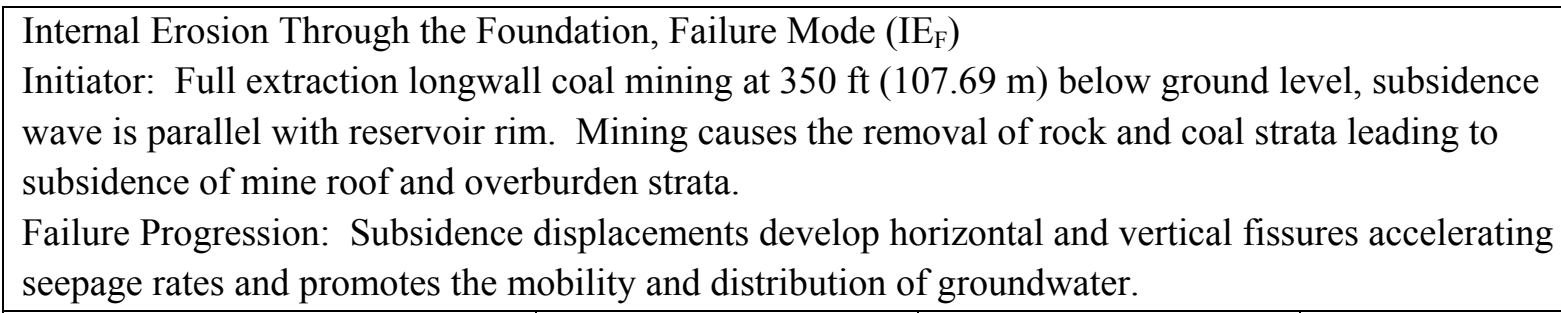

\begin{tabular}{|c|c|c|c|}
\hline Factors or Conditions & More Likely & Neutral & Less Likely \\
\hline $\begin{array}{c}\text { Hydraulic gradient across } \\
\text { foundation }\end{array}$ & High & Average & Low \\
\hline Foundation type & $\begin{array}{c}\text { Sedimentary soils, w/ } \\
\text { high clay \% }\end{array}$ & $\begin{array}{c}\text { Fractured sandstone } \\
\text { with fault lines }\end{array}$ & $\begin{array}{c}\text { Intact sandstone w/ } \\
\text { minimal fault line }\end{array}$ \\
\hline Relative Density or consistency & Loose / Soft & Medium dense / Stiff & Dense / Very stiff \\
\hline Pool Elevation & $\begin{array}{c}\text { High, history of high } \\
\text { flood levels with high } \\
\text { PMF storage }\end{array}$ & $\begin{array}{c}\text { Average, PMF } \\
\text { storage is low }\end{array}$ & $\begin{array}{c}\text { Low, no PMF } \\
\text { storage }\end{array}$ \\
& & \\
\hline
\end{tabular}

Table 6: Influence on Likelihood of Seepage Increase

\section{$\underline{\text { Pool level elevation }}$}

The change pool level from summer elevations and the expected frequency of occurrence (for example, the likelihood that a probable maximum flood will occur during mining operations). This must be taken into account to defend possibility of occurrence while theoretically unlikely. Lowering of elevation will cause the probability of seepage to diminish, however it may cause 
periods of saturation to unsaturated soils breaking up the particles in the soil increasing the likelihood of erosion.

The time frame of operations

Determination of whether mining is currently taking place or the length of time that has passed since mining operations have occurred affects the probability of the change in order of magnitude in permeability (order of magnitude $1 \mathrm{x}-1000 \mathrm{x}$ ).

Each of these initial conditions determines the probability of occurrence for each level in the event tree.

\section{Probability Levels}

The following are the probability levels that will affect the potential for erosion. The likelihood of each branch to occur is based on factors determined in the field and discussed previously for room and pillar and longwall mining.

\section{$\underline{\text { Level } 1 \text { Angle of Draw }}$}

The angle of draw determines the horizontal surface distance from the mine that subsidence occurs. The average angle for the Appalachian mountain range is 23-25 degrees, while field tests have shown this angle extending up to 42 degrees. In this range there is an expectancy of surface fracturing and strains greater than $0.001 \mathrm{in} / \mathrm{in}$. The probability of continuation for failure is based on the proximity of this zone to the pool rim. If the reservoir edge lies within the angle of draw the probability of seepage will lie near $100 \%$. If it lies outside of the angle of draw, the probability will become based on the expectancy of groundwater draw.

\section{Level 2 Angle of Groundwater draw}

The angle of groundwater draw determines the horizontal distance from the mine that change in groundwater flow is likely to occur. This angle is correlated to the angle of draw but not dependant on it. However, in all conditions it is expected to extend past the angle of subsidence. In the Appalachian mountain range this angle generally falls between 30 and 40 degrees with maximum angles up to 60 degrees. If the rim falls within this horizontal range, the probability of seepage and erosion will be near 1.00. Studies have shown that water levels have shown to drop outside this range due to locations of aquifers and horizontal groundwater flow. The probability of failure for rims lying outside the angle of groundwater draw are based on field studies 
conducted on the region. As the horizontal distance (L) increases, the probability of continuation to the next level decreases.

\section{Level 3 Permeability Increase}

The probability of permeability increase at the reservoir rim is based on the distance between the extents of subsidence and groundwater draw to the pool. The closer either of these extents are, the greater the likelihood of continuation for failure. The characteristics of the strata will have an effect on the amount of change in permeability. During mining operations a condition called a subsidence wave occurs that creates zones of tension and compression. Typically compression occurs within the mine trough while tension occurs at the edges extending outwards. However changes from compression to tension, or vice versa, will occur at mining passes or concludes.

Typical changes in permeability range from $10 \mathrm{x}$ to $1000 \mathrm{x}$ normal conditions in tensional areas and $-10 \mathrm{x}$ in compressional areas. Once mining has concluded, the permeability tends to fall back towards it normal conditions but never fully recover. Therefore the probability of permeability increase is also a function of time.

Conditional Event - Erosion

Based on the reservoir event tree, the probability of erosion is determined based on the preceding factors. The potential for erosion to occur is predicted by determining the likelihood of the initialing events occurring. Figure 18 shows the event tree for Longwall mining. Each decision and probability level is split into factors that would affect the overall risk. The actual amount of branches for each level would be determined by the overall change in risk from the low end and high end of each branch. For example, if a 10 degree angle of groundwater draw poses minimal risk to a reservoir but a 20 degree angle represents considerable risk, the range of that branch would be to great and required to be broken down into several branches. For this analysis, only generalized values were used and would need to be detailed further.

\section{Qualifications for Sensitivity Analysis}

For the purpose of this analysis, longwall mining was the preferred method as it predicted the worst case in a relatively short period of time. This was due to the availability of data concerning the timeframe of subsidence and the angles for draw and groundwater influence. Room and pillar mining has shown that subsidence will continue to occur as the pillars fail and the overburden caves. Maximum subsidence occurs when the pillars completely fail and the roof collapses into the mine void. This is time dependent based on factors such as rock strength, degree of fracturing and water presence (Singh 1992). 
Studies have shown that this can occur over long periods of time and in several cases, subsidence from room and pillar mining was continuing to occur over one hundred years (Singh 1992). There is no common trend for the time frame of pillar collapse. Therefore analysis for this method of mining cannot be easily generalized and would require site specific information. However, when considering in perpetuity, likelihood of pillar failure and maximum subsidence becomes great and could be treated as full extraction mining under this analysis. The only exception would be that, because it occurs over a longer period of time, shale and clays found in the overburden may potentially self heal and total increase in hydraulic conductivity may not be as dramatic as longwall mining.

Unlike room and pillar mining which can take decades for maximum subsidence to occur, subsidence from longwall mining occurs over a short period; generally 2 to 3 years. Subsidence from full extraction mining occurs within the lifespan of the mine, making it more identifiable. As previously discussed, multiple variables in the geologic profile above a mine can affect the timeframe of subsidence in room and pillar mining due to pillar failure. Full extraction mining does not have the same qualifications since rooms are completely mined.

The initiating conditions and probabilistic levels for potential erosion due to longwall mining is shown in Figure 18. Each branch in a column will connect to every branch in the preceding column. 
Reservoir Soil Rim Progressive Seepage Failure Event Tree

Overview For $\mathrm{L}=\mathrm{L}$ min

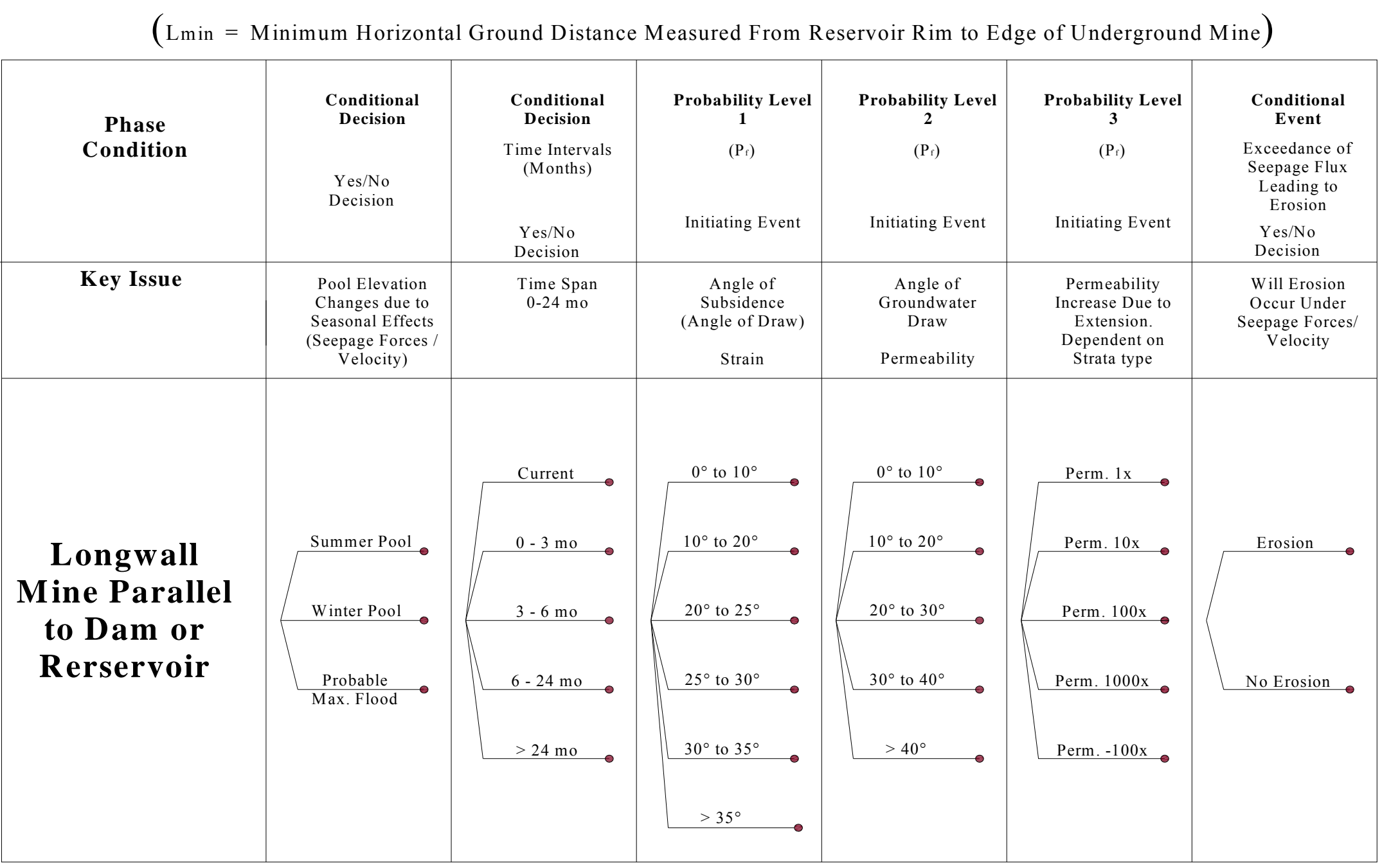

Figure 18- Generalized event tree for Longwall mining 


\section{PROBABILITY ANALYSIS}

Field data was limited while performing this analysis. Peng (1995) developed a database of case studies for subsidence. 110 studies were analyzed with the angles of draw given. For the purposes of this research, 34 of these occurrences were used because they ranged at depths below 350 feet $(107.69 \mathrm{~m})$. This data was used to determine the probability of angle of draw based on occurrence (Peng 1995).

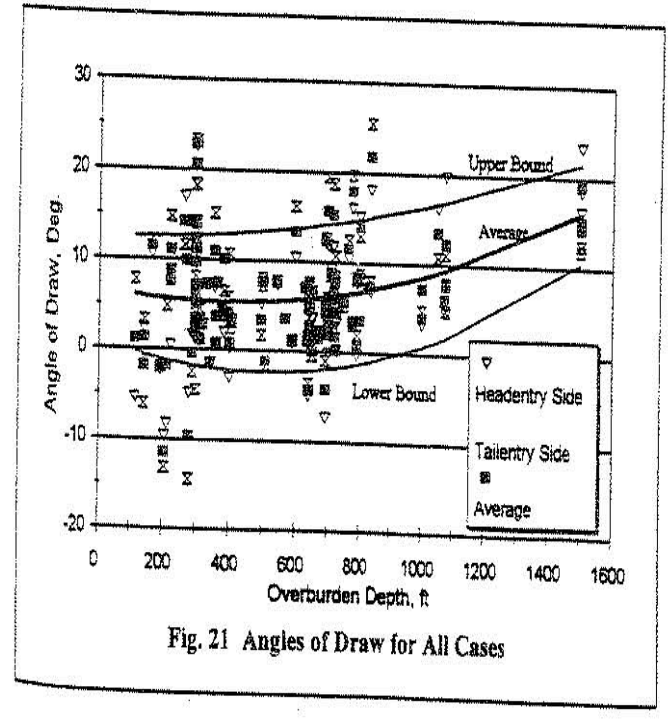

\begin{tabular}{|l|l|}
\hline \multicolumn{2}{|l|}{ Boundary Conditions } \\
\hline $\begin{array}{l}\text { Angle of } \\
\text { Subsidence }\end{array}$ & 0 to $30^{\circ}$ \\
\hline Overburden & 0 to $350 \mathrm{Ft}$ \\
\hline
\end{tabular}

\begin{tabular}{|l|l|}
\hline $\begin{array}{l}\text { Angle of } \\
\text { Subsidence }\end{array}$ & $\begin{array}{l}\text { Number of } \\
\text { Occurrences }\end{array}$ \\
\hline $0^{\circ}$ to $10^{\circ}$ & 18 \\
\hline $10^{\circ}$ to $20^{\circ}$ & 13 \\
\hline $20^{\circ}$ to $25^{\circ}$ & 3 \\
\hline $25^{\circ}$ to $30^{\circ}$ & 0 \\
\hline $30^{\circ}$ to $35^{\circ}$ & 0 \\
\hline$>35^{\circ}$ & 0 \\
\hline
\end{tabular}

Figure 19- Angles of draw from field data (Peng 1995)

Reference data from the SME Handbook (Singh 1992) and Booth (Booth 2006) provide ranges for the angle of subsidence. These values were similar in nature ranging from 10 to 40 degrees. No field data was given so estimates were used. The mean angle of draw was used as the highest probability based on the ranges. The other possible angles of subsidence decreased in probability as they moved farther from the mean value. Low probability was given to angles of draw that fell out of the data given by the two sources. This was for an event that fell outside the ranges given.

\begin{tabular}{|l|c|c|c|c|c|c|c|c|c|}
\hline & X-Bar & Range & Center & Upper & Lower & Upper & Lower & Upper & R Center \\
\hline Control Data & & & Line & Ctrl Limit & Sig2 Limit & Sig2 Limit & Sig1 Limit & Sig1 Limit & Line \\
\hline $\mathbf{1}$ & 17.5 & 15 & 21.5 & 43.79 & 6.64 & 36.36 & 14.07 & 28.93 & 11.86 \\
\hline $\mathbf{2}$ & 21 & 12 & 21.5 & 43.79 & 6.64 & 36.36 & 14.07 & 28.93 & 11.86 \\
\hline $\mathbf{3}$ & 30 & 16 & 21.5 & 43.79 & 6.64 & 36.36 & 14.07 & 28.93 & 11.86 \\
\hline $\mathbf{4}$ & 14.5 & 5 & 21.5 & 43.79 & 6.64 & 36.36 & 14.07 & 28.93 & 11.86 \\
\hline $\mathbf{5}$ & 26 & 6 & 21.5 & 43.79 & 6.64 & 36.36 & 14.07 & 28.93 & 11.86 \\
\hline $\mathbf{6}$ & 22.5 & 15 & 21.5 & 43.79 & 6.64 & 36.36 & 14.07 & 28.93 & 11.86 \\
\hline $\mathbf{7}$ & 19 & 14 & 21.5 & 43.79 & 6.64 & 36.36 & 14.07 & 28.93 & 11.86 \\
\hline
\end{tabular}

Table 7- Probability values for Ranges from SME Handbook 


\begin{tabular}{|c|c|c|}
\hline 950 & $\begin{array}{l}\text { ENGINEERING HANDBOOK } \\
\text { Typical Values of Angle of Draw }\end{array}$ & \\
\hline Coalfield/Country & Reference & $\begin{array}{c}\text { Angle of Draw } \\
\text { (degrees) }\end{array}$ \\
\hline $\begin{array}{l}\text { Limburg/Netherlands } \\
\text { Limburg/Nethellands } \\
\text { Northern France } \\
\text { USSR } \\
\text { Ruhr/Germany } \\
\text { Ruhr/Germany } \\
\text { Saar/Germany } \\
\text { UK } \\
\text { Midlands/UK }\end{array}$ & $\begin{array}{l}\text { Brauner (1973) } \\
\text { Pottgens (1978) } \\
\text { Brauner (1973) } \\
\text { Brauner (1973) } \\
\text { Brauner (1973) } \\
\text { Kratzsch (1983) } \\
\text { Kratzsch (1983) } \\
\text { ICE (Anon, 1977) } \\
\text { Orchard (1957), Wardell (1969), NCB (1975) }\end{array}$ & $\begin{array}{c}35-45 \\
45 \\
35 \\
30 \\
30-45 \\
55 \\
40 \\
25-35 \\
35\end{array}$ \\
\hline $\begin{array}{c}\text { East - Anthracite } \\
\text { Southwestern, PA } \\
\text { Appalachian } \\
\text { Appalachian } \\
\text { Northern Appalachian } \\
\text { Central - Illinois } \\
\text { Illinois } \\
\text { Illinois } \\
\text { Illinois } \\
\text { Illinois }\end{array}$ & $\begin{array}{l}\text { Montz and Norris (1930) } \\
\text { Newhal and Plein (1936) } \\
\text { Cortis (1969) } \\
\text { Peng and Chyan (1981) } \\
\text { Adamek and Jeran (1981) } \\
\text { Wade and Conroy (1977) } \\
\text { Conroy (1979) } \\
\text { Bauer and Hunt (1981) } \\
\text { Hood (1981) }\end{array}$ & $\begin{array}{c}25 \\
10-25 \\
15-27 \\
22-38 \\
12-17 \\
23-29 \\
15-30 \\
12-26 \\
17-18 \text { (long.) } \\
42-44 \text { (trans.) }\end{array}$ \\
\hline $\begin{aligned} \text { West - } & \text { Raton, NM } \\
& \text { Deer Creek, Emery, UT } \\
& \text { Somerset, Gunnison, CO } \\
& \text { Salina, UT } \\
& \text { Sheridan, WY }\end{aligned}$ & $\begin{array}{l}\text { Gentry and Abel (1977) } \\
\text { Allgaier (1988) } \\
\text { Dunrud (1984) } \\
\text { Dunrud (1984) } \\
\text { Dunrud (1984) }\end{array}$ & $\begin{array}{l}72-47 \text { (1) } \\
30 \\
15-25 \\
8-20 \\
6-9\end{array}$ \\
\hline
\end{tabular}

Figure 20- Angles of draw values for longwall mining (Singh 1992)

The following method was used to determine the probabilities for angle of subsidence using SME ranges. Table 7 shows the mean for the data provided and the upper and lower standard deviation limits. The mean for all the ranges is 21.5 . The upper and lower first standard deviation limits $(\sigma 1)$, which represent approximately $68 \%$ of the data for normal distribution, are approximately 14 and 28 respectively. The range of the $2^{\text {nd }}$ standard deviation limits $(\sigma 2)$ are 6.64 and 36.36 respectively. The $\sigma 2$ boundaries represent approximately $95 \%$ of the data. This is graphically shown in Figure 21. The center line is the mean for all of the ranges

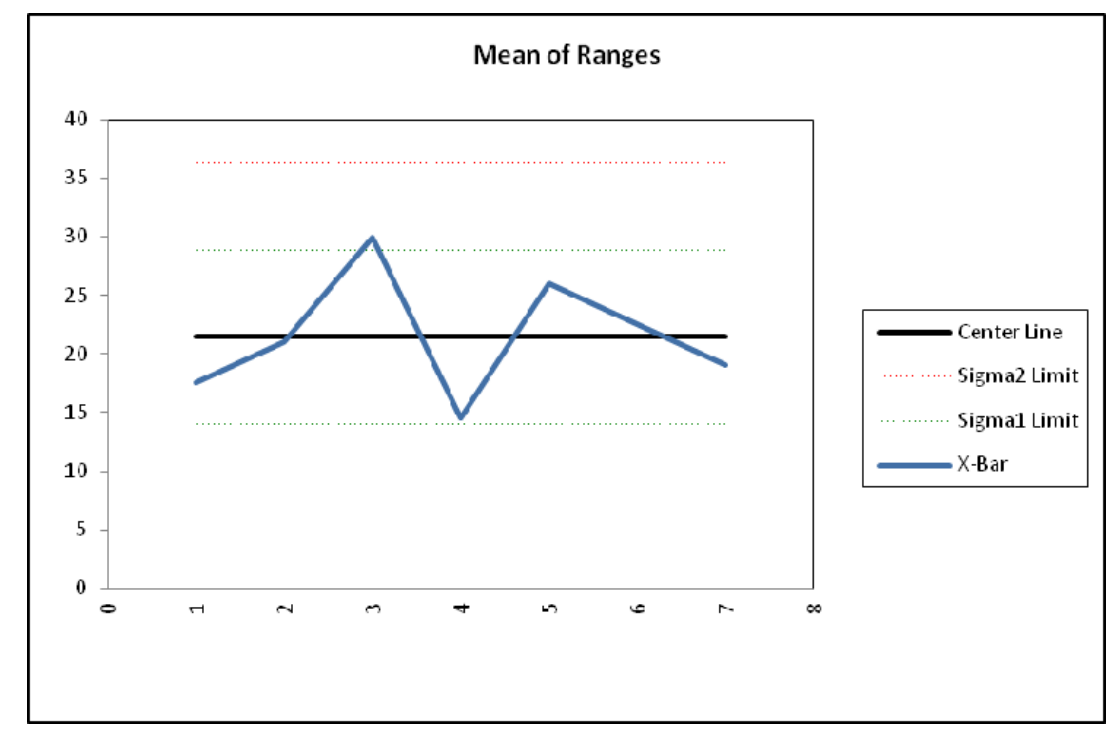

Figure 21-Mean values for data provided by SME Handbook 
Figure 22 shows the X-bar or the total range of each data set. The center line represents the average range for the entire set. It shows that the majority of the data falls within approximately one standard deviation.

Given the details from the R (Figure 21) and X-bar charts (Figure 22), the probability for angle of subsidence was determined. The mean data value for the ranges was approximately 21.5 degrees. This fell within the event tree branch of 20 to 25 degrees angle of subsidence. Because this was based on ranges of data, a 0.5 probability was given for this branch. The two branches extending on either side of this were given a 0.2 probability for normal distribution. This represents a higher total probability than the $\sigma 1$ would suggest. However due to these branches covering the lowest and second highest range values, the expectancy were for the majority of the angles of subsidence to fall within this range. 30 to 35 degree angle of subsidence was given a 0.06 probability because one range value did show a 38 degree angle of subsidence. A similar method was used to determine the probabilities for ranges found in literature by Booth(2006).

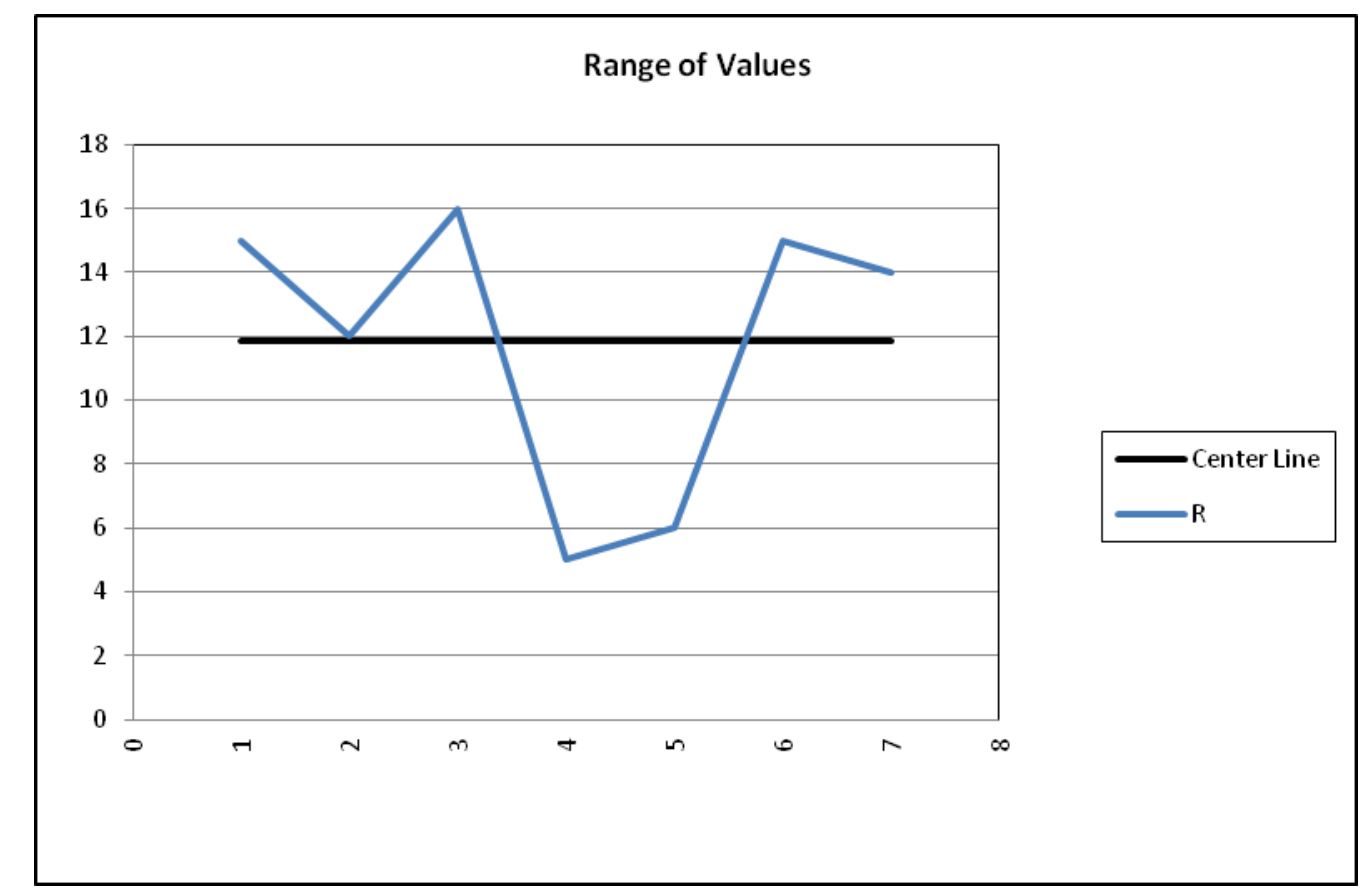

Figure 22- R chart for data provided by SME Handbook

The angle of groundwater influence defines the zone in which groundwater flow is changed due to subsidence. There is no direct correlation between this angle and the angle of draw from subsidence except that it extends past the angle of draw. The probabilities used for this analysis are based upon the expectation that groundwater influence occurs past the zone of subsidence. The highest probabilities are given to the ranges equal to or slightly past the angle of draw. As the angle of groundwater influence extends farther past the subsidence zone, the likelihood of a 
change in permeability decreases. This represents a left skewed curve beginning at the angle of subsidence.

The probability of increased permeability was estimated based on Booth (Booth 2006). This factor is dependent on the type of overburden, therefore it is site specific. Sandstones tend to increase in permeability in the range of one order of magnitude while shale increases by a magnitude of 2 to 3 times (Van Roosendaal 1995). These are the maximum changes in the permeability of the rock and will decrease over time. However, permanent change for hydraulic conductivity is normally an increase in 1 order of magnitude. The values for this analysis assumed the greatest likelihood of increase to be 100x (2 orders of magnitude) with slightly lower probability for an increase of 10x and 1000x.

The tables given below show the values used for probability levels 2 and 3 for each of the subsidence ranges explained previously. They were used to determine the probability that erosion may occur if the proper conditions were met.

\section{Probabilities Levels Using SME Handbook Ranges for Subsidence}

Table 8 shows the probability for the angle of groundwater draw based on subsidence ranges from the SME Handbook. The values in the table depict groundwater being affected past the angle of subsidence.

\begin{tabular}{|c|c|c|c|c|c|c|}
\hline & \multicolumn{6}{|c|}{ Angle of Subsidence } \\
\hline $\begin{array}{c}\text { Groundwater } \\
\text { Draw (Booth } \\
\text { 2006) }\end{array}$ & $\begin{array}{c}0-10 \\
\text { Degrees }\end{array}$ & $\begin{array}{c}10-20 \\
\text { Degrees }\end{array}$ & $\begin{array}{c}20-25 \\
\text { Degrees }\end{array}$ & $\begin{array}{c}25-30 \\
\text { Degrees }\end{array}$ & $\begin{array}{c}30-35 \\
\text { Degrees }\end{array}$ & $\begin{array}{c}>35 \\
\text { Degrees }\end{array}$ \\
\hline 0-10 Degrees & 0.20 & 0.01 & 0.01 & 0.01 & 0.01 & 0.01 \\
\hline 10-20 Degrees & 0.50 & 0.19 & 0.01 & 0.01 & 0.01 & 0.01 \\
\hline 20-30 Degrees & 0.20 & 0.50 & 0.23 & 0.18 & 0.01 & 0.01 \\
\hline 30-40 Degrees & 0.09 & 0.20 & 0.50 & 0.55 & 0.22 & 0.17 \\
\hline$>40$ Degrees & 0.01 & 0.10 & 0.25 & 0.25 & 0.75 & 0.80 \\
\hline $\begin{array}{c}\text { Total } \\
\text { Probability }\end{array}$ & 1.00 & 1.00 & 1.00 & 1.00 & 1.00 & 1.00 \\
\hline
\end{tabular}

Table 8 - Probability of groundwater draw based on angle of subsidence 
Table 9 provides estimates for the increase in permeability within the zone of groundwater draw. As detailed previously, the actual change is dependent on strata type and distributed strain. Since this is site specific, the values are similar for each angle of groundwater draw. Highest probability was given for an increase by two orders of magnitude because both shale and sandstone can fall into this range. For groundwater draw occurring within 10 degrees of the mine, a slightly higher probability for a decrease in permeability was given. For this analysis, any increase in permeability was determined to have potential for erosion to occur.

\begin{tabular}{|c|c|c|c|c|c|}
\hline & \multicolumn{5}{|c|}{ Groundwater Draw } \\
\hline $\begin{array}{c}\text { Permeability } \\
\text { (Van } \\
\text { Roosendaal, } \\
\text { et al. 1995) }\end{array}$ & $\begin{array}{c}0-10 \\
\text { Degrees }\end{array}$ & $\begin{array}{c}10-20 \\
\text { Degrees }\end{array}$ & $\begin{array}{c}20-30 \\
\text { Degrees }\end{array}$ & $\begin{array}{c}30-40 \\
\text { Degrees }\end{array}$ & $\begin{array}{c}>40 \\
\text { Degrees }\end{array}$ \\
\hline No Increase & 0.15 & 0.15 & 0.15 & 0.15 & 0.15 \\
\hline Increase 10x & 0.25 & 0.25 & 0.25 & 0.25 & 0.25 \\
\hline Increase 100x & 0.30 & 0.35 & 0.35 & 0.35 & 0.35 \\
\hline $\begin{array}{c}\text { Increase } \\
\text { 1000x }\end{array}$ & 0.25 & 0.22 & 0.24 & 0.24 & 0.24 \\
\hline $\begin{array}{c}\text { Decrease } \\
\text { 100x }\end{array}$ & 0.05 & 0.03 & 0.01 & 0.01 & 0.01 \\
\hline $\begin{array}{c}\text { Total } \\
\text { Probability }\end{array}$ & 1.00 & 1.00 & 1.00 & 1.00 & 1.00 \\
\hline
\end{tabular}

Table 9- Changes in probability of permeability based on angle of groundwater draw

\section{RESULTS}

Using event trees based on longwall mine subsidence and groundwater draw, the probability for seepage to occur above was determined for offset distances of 200, 400 and $600 \mathrm{ft}(61.54$, $123.08,184.62 \mathrm{~m})$. The results are shown in tables 10,11 and 12 respectively. These were based on values of angle of subsidence taken from literature. The data provides the likelihood that changes in seepage will occur at a reservoir rim or foundation during maximum flood conditions. 


\begin{tabular}{|c|c|c|c|}
\hline $200 \mathrm{ft}(61.54 \mathrm{~m})$ Offset & \multicolumn{3}{|c|}{ Probability of Exceedance } \\
\hline Angle of Draw & Peng & SME & Booth \\
\hline 0-10 Degrees & $1.34 \mathrm{E}-01$ & $7.56 \mathrm{E}-03$ & $1.26 \mathrm{E}-02$ \\
\hline 10-20 Degrees & $2.55 \mathrm{E}-01$ & $1.34 \mathrm{E}-01$ & $1.01 \mathrm{E}-01$ \\
\hline 20-25 Degrees & $7.41 \mathrm{E}-02$ & $4.12 \mathrm{E}-01$ & $2.06 \mathrm{E}-01$ \\
\hline 25-30 Degrees & $0.00 \mathrm{E}+00$ & $1.65 \mathrm{E}-01$ & $2.06 \mathrm{E}-01$ \\
\hline 30-35 Degrees & $0.00 \mathrm{E}+00$ & $4.94 \mathrm{E}-02$ & $1.65 \mathrm{E}-01$ \\
\hline >35 Degrees & $0.00 \mathrm{E}+00$ & $8.23 \mathrm{E}-03$ & $8.23 \mathrm{E}-02$ \\
\hline $\begin{array}{c}\text { Total Probability of } \\
\text { exceedance }\left(\mathrm{P}_{\mathrm{f}}\right)\end{array}$ & 0.46 & 0.78 & 0.77 \\
\hline
\end{tabular}

Table 10 - Probability of Exceedance for $200 \mathrm{ft}$ (61.54 m) offset

\begin{tabular}{|c|c|c|c|}
\hline $\begin{array}{c}400 \mathrm{ft}(123.08 \mathrm{~m}) \\
\text { Offset }\end{array}$ & \multicolumn{3}{|c|}{ Probability of Exceedance } \\
\hline Angle of Draw & Peng & SME & Booth \\
\hline 0-10 Degrees & $1.59 \mathrm{E}-02$ & $9.00 \mathrm{E}-04$ & $1.50 \mathrm{E}-03$ \\
\hline 10-20 Degrees & $5.02 \mathrm{E}-02$ & $2.64 \mathrm{E}-02$ & $1.98 \mathrm{E}-02$ \\
\hline 20-25 Degrees & $2.97 \mathrm{E}-02$ & $1.65 \mathrm{E}-01$ & $8.25 \mathrm{E}-02$ \\
\hline 25-30 Degrees & $0.00 \mathrm{E}+00$ & $6.84 \mathrm{E}-02$ & $8.55 \mathrm{E}-02$ \\
\hline 30-35 Degrees & $0.00 \mathrm{E}+00$ & $4.10 \mathrm{E}-02$ & $1.37 \mathrm{E}-01$ \\
\hline >35 Degrees & $0.00 \mathrm{E}+00$ & $7.13 \mathrm{E}-03$ & $7.13 \mathrm{E}-02$ \\
\hline $\begin{array}{c}\text { Total Probability of } \\
\text { Exceedance }(\mathrm{Pf})\end{array}$ & 0.096 & 0.309 & 0.397 \\
\hline
\end{tabular}

Table 11 - Probability of Exceedance for $400 \mathrm{ft}(123.08 \mathrm{~m})$ offset

\begin{tabular}{|c|c|c|c|}
\hline $\begin{array}{c}600 \mathrm{ft}(184.62 \mathrm{~m}) \\
\text { Offset }\end{array}$ & \multicolumn{3}{|c|}{ Probability of Exceedance } \\
\hline Angle of Draw & Peng & SME & Booth \\
\hline 0-10 Degrees & $1.27 \mathrm{E}-03$ & $7.20 \mathrm{E}-05$ & $1.20 \mathrm{E}-04$ \\
\hline 10-20 Degrees & $9.12 \mathrm{E}-03$ & $4.80 \mathrm{E}-03$ & $3.60 \mathrm{E}-03$ \\
\hline 20-25 Degrees & $5.40 \mathrm{E}-03$ & $3.00 \mathrm{E}-02$ & $1.50 \mathrm{E}-02$ \\
\hline $25-30$ Degrees & $0.00 \mathrm{E}+00$ & $1.20 \mathrm{E}-02$ & $1.50 \mathrm{E}-02$ \\
\hline 30-35 Degrees & $0.00 \mathrm{E}+00$ & $1.08 \mathrm{E}-02$ & $3.60 \mathrm{E}-02$ \\
\hline$>35$ Degrees & $0.00 \mathrm{E}+00$ & $1.92 \mathrm{E}-03$ & $1.92 \mathrm{E}-02$ \\
\hline $\begin{array}{c}\text { Total Probability of } \\
\text { Exceedance }(P f)\end{array}$ & 0.016 & 0.060 & 0.089 \\
\hline
\end{tabular}

Table 12 - Probability of Exceedance for $600 \mathrm{ft}$ (184.62 m) offset 
The results show that at a $200 \mathrm{ft}(61.54 \mathrm{~m})$ offset (guidelines set by IC8741) the probability for seepage to occur ranges from $46 \%$ to $78 \%$. The values used from Peng are based on field data that showed subsidence angles less than 24 degrees. Ranges from SME and Booth were similar in nature and provided similar results. At $400 \mathrm{ft}(123.08 \mathrm{~m})$ the probability of seepage ranged from $9.6 \%$ to $39.7 \%$ and at $600 \mathrm{ft}(184.62 \mathrm{~m})$ the range fell between $1.6 \%$ and $8.9 \%$. This shows that permeability changes can occur at or under a reservoir rim during maximum flood conditions 1 out of 11.24, to 1 out of 62.50 times at an offset of $600 \mathrm{ft}(184.62 \mathrm{~m})$.

An example event tree using SME ranges for angle of subsidence is shown in Figure 23. It represents the branches that exist for a subsidence angle between 20 and 25 degrees for a $200 \mathrm{ft}$ offset. This is one-sixth of the actual event tree for the values used for current mining conditions. A full scale probabilistic event tree for this example is shown in Figure 24. Each range of the angle of draw under probability level 1 would have branches similar to Figure 24 . The probabilities highlighted are added to determine the risk based on this offset and angle of draw.

There are 5 potential ranges for angle of groundwater draw in probability level 2. For visualization purposes, only the three that contain values with a potential for erosion are shown. The two not shown are for angles of groundwater draw between 0-10 degrees and 10-20 degrees. These represent values less than the angle of subsidence in this example and would not extend near the $200 \mathrm{ft}$ offset at a depth of $350 \mathrm{ft}$. Because the angle of groundwater draw is unlikely to be less than that of subsidence, minimum probability $(0.01$ or $1 \%)$ for these branches was used. 
Probable Maximum Flood

Reservoir Soil Rim Progressive Seepage Failure Event Tree

Overview For $L=L_{m}$ in

( $\mathrm{L}_{\mathrm{min}}=$ Minimum Horizontal Ground Distance Measured From Reservoir Rim to E dge of Underground Mine )

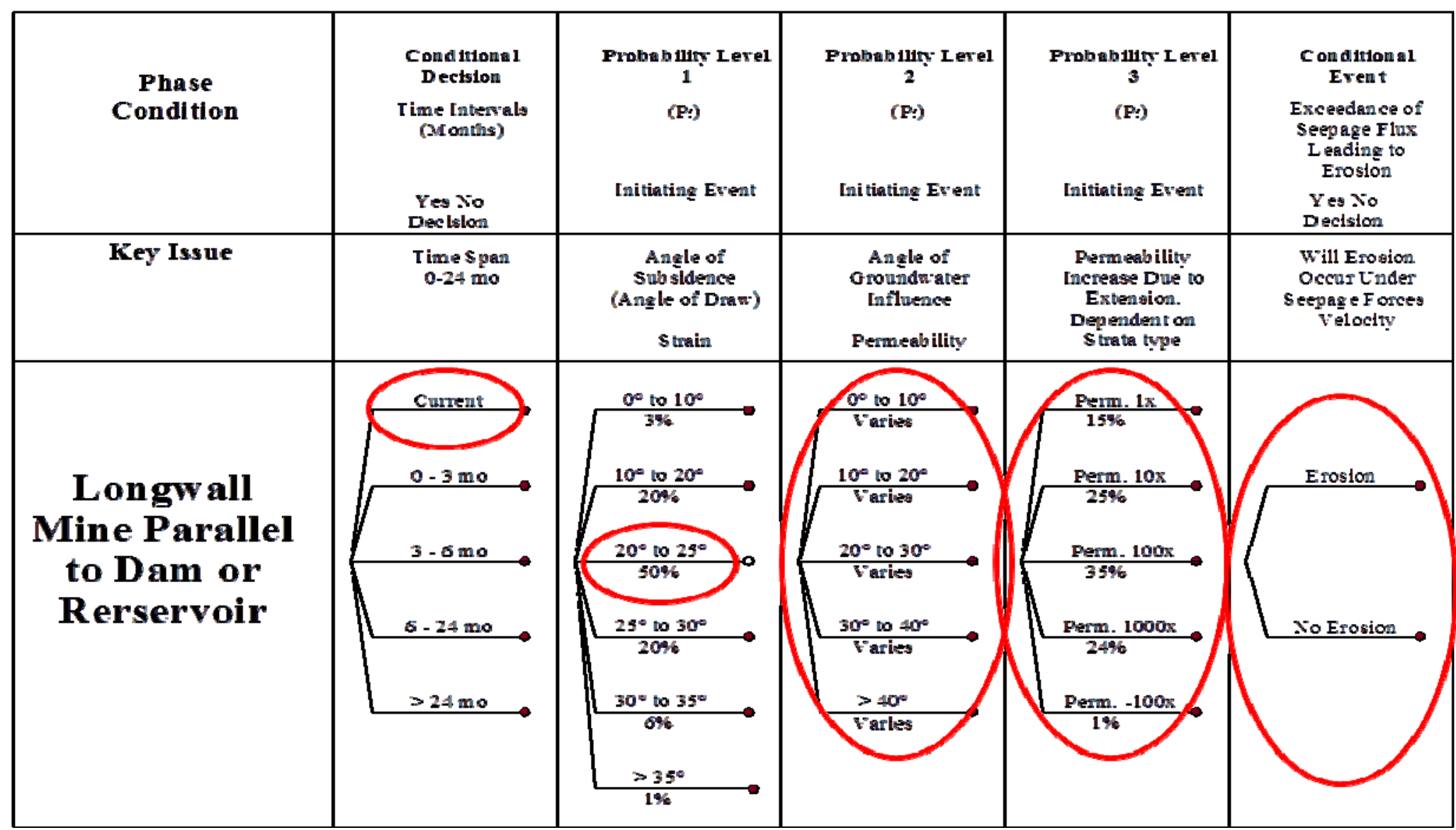

Figure 23- Example path for event tree analysis 


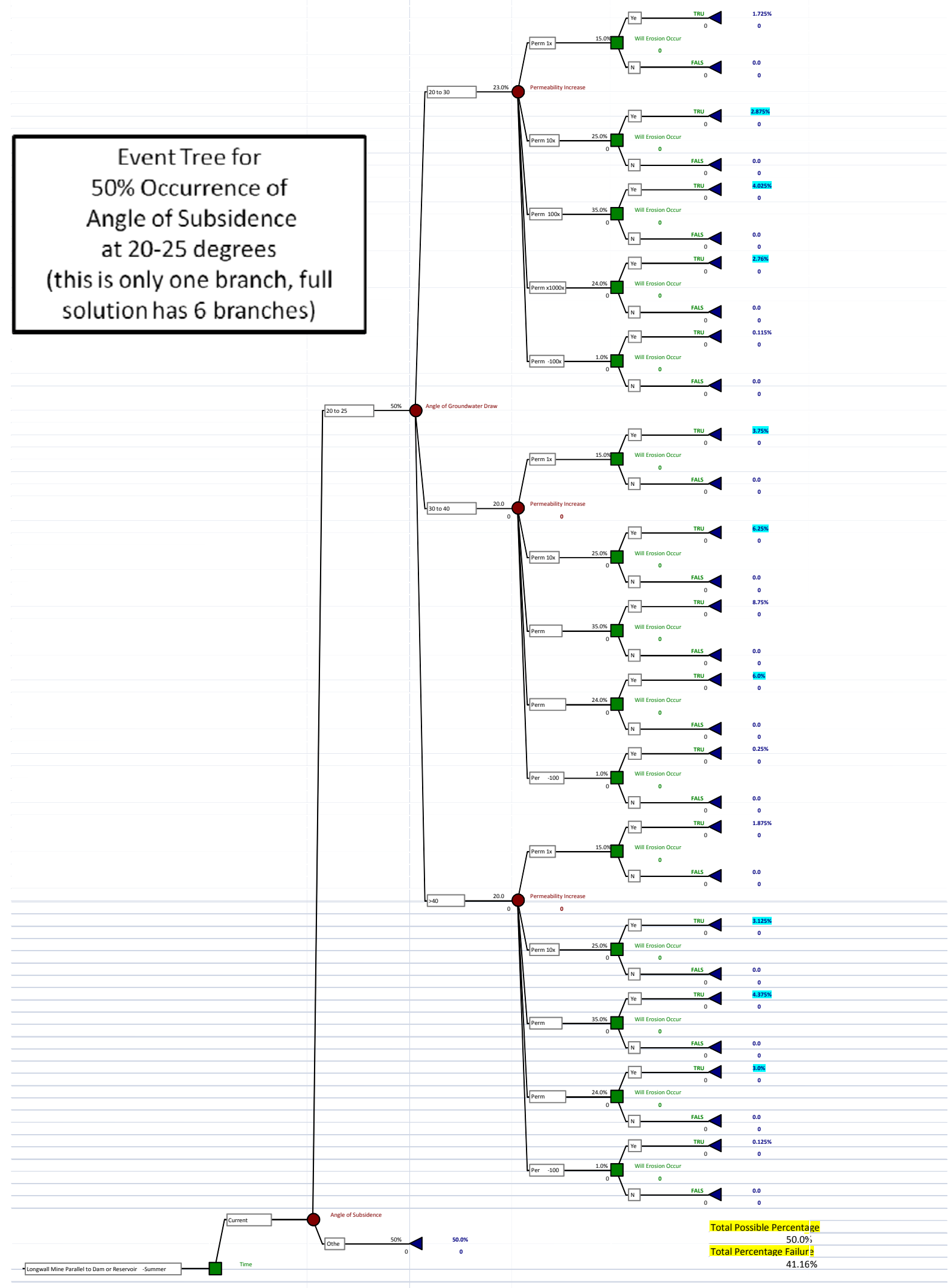

Figure 24- Partial event tree for 20 to 25 degree angle of subsidence 
Figure 25 shows one potential path for erosion to occur due to longwall mining. The final probability given at the end will be added to all other paths in the event tree. The total values are multiplied by the probability of erosion to occur given these events take place.

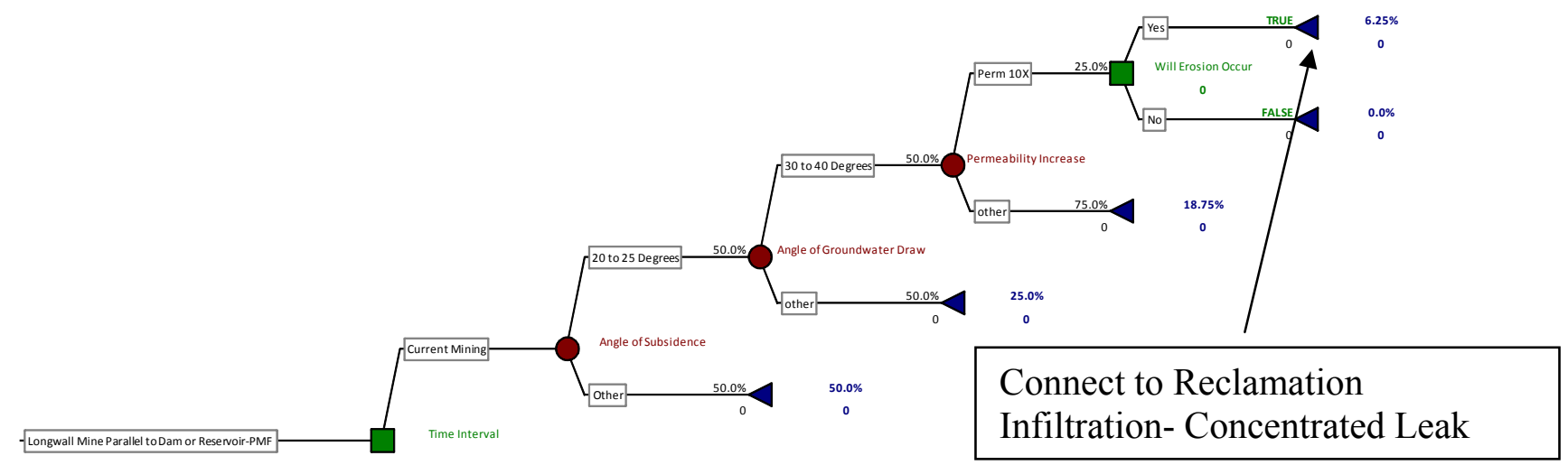

Figure 25- Example of one path for erosion probability analysis

An example of an event tree for erosion due to infiltration - concentrated leak is shown in Figure 26. This was based from Risk Analysis Methodology from the Bureau of Reclamation. It details the progression of changes within the soil structure for initiation to begin. Figure 26 would attach to the end of each branch on the event tree shown in Figure 24. The values given in for progression of erosion are for illustration purposes only and do not reflect actual probabilities. Actual values for the erosion event tree are site specific and would be determined based on subsurface characteristics such as soil type and pre mining hydraulic conductivity.

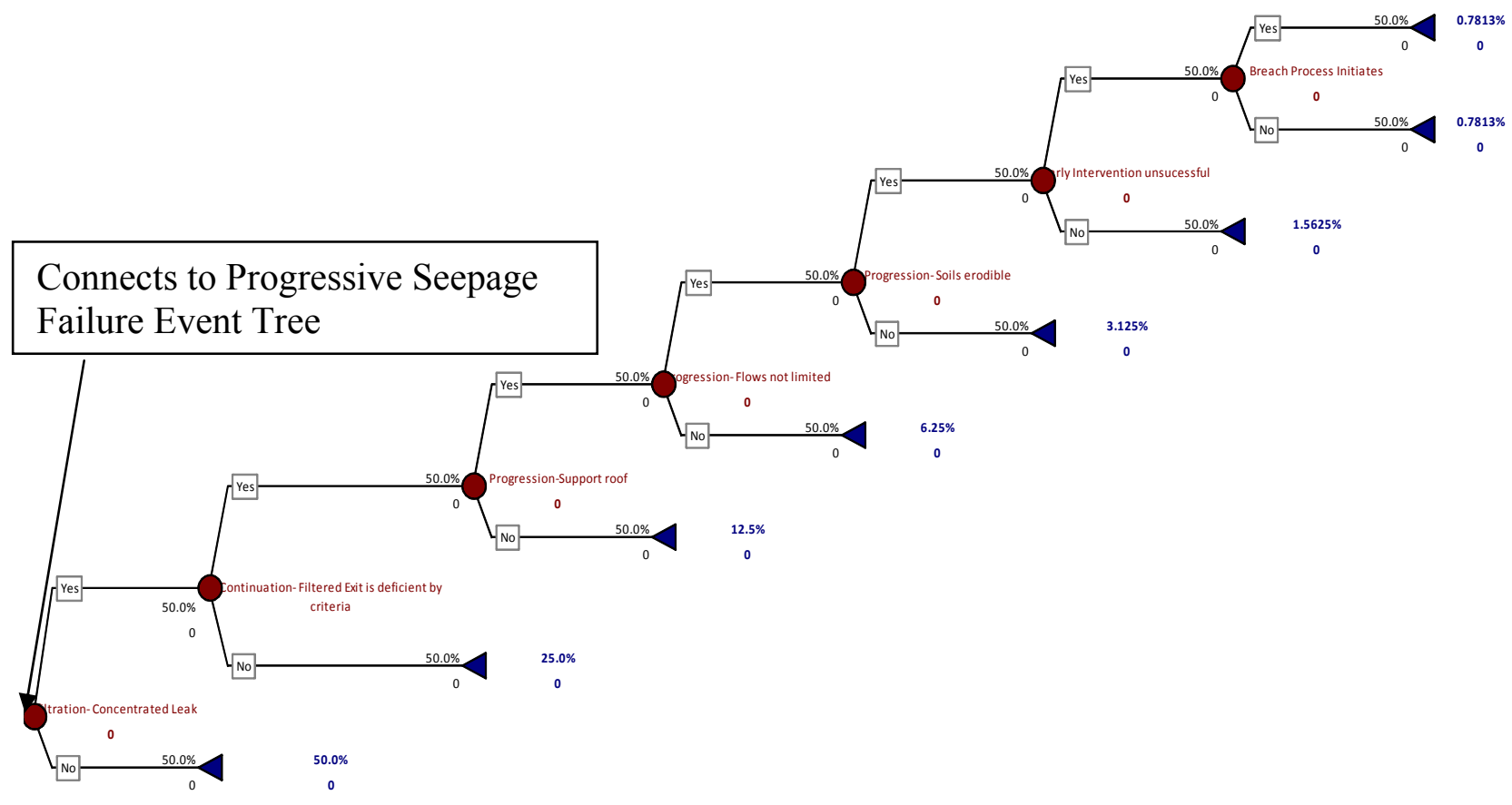

Figure 26- Risk Analysis Methodology Appendix E, Version 2.52001 
For this analysis, estimated probabilities were used in lieu of the event tree for erosion to determine overall probabilities for risk due to mining near surface bodies of water. Using the event tree data gathered on seepage, it was combined with documented USBR data, shown in Figure 27, for average estimated values ranging from $2 \times 10^{-3}$ to $1 \times 10^{-2}$ of initiating probability for foundation erosion due to seepage (Gobla 2012). This range is considered for purposes of this sensitivity analysis only. Actual ranges for foundation or sub-surface erosion are site specific.

Proposed "Best Estimate" Values of
Annual Probability of Initiation
- Applies only to Reclamation embankments
- Values serve only as "starting points" - each dam is
unique and must be evaluated separately, looking at site
specific features/vulnerabilities

Figure 27- Best estimate range of probability for initiation of erosion

The final probability gives the risk that sub-surface erosion will occur at the given offset distances. These probabilities take the likelihood of exceedance determined above and multiply it by the estimated probability of sub-surface erosion. In this analysis $1 \times 10^{-2}$ was used, this is the minimum value range per the USBR. While this value is for sub-surface erosion in a foundation, it was also estimated to be the initiating probability for sub-surface erosion at a reservoir rim. The probability shows that sub-surface erosion is likely to occur between $0.463 \%$ and $0.776 \%$ of the time at a $200 \mathrm{ft}(61.54 \mathrm{~m})$ offset distance. At $400 \mathrm{ft}(123.08 \mathrm{~m})$ the probability reduces in range of $0.0958 \%$ to $0.397 \%$ and at $600 \mathrm{ft}(184.62 \mathrm{~m})$ the range is between $0.0158 \%$ and $0.0889 \%$ for sub-surface erosion to occur. An example of the total probability of exceedance for the 200,400 , and $600 \mathrm{ft}(61.54,123.08,184.62 \mathrm{~m})$ offsets are shown in tables $13-15$. 


\begin{tabular}{|c|c|c|c|}
\hline $\begin{array}{c}\text { Barrier Offset } \\
(\mathrm{L})\end{array}$ & $\begin{array}{c}\text { Total Estimated } \\
\text { Probability due to } \\
\text { longwall mining }\end{array}$ & $\begin{array}{c}\text { Bureau of } \\
\text { Reclamation } \\
\text { (Foundation only) }\end{array}$ & $\begin{array}{c}\text { Total Probability } \\
\text { of exceedance for } \\
\text { erosion }\end{array}$ \\
\hline Peng & $4.63 \mathrm{E}-01$ & $1.00 \mathrm{E}-02$ & $4.63 \mathrm{E}-03$ \\
\hline $\begin{array}{c}\text { SME } \\
\text { Handbook }\end{array}$ & $7.76 \mathrm{E}-01$ & $1.00 \mathrm{E}-02$ & $7.76 \mathrm{E}-03$ \\
\hline Booth & $7.72 \mathrm{E}-01$ & $1.00 \mathrm{E}-02$ & $7.72 \mathrm{E}-03$ \\
\hline
\end{tabular}

Table 13 - Probability of Erosion at $200 \mathrm{ft}(61.54 \mathrm{~m})$ offset

\begin{tabular}{|c|c|c|c|}
\hline $\begin{array}{c}\text { Barrier Offset } \\
(\mathrm{L})\end{array}$ & $\begin{array}{c}\text { Total Estimated } \\
\text { Probability due to } \\
\text { longwall mining }\end{array}$ & $\begin{array}{c}\text { Bureau of } \\
\text { Reclamation } \\
\text { (Foundation only) }\end{array}$ & $\begin{array}{c}\text { Total Probability } \\
\text { of exceedance for } \\
\text { erosion }\end{array}$ \\
\hline Peng & $9.58 \mathrm{E}-02$ & $1.00 \mathrm{E}-02$ & $9.58 \mathrm{E}-04$ \\
\hline $\begin{array}{c}\text { SME } \\
\text { Handbook }\end{array}$ & $3.09 \mathrm{E}-01$ & $1.00 \mathrm{E}-02$ & $3.09 \mathrm{E}-03$ \\
\hline Booth & $3.97 \mathrm{E}-01$ & $1.00 \mathrm{E}-02$ & $3.97 \mathrm{E}-03$ \\
\hline
\end{tabular}

Table 14 - Probability of Erosion at $400 \mathrm{ft}$ (123.08 m) offset

\begin{tabular}{|c|c|c|c|}
\hline $\begin{array}{c}\text { Barrier Offset } \\
(\mathrm{L})\end{array}$ & $\begin{array}{c}\text { Total Estimated } \\
\text { Probability due to } \\
\text { longwall mining }\end{array}$ & $\begin{array}{c}\text { Bureau of } \\
\text { Reclamation } \\
\text { (Foundation only) }\end{array}$ & $\begin{array}{c}\text { Total Probability } \\
\text { of exceedance for } \\
\text { erosion }\end{array}$ \\
\hline Peng & $1.58 \mathrm{E}-02$ & $1.00 \mathrm{E}-02$ & $1.58 \mathrm{E}-04$ \\
\hline $\begin{array}{c}\text { SME } \\
\text { Handbook }\end{array}$ & $5.96 \mathrm{E}-02$ & $1.00 \mathrm{E}-02$ & $5.96 \mathrm{E}-04$ \\
\hline Booth & $8.89 \mathrm{E}-02$ & $1.00 \mathrm{E}-02$ & $8.89 \mathrm{E}-04$ \\
\hline
\end{tabular}

Table 15 - Probability of Erosion at $600 \mathrm{ft}$ ( $184.61 \mathrm{~m})$ offset

The final offset distances (L) for the SME subsidence values are shown in Figure 28. It shows the potential risk for erosion to occur at the three offset distances. The further a mine is offset from a reservoir, the less likely initiating events will occur. This is due to the angle of groundwater draw not extending near or past the given offset distances. Since geology and terrain type will have an impact on the extent of groundwater influence, this is a generalized analysis and additional offset may be required on a site by site basis. Furthermore, as the depth of a mine increases or decreases, the extents the angles of subsidence and groundwater draw reach beyond the mine will also fluctuate. A deeper mine will have a larger range of impact on groundwater than a shallow mine with the same angle of influence. 


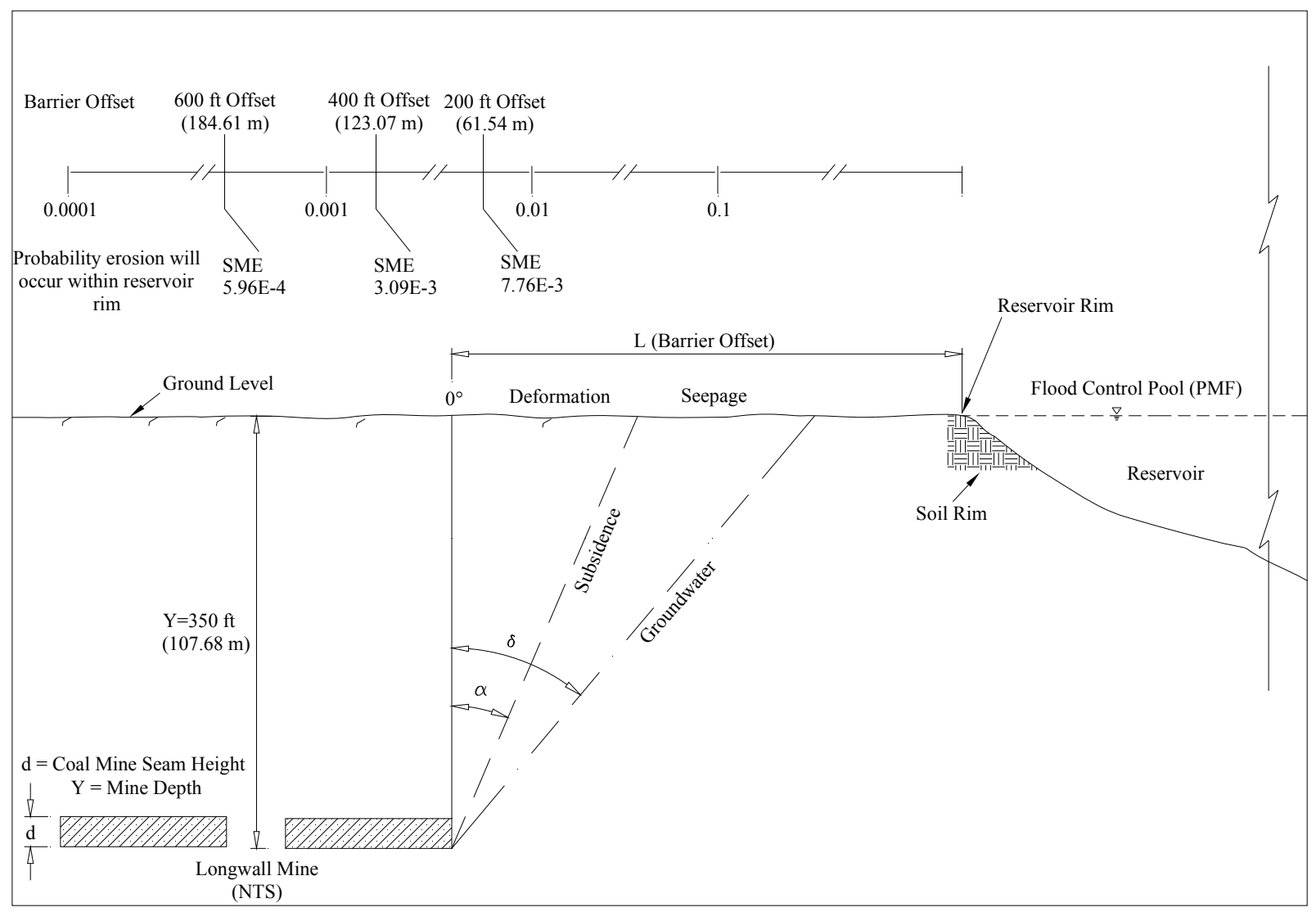

Figure 28: Probability of erosion based on offset distance using SME Handbook ranges of Subsidence

\section{CONCLUSIONS}

IC8741 is an empirical approach used for improving the safety of miners working under bodies of water (Babcock and Hooker 1977). These methods present offset distances and identify values for strain which are 8.75 times larger than the strain values known to cause permanent permeability increases in overburden soils (Bai 1995). Coupled with mining techniques and the dynamics of the subsidence waves which develop zones of tension and compression, it leaves questions as to whether IC8741 remains appropriate for use when mining near critical infrastructure such as dams and reservoirs owned by the public and managed by the USACE and USBR which rely on risk based analysis.

The methods presented in this research show that while guidelines based on subsidence may limit hazards to miners, it may not be sufficient for protection of the surface water body. Changes in groundwater flow can affect the integrity of a public surface structure through subsurface erosion. 
In summary, the contrast between IC8741 and research from the areas of subsidence and hydrogeology indicate the following:

- The angle of subsidence draw in Appalachia ranges upwards of 40 degrees while the angle of draw recommended by IC8741 using a $350 \mathrm{ft}(107.69 \mathrm{~m})$ deep mine offset at $200 \mathrm{ft}(61.54 \mathrm{~m})$ is a 29.74 degree angle of draw. Therefore IC8741 can underestimate the subsidence effect on strain.

- IC8741 recommends a $0.0087 \mathrm{~mm} / \mathrm{m}$ maximum tensile strain in overburden strata. Literature indicates that a tensile strain of $0.001 \mathrm{in} /$ in causes permanent increase in permeability (Kendorski 1993).

- IC8741 does not address development of the groundwater angle of influence. In Appalachia this angle can extend up to 70 degrees from the vertical edge of a mine affecting surface water head and flow (Reed and Rauch 2001).

- The IC8741 guidelines are intended only for the life of the mine. No information is provided for the following conditions: when pillar deterioration occurs, when pillar's punch through roof or floor layers, or for full extraction retreat mining.

This analysis estimated offset distances for potential sub-surface erosion to occur based on angles of draw and groundwater influence. Correlated with changes in permeability dependant on strata type, the estimates determine the probability there will be changes in seepage at or below a reservoir at various offset distances. For the ranges provided by the SME Handbook, the analysis determined that at a $200 \mathrm{ft}(61.54 \mathrm{~m})$ offset permeability increase will occur below the rim of a reservoir $78 \%$ of the time. As the offset increases to $600 \mathrm{ft}(184.61 \mathrm{~m})$, the probability of increased permeability will reduce to $6 \%$. The potential for initiation of erosion, based on the USBR analysis, is combined with these values to determine the total likelihood erosion will occur at a particular offset. This is illustrated under the conditions that the probability of exceedance $(\mathrm{P})$ for sub-surface erosion reduces from $\mathrm{P}=7.76 \mathrm{E}-3$ at $200 \mathrm{ft}(61.54 \mathrm{~m})$ offset to $\mathrm{P}=$ $5.96 \mathrm{E}-4$ at $600 \mathrm{ft}(184.61 \mathrm{~m})$ offset.

This sensitivity analysis shows that risk for erosion due to mining near surface bodies of water can be determined based on the angles of subsidence and groundwater draw. The method was generalized using estimated probabilities found in literature. The actual conditions that affect probability would include site specific information, but would follow the same approach. For partial extraction mining, pillar failure would initiate maximum subsidence conditions.

Determination of probability of pillar failure would be required and connected with the event tree for full extraction mining. For in perpetuity, room and pillar mining would be similar to longwall mining given the expectancy of eventual pillar collapse. 
The results show sub-surface erosion can occur from mining at distances far exceeding current IC8741offset guidelines. Further research needs to be conducted to determine the effects on groundwater draw from subsidence related issues to determine the actual risk to reservoirs and critical infrastructure when mining occurs.

The values given in this report are an estimation of risk for sub-surface erosion to occur at several offset distances. The results may provide the information necessary to evaluate risk and develop accurate offset guidelines for protection of the miners and surface water bodies. The data provided may allow those responsible for maintaining the safety of a dam or water body to determine an appropriate offset distances based on acceptable risk parameters. This research is designed to estimate probability of sub-surface erosion due to mining, not to stipulate minimum offset distances. 


\section{REFERENCES}

Army Corps of Engineers (USACE) (2008), Establishment of Risk Management Center (RMC) as an Expertise Center (CX) and Directory of Expertise (DX) at the U.S. Army Institute for Water Resources (CEIWR). Department of the Army, U.S. Army Corps of Engineers, Washington, D.C., November 20, 2008

Babcock, C.O., Hooker, V.E. (1977). Results of Research to Develop Guidelines for Mining Near Surface and Underground Bodies of Water, IC 8741. [Washington, D.C.] US Department of Interior, Bureau of Mines Information Circular.

Bai, M., Kendorski, F.S., Roosendaal, D. J. (1995). Chinese and North American HighExtraction Underground Coal Mining Strata Behavior and Water Protection Experience and Guidelines. 14th Conference on Ground Control in Mining. Morgantown, WV: 209-217.

Booth, C. J. (2002). The effects of longwall coal mining on overlying aquifers. Mine Water Hydrogeology and Geochemistry. London, Geological Society. 198: 17-45.

Booth, C. J. (2006). "Groundwater as an environmental constraint of longwall coal mining." Environmental Geology 49(6): 796-803.

Booth, C. J., A. M. Curtiss, Demaris, P.J., Bauer, R.A. (2000). "Site-specific variation in the potentiometric response to subsidence above active longwall mining." Environmental \& Engineering Geoscience 6(4): 383-394.

Brown, A.J., Bridle, R.C. (2008). Progress in assessing internal erosion. Ensuring Reservoir Safety into the future. London, UK.

Bureau of Land Management. US Department of the Interior. 9 Dec 2011. WEB 8 May 2012. $<$ http://www.blm.gov/es/st/en/prog/est_lynn_lake_coal.html

Craft, J. L. (1992) "Classification of Mine-Related Subsidence East of the Mississippi River, U.S.A.," 11th International Conference on Ground Control in Mining, The University of Wollongong, N.S.W.

Dolinar, D. R. (1999). Variation of Horizontal Stresses and Strains in Mines in Bedded Desposits in the Eastern and Midwestern United States. Pittsburgh, PA, National Institute for Occupational Safety and Health: 8.

Farmer, I. (1992). Room and Pillar Mining. SME Mining Engineering Handbook. H. L. Hartman. Littleton, Colorado, Society for Mining, Metallurgy and Exploration, Inc. 2: 16811701.

Fell, R., Bowles, D.S., Anderson, L.R., Bell, G. (2000). The Status of Methods for Estimation of the Probability of Failure of Dams for Use in Quantitative Risk Assessment. International Commission on Large Dams 20th Congress. Beijing, China: 20. 
Hopey, Don (2008). "Pennsylvania Says Mining destroyed lake dam in park Consol Energy sued for $\$ 58$ million to fix Greene Co. damage,” Pittsburgh Post-Gazette, Friday, February 01, 2008.

Gray, Kathy L (2011). “Judge Won’t Stop Mining Under State Park,” Columbus Dispatch, Columbus, Ohio May 12, 2011.

Gobla, Michael (2012). "Dams without filters" National Dam Safety Program Technical Seminar \#19, Feb 22, 2012, FEMA

Guo, W., K. Morsy, Peng S. (2007). Relationship between Mining Subsidence and Mining Depth in Strip Pillar Mining. 26th International Conference on Ground Control in Mining. Morgantown, WV: 85-88.

Karmis, M., Haycocks, C., Agioutantis, Z. (1992). The Prediction of Ground Movements caused by Mining. Proceedings, 3rd Workshop on Surface Subsidence due to Underground Mining, Morgantown, WV: 1-9

Kelleher, J. T., Van Roosendaal, D.J., Mehnert, B.B., Brutcher, D.F., Bauer, R.A. (1991). Overburden Deformation and Hydrologic Changes Due to Lonwall Coal Mine Subsidence on the Illinois Basin. Fourth Internation Symposium on Lans Subsidence: 10.

Kendorski, F. S. (1993). Effect of High-Extraction Coal Mining on Surface and Ground Water. Proceedings, 12th International Conference on Ground Control in Mining. Morgantown, WV: 412-425.

Kendorski, F. S., Singh, M.M. (1979). Criteria for Determining When a Body of Surface Water Constitutes a Hazard to Mining. Downers Grove, Ill, Engineers International, INC: 364.

Mine Safety and Health Administration (MSHA) and Office of Surface Mining (OSM) (2003), "Report to Congress, Responses to Recommendations In the National Research Council's Report Coal Waste Impoundments: Risks, Responses, and Alternatives," US Department of Labor and US Office of Department of Interior, Washington, D.C.

Office of Surface Mining, Reclamation, and Enforcement (OSM) (2006), "Slurry Impoundment Breakthroughs," Charleston Field Office, US Department of Interior, Charleston, WV.

RECLAMATION (2011), "Dam Safety Risk Analysis Best Practices Training Manual, Version 2.2 - April 2011.” US Department of Interior, Bureau of Reclamation, Denver, CO.

Peng, S.S., Chiang, H.S. (1992). Mine Subsidence. SME Mining Engineering Handbook. H. L. Hartman. Littleton, Colorado, Society for Mining, Metallurgy, and Exploration, Inc. Volume 2: $1780-1788$. 
Peng, S. S., Luo, Y., Zhang, Z.M. (1995). Development of a Subsidence Database and Determination of Subsidence Parameters. 14th Conference on Ground Control in Mining. Morgantown, WV: 226-235.

Reed, C., Rauch, H. (2001), Mining Induced Streamflow Loss for Spruce Laurel Fork in Boone County, West Virginia, Proc. 2001 National Association of Abandoned Mine Land Programs Annual Conference, Athens, Ohio: 24.

Singh, M. M. (1992). Mine Subsidence. SME Mining Engineering Handbook. H. L. Hartman. Littleton, Colorado, Society for Mining, Metallurgy, and Exploration, Inc. Volume 1: 939971.

Skelly and Loy (1976). "Guidelines for Mining Near Water Bodies, Phase III - Final Report." U.S. Department of Interior, Bureau of Mines, Project No. HO252083, Denver, CO.

Van Roosendaal, D. J., Kendorski, F.S., Padgett, J.T. (1995). Application of Mechanical and Groundwater-Flow Models to Predict the Hydrogeologic Effects of Longwall Subsidence- A Case Study. 14th Conference on Ground Control in Mining. Morgantown, WV: 252-260.

Vick, S.G. (2002). Degrees of Belief: Subjective Probability and Engineering Judgment, ASCE Press, Reston, Virginia: 455.

Wardell, K., and Partners (1976). Guidelines For Mining Under Surface Water. Phase III and Final Report, U.S. Bureau of Mines - Contract No. HO.25201, K. Wardell \& Partners, Newcastle Staffs [England].

West Virginia Department of Environmental Protection (WVDEP), (2011), Permit ID U200406, Tygart \#1 Mine. 